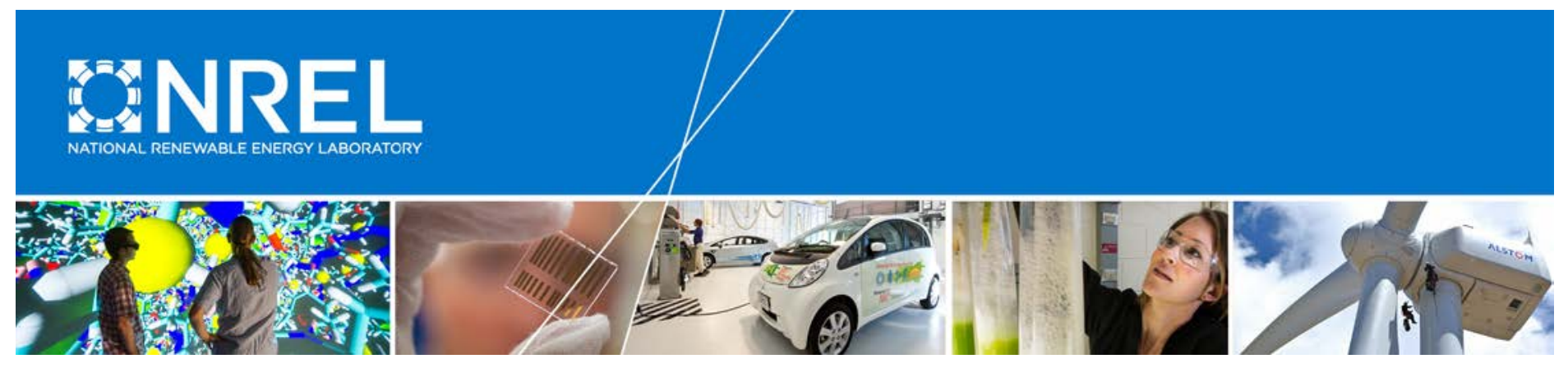

\title{
Assessing the Future of Distributed Wind: Opportunities for Behind-the-Meter Projects
}

Eric Lantz, Benjamin Sigrin, Michael Gleason, Robert Preus, and lan Baring-Gould National Renewable Energy Laboratory

NREL is a national laboratory of the U.S. Department of Energy Office of Energy Efficiency \& Renewable Energy Operated by the Alliance for Sustainable Energy, LLC

This report is available at no cost from the National Renewable Energy Laboratory (NREL) at www.nrel.gov/publications.

Technical Report

NREL/TP-6A20-67337

November 2016

Contract No. DE-AC36-08GO28308 


\section{Assessing the Future of Distributed Wind: Opportunities for Behind-the- Meter Projects}

Eric Lantz, Benjamin Sigrin, Michael Gleason, Robert Preus, and lan Baring-Gould National Renewable Energy Laboratory

Prepared under Task No. WE15.2E30

NREL is a national laboratory of the U.S. Department of Energy Office of Energy Efficiency \& Renewable Energy Operated by the Alliance for Sustainable Energy, LLC

This report is available at no cost from the National Renewable Energy Laboratory (NREL) at www.nrel.gov/publications.

National Renewable Energy Laboratory 15013 Denver West Parkway Golden, CO 80401

303-275-3000 • www.nrel.gov

\section{Technical Report}

NREL/TP-6A20-67337

November 2016

Contract No. DE-AC36-08G028308 


\section{NOTICE}

This report was prepared as an account of work sponsored by an agency of the United States government. Neither the United States government nor any agency thereof, nor any of their employees, makes any warranty, express or implied, or assumes any legal liability or responsibility for the accuracy, completeness, or usefulness of any information, apparatus, product, or process disclosed, or represents that its use would not infringe privately owned rights. Reference herein to any specific commercial product, process, or service by trade name, trademark, manufacturer, or otherwise does not necessarily constitute or imply its endorsement, recommendation, or favoring by the United States government or any agency thereof. The views and opinions of authors expressed herein do not necessarily state or reflect those of the United States government or any agency thereof.

This report is available at no cost from the National Renewable Energy Laboratory (NREL) at www.nrel.gov/publications.

Available electronically at SciTech Connect http:/www.osti.gov/scitech

Available for a processing fee to U.S. Department of Energy and its contractors, in paper, from:

U.S. Department of Energy

Office of Scientific and Technical Information

P.O. Box 62

Oak Ridge, TN 37831-0062

OSTI http://www.osti.gov

Phone: 865.576.8401

Fax: 865.576.5728

Email: reports@osti.gov

Available for sale to the public, in paper, from:

U.S. Department of Commerce

National Technical Information Service

5301 Shawnee Road

Alexandria, VA 22312

NTIS http://www.ntis.gov

Phone: 800.553 .6847 or 703.605 .6000

Fax: 703.605 .6900

Email: orders@ntis.gov 


\section{Acknowledgments}

This work was supported by the U.S. Department of Energy (DOE) under Contract No. DEAC36-08GO28308 with the National Renewable Energy Laboratory (NREL). Funding for the work was provided by the DOE Office of Energy Efficiency and Renewable Energy, Wind Energy Technologies Office. The authors thank Mike Bergey (Bergey Wind Power), Padma Kasthurirangan (Niagara Wind and Solar), Tom Wind (Wind Utility Consulting), and Alice Orrell (Pacific Northwest National Laboratory) for providing support and assistance as part of the project's Technical Review Group and for reviewing prior versions of this manuscript. We thank Charles Newcomb (previously of Endurance Wind Power) for supporting this project as part of the Technical Review Group. We also thank Trudy Forsyth (Wind Advisors Team), Bret Barker (Barker Advisory, contractor to DOE), Rich Tusing (Allegheny Science and Technology, contractor to DOE), Patrick Gilman (DOE), Mark Higgins (DOE), Mike Derby (DOE), and Jose Zayas (DOE) for their strategic input and guidance in the development and execution of this work. We thank our NREL colleagues Maureen Hand, Tony Jimenez, Maggie Mann, Dave Mooney, Brian Smith, Gian Porro, and Robin Newmark for reviewing prior versions of this manuscript. Finally, thanks to Sheri Anstedt (NREL) and Mary Lukkonen (contractor to NREL) for editing support. Opinions represented in this article are the authors' own and do not reflect the view of the U.S. Department of Energy or the U.S. government. Of course, any remaining errors or omissions are the sole responsibility of the authors. 


\section{List of Acronyms}

$\begin{array}{ll}\text { AEO } & \text { Annual Energy Outlook } \\ \mathrm{C}_{\mathrm{p}} & \text { coefficient of performance } \\ \text { DOE } & \text { U.S. Department of Energy } \\ \text { dWind } & \text { Distributed Wind Market Demand Model (NREL) } \\ \text { EIA } & \text { Energy Information Administrations } \\ \text { GW } & \text { gigawatt } \\ \text { ITC } & \text { investment tax credit } \\ \text { kW } & \text { kilowatt } \\ \text { LCOE } & \text { levelized cost of energy } \\ \text { m } & \text { meter } \\ \text { MACRS } & \text { Modified Accelerated Cost Recovery System } \\ \text { MW } & \text { megawatt } \\ \text { NPV } & \text { net present value } \\ \text { NREL } & \text { National Renewable Energy Laboratory } \\ \text { NYSERDA } & \text { New York State Energy Research and Development Authority } \\ \text { OEM } & \text { original equipment manufacturer } \\ \text { O\&M } & \text { operation and maintenance } \\ \text { PNNL } & \text { Pacific Northwest National Laboratory } \\ \text { PTC } & \text { production tax credit } \\ \text { PV } & \text { photovoltaic } \\ \text { WACC } & \text { weighted average cost of capital }\end{array}$




\section{Executive Summary}

Wind power is one of the fastest growing sources of new electricity generation in the United States. Cumulative installed capacity was more than 74,000 megawatts (MW) at year-end 2015 and wind power supplied 4.7\% of total 2015 U.S. electricity generation. Despite the growth of the wind power industry, the distributed wind market has remained limited. Cumulative installations of distributed wind through 2015 totaled $934 \mathrm{MW}$. This first-of-a-kind exploratory analysis characterizes the future opportunity for behind-the-meter distributed wind, serving primarily rural or suburban homes, farms, and manufacturing facilities.

This work focuses only on the grid-connected, behind-the-meter subset of the broader distributed wind market. ${ }^{1}$ We estimate this segment to be approximately half of the $934 \mathrm{MW}$ of total installed distributed wind capacity at year-end 2015. Potential from other distributed wind market segments including systems installed in front of the meter (e.g., community wind) and in remote, off-grid locations is not assessed in this analysis and therefore, would be additive to results presented here. These other distributed wind market segments are not considered in this initial effort because of their relatively unique economic and market attributes.

Opportunities for behind-the-meter distributed wind are considered from three perspectives: addressable resource potential, economic potential, and market potential. The first of these perspectives is intended to frame the overall scale of the opportunity ${ }^{2}$; the second quantifies the potential capacity of systems that could generate a positive net present value (NPV) at a specific point in time; the third considers economics as well as consumer adoption behaviors to estimate potential deployment levels for the specific conditions assessed.

For addressable resource potential, we identify a single estimate for all theoretical behind-themeter distributed wind applications. We use scenarios or an array of future conditions to more fully explore economic and market potential. Variables in our scenarios include capital and operation and maintenance costs, technology performance, the value of distributed generation, system financing and leasing costs, consumer adoption rates, and siting criteria. More details on the scenario framework including the Combined scenarios as well as explicit Low, Reference, High, and Breakthrough values are provided in Section 1.1.

Consistent with prior distributed generation analyses conducted at the National Renewable Energy Laboratory and as a first assessment of the opportunity for behind-the-meter distributed wind, this work does not consider potential competition from alternative distributed-generation sources such as rooftop solar photovoltaics, assumes federal and state tax incentives and renewable portfolio standards as legislated, and may not capture all costs of integration into the distribution network. Also, consistent with prior work, net metering and siting setbacks are varied within the range of existing policies today.

\footnotetext{
${ }^{1}$ Aggregated net metering, which may be considered a behind-the-meter application, is excluded from this analysis.

${ }^{2}$ As there are many locations in the United States that could be used either to serve local consumption or (larger) wholesale power needs, the addressable resource quantified here may be interpreted as a subset of more comprehensive estimates of land-based wind potential. However, in locations where siting a megawatt-scale turbine is not feasible, the addressable resource includes additional new resources not previously considered.
} 


\section{Total Addressable Resource}

The addressable resource potential of distributed wind is large, potentially supporting millions of systems and thousands of gigawatts (GW) of power production capacity. We define addressable resource potential as the maximum amount of wind resource in the continental United States that could be sited proximal to electricity demand and constrained by key siting considerations in those areas (see Section 3). As currently estimated, the addressable resource for distributed wind does not account for potential alternative uses of developable land by other power generation technologies, including multimegawatt utility-scale wind facilities.

In aggregate terms, the addressable resource potential for distributed wind exceeds the total U.S. electricity demand. Submegawatt-scale $(<1,000$ kilowatts $[\mathrm{kW}])$ distributed wind turbines could provide up to approximately 3.0 terawatts (TW) of capacity, and with current wind turbine performance levels could produce 4,400 terawatt-hours (TWh) of annual energy generation. The Energy Information Administration reported the total U.S. electricity demand in 2015 to be 3,700 TWh. Megawatt-scale turbines, which can serve behind-the-meter loads for large commercial or industrial users, could provide an additional $5.1 \mathrm{TW}$ of capacity and $14,000 \mathrm{TWh}$ of annual energy generation.

\section{Economic Potential}

Focusing on sites that can generate a positive net present value under Reference scenario conditions, ${ }^{3} 42 \mathrm{GW}$ of capacity is estimated to be economically viable in 2020; this quantity decreases to $19 \mathrm{GW}$ in 2030 and settles at $37 \mathrm{GW}$ by 2050 (Figure ES-1). These estimates limit site-specific potential to quantities required to serve on-site load, but may include turbines of any size depending on the load to be served; relevant financial characteristics are also considered. Estimates are annual and reflect several time-varying trends - the most important of which is that the production tax credit and associated investment tax credit options are not extended. These tax credit expirations drive the decline in observed potential between 2020 and 2030. Additional important factors are technology-cost reductions and the evolution of the netmetering policy, which is assumed to expire as anticipated in current statutes.

\section{Considering more favorable (for distributed wind) technology, finance, and retail} electricity rate conditions associated with the Combined High scenario inputs, ${ }^{4}$ the 2030 and 2050 annual outlooks for economic viability are improved for residential, commercial, and midsize turbine classes (Figure ES-1). In this scenario, an estimated $48 \mathrm{GW}$ of capacity could be economically viable in 2030 , with more than $85 \mathrm{GW}$ in 2050 . Under these more favorable economic conditions, factors beyond direct costs including consumer adoption, access

\footnotetext{
${ }^{3}$ Project levelized cost of energy is $52 \%$ lower than 2014 costs by 2030 for submegawatt turbines and 33\% lower by 2030 for turbines $1 \mathrm{MW}$ and larger. Financing conditions assume typical long-term interest rates and debt to cover $60 \%$ of project costs. Retail electricity rate escalation tracks the Annual Energy Outlook 2016 Reference Case (Energy Information Administration 2016). Siting criteria require 1.1 times the maximum blade tip height setback from parcel boundaries. For additional detail see Section 2.

${ }^{4}$ Project levelized cost of energy is $59 \%$ lower than 2014 costs by 2030 for turbines less than $1 \mathrm{MW}$ and $33 \%$ lower by 2030 for turbines more than $1 \mathrm{MW}$. Financing conditions assume current interest rates remain flat indefinitely, and debt is available to cover $80 \%$ of residential-sector project costs and $70 \%$ of commercial and industrial project costs. Retail electricity rate escalation tracks the Annual Energy Outlook 2016 Low Oil and Gas Recovery Scenario (i.e., high natural gas prices). Siting criteria require 1.0 times the maximum blade tip height setback from parcel boundaries.
} 
to finance, siting policy, and competition from alternative distributed-generation sources are anticipated to become increasingly significant in determining market potential.
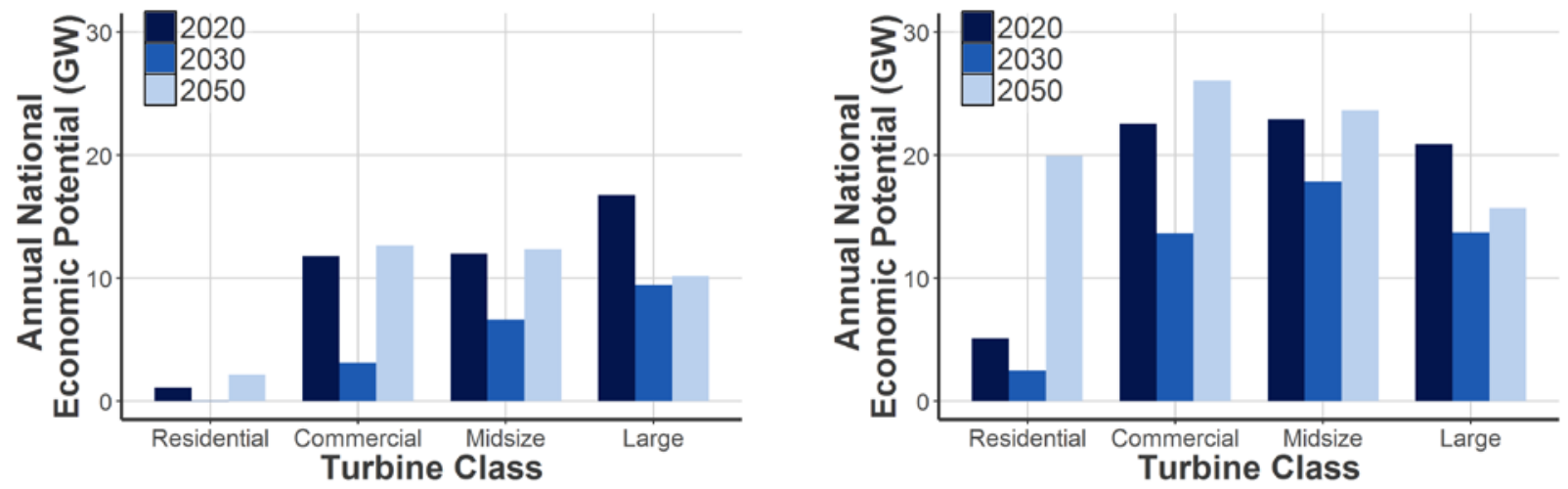

Figure ES-1. Economic potential by turbine size class for the Reference scenario (left) and Combined High scenario (right)

Note: The turbine class label refers to the size of the turbine as defined by rated capacity, independent of end-use sector. Residential turbines are 2-20 kW, commercial turbines are 21-100 kW, midsize turbines are 101-999 kW, and large turbines are $\geq 1,000 \mathrm{~kW}$. Turbines are placed in a location based on siting criteria and on-site consumer load constraints. For additional detail on turbine size and siting considerations, see Section 2 and Section 3.

Although these estimates suggest conditions under which large quantities of distributed wind could become economically viable, there are significant uncertainties and anticipated regional variation in key analysis assumptions that may alter the economic landscape for behind-the-meter distributed wind. Economic potential estimates are highly dependent on assumed retail electricity rates, the presence of net energy metering policies, financial incentives, and financing costs. Although highly uncertain and partially captured through the scenario framework applied here, these factors are likely to vary by state and local jurisdiction.

\section{Market Potential}

\section{When considering consumer adoption trends, Reference scenario inputs ${ }^{5}$ suggest an} opportunity for approximately $1.5 \mathrm{GW}$ of cumulative deployed capacity in 2030 and 3.7 GW in 2050 (Figure ES-2). Assuming behind-the-meter applications are approximately half of today's installed distributed wind capacity (approximately $500 \mathrm{MW}$ ), this represents an approximately $300 \%$ increase in the market by 2030 and a nearly eight-fold increase (three doublings) in cumulative capacity by 2050 .

The Combined High scenario ${ }^{6}$ suggests a multiplicative effect associated with an array of conditions becoming more favorable for behind-the-meter distributed wind, and results in a cumulative market of $3.9 \mathrm{GW}$ in 2030 and nearly $20 \mathrm{GW}$ in 2050 (Figure ES-2). Cumulative capacity in the Combined High scenario reflects a nearly eight-fold increase in the

\footnotetext{
${ }^{5}$ Scenario inputs are per footnote 3 and include consumer adoption rates of 49 years for residential consumers and 57 years for commercial and industrial consumers, as informed by consumer behavior patterns from distributed photovoltaic adoption. The authors acknowledge that photovoltaics and wind have different attributes that may alter their respective acceptance and subsequent diffusion rates, even under comparable economics. See also Section 5.

${ }^{6}$ Scenario inputs per footnote 4 and including consumer adoption rates of 37 years for residential consumers and 46 years for commercial and industrial consumers. See also Section 5.
} 
next 14 years - by 2050, installed capacity is increased by a factor of approximately 40 , or more than five doublings of cumulative capacity. Despite sizable near-term cost reductions and robust economic potential across turbine classes, consumer adoption rates applied here indicate a relatively limited ability to improve the near-term (2020) outlook for these systems.

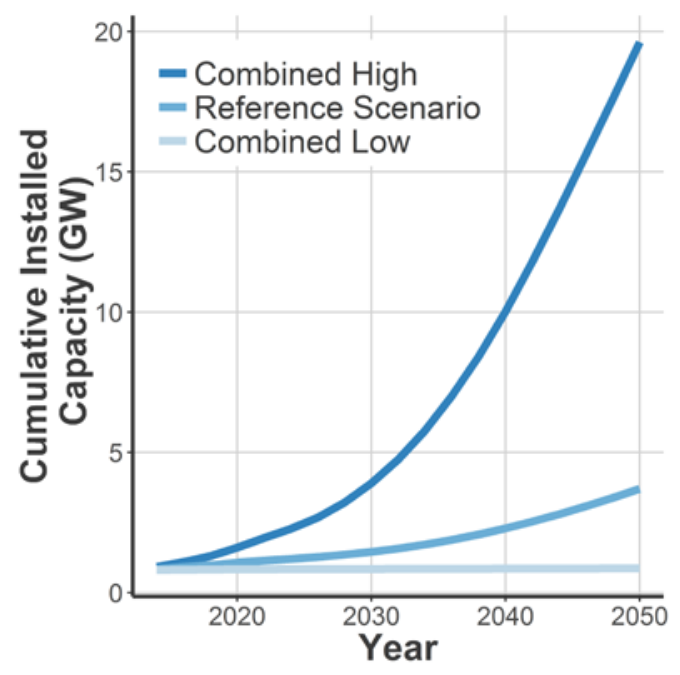

Figure ES-2. Cumulative national installed capacity for the Combined High, Reference, and Combined Low scenarios

Note: Similar in principal to the Combined High scenario, the Combined Low scenario reflects the combined effect of all our low input values occurring simultaneously; see also Section 1.1.

\section{Conclusions}

This first-of-a-kind assessment suggests that there could be a substantive role in the nation's electricity future for behind-the-meter distributed wind. Notwithstanding some potential overlap with the multimegawatt-utility-focused wind power resource and the current exclusion of competition from other distributed generation resources, its resource is large, and there are conditions under which the economics for large quantities (tens of gigawatts) become viable over time. To realize the opportunities presented by scenarios that consider relatively favorable conditions for behind-the-meter distributed wind, our analysis suggests that technology cost reduction, including cost reductions in balance of plant and installation, and performance improvements are necessary but not sufficient conditions to foster more robust growth. Finding mechanisms to facilitate and encourage consumer adoption as well as develop new business models that can access low-cost capital, support turnkey solutions, and drive industry-wide efficiencies are also anticipated to be essential components of a vibrant market. 


\section{Table of Contents}

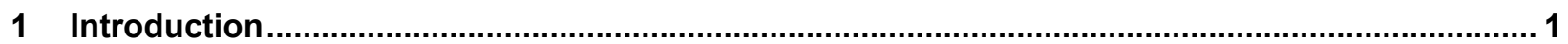

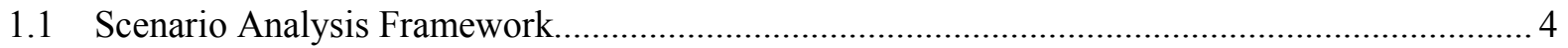

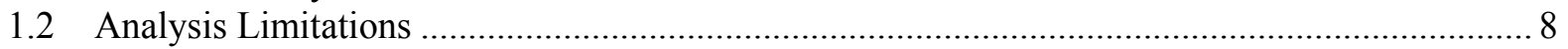

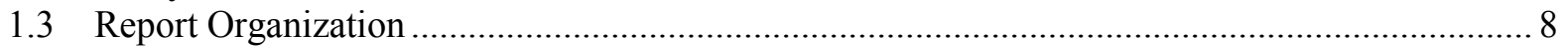

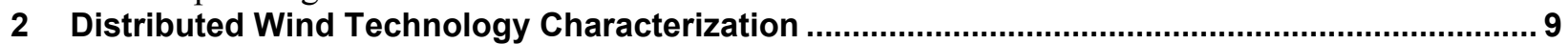

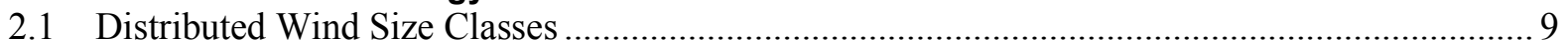

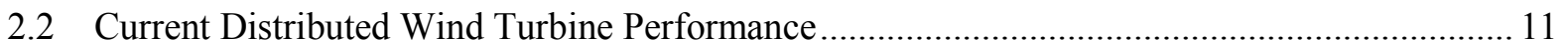

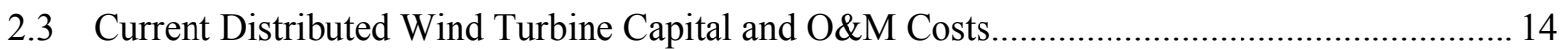

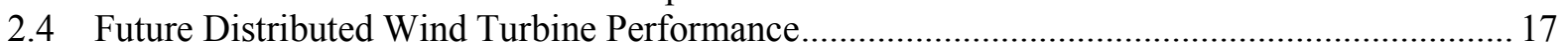

2.5 Future Distributed Wind Turbine Capital and O\&M Cost...................................................... 18

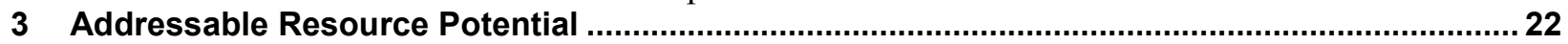

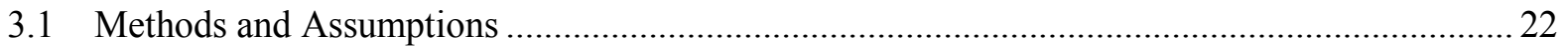

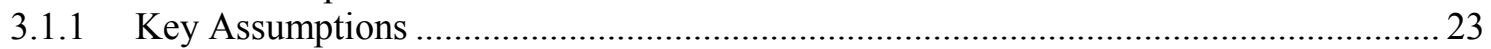

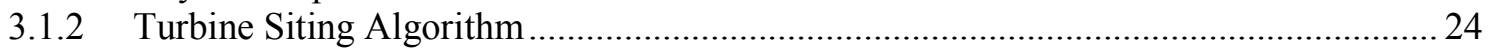

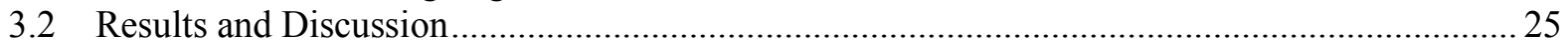

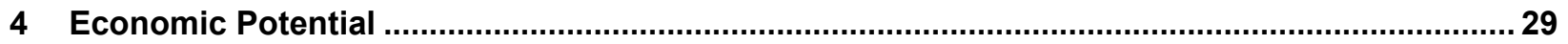

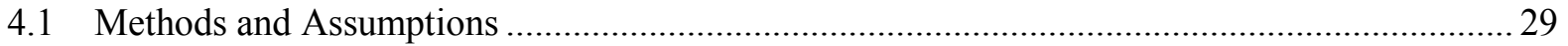

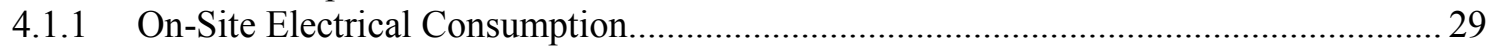

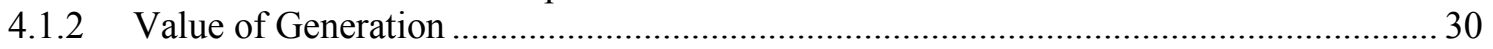

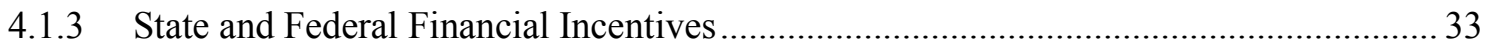

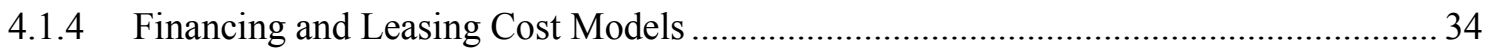

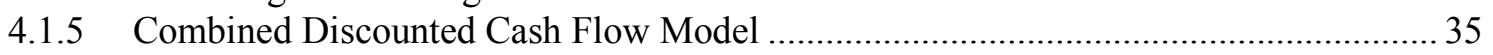

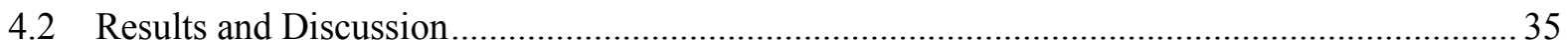

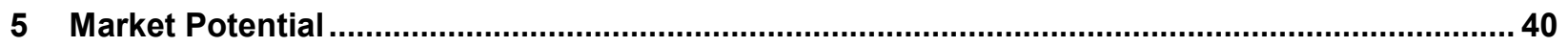

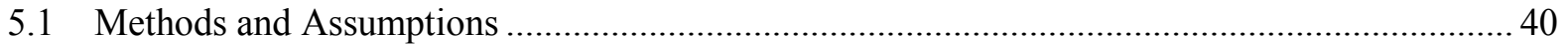

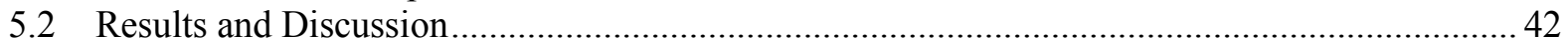

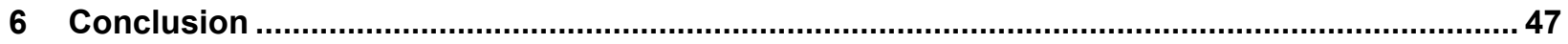

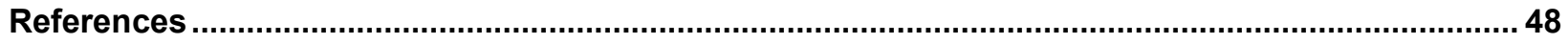

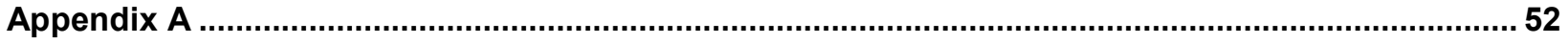

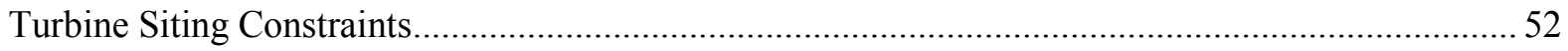

Proximity to Electricity Demand Power Density ……........................................................... 52

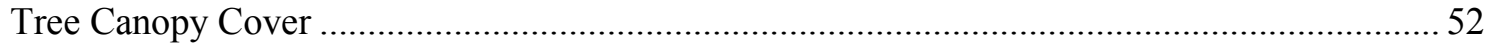

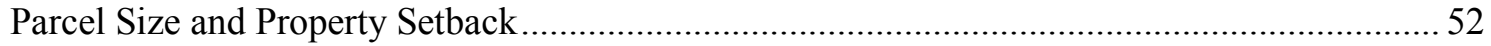

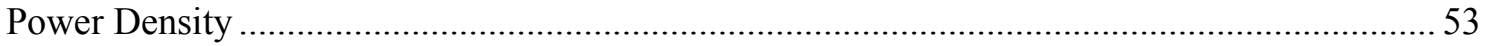




\section{List of Figures}

Figure ES-1. Economic potential by turbine size class for the Reference scenario (left) and Combined High scenario (right) vii

Figure ES-2. Cumulative national installed capacity for the Combined High, Reference, and Combined Low scenarios viii

Figure 1. Framework for assessing renewable energy potential 3

Figure 2. Distributed wind technology size classes and discrete representations in dWind ..................... 10

Figure 3. Estimated capacity factors for actual turbines satisfying the applied screening criteria and the representative residential size class power curve at multiple wind speed points .................. 12

Figure 4. Representative generic power curves applied to each turbine size class....

Figure 5. Empirical market data and statistical curve fit utilized to inform estimates of current capital

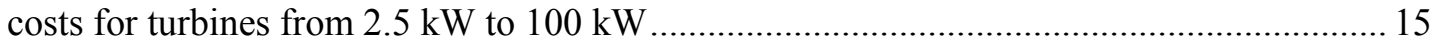

Figure 6. Estimated current (2014) O\&M costs for distributed wind turbines ........................................ 16

Figure 7. Applied trends in distributed wind turbine capacity factors with time by turbine size class....... 18

Figure 8. Distributed wind LCOE trajectories utilized in modeling analysis .........................................2 20

Figure 9. Applied trends in distributed wind turbine capital cost with time by discrete turbine size ......... 21

Figure 10. Addressable resource in system counts by system size and size class .................................. 25

Figure 11. Addressable resource in capacity by system size and class...............................................26

Figure 12. Addressable resource of sub-megawatt scale turbines by state ............................................2 27

Figure 13. Addressable resource of megawatt-scale turbines by state.................................................2 28

Figure 14. Terawatt-hours of consumer load by sector for all end-users, for buildings without siting restrictions, and for buildings that could achieve $\geq 20 \%$ capacity factor............................... 30

Figure 15. Retail cost of electricity for residential customers by county ................................................ 31

Figure 16. Economic potential by turbine class - Reference scenario................................................ 36

Figure 17. Economic potential by turbine class - Combined High scenario ............................................ 37

Figure 18. Impact of sensitivities on 2030 (top) and 2050 (bottom) economic potential ........................ 38

Figure 19. Maximum technology penetration levels modeled based on payback period .......................... 42

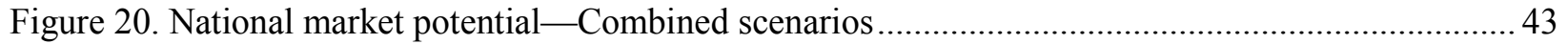

Figure 21. National market potential by turbine class - Reference scenario ......................................... 44

Figure 22. National market potential by turbine class — Combined High scenario .................................. 44

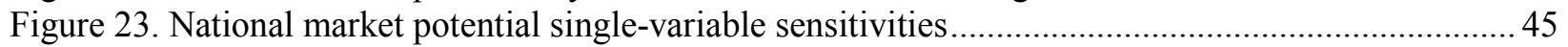

Figure 24. Impact of sensitivities on 2050 market potential .................................................................. 46 


\section{List of Tables}

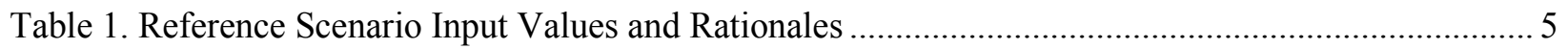

Table 2. Low, Reference, High, and Breakthrough Input Values............................................................ 6

Table 3. Discrete Turbine Sizes and Dimensions Considered by dWind .............................................. 10

Table 4. Estimated Capital Cost and Associated Turbine Parameters for Current (2014) Technology...... 15

Table 5. Allowable System Sizes and Projected Last Year of Net-Metering Coverage as Represented in

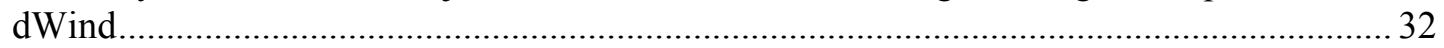

Table 6. Distributed Wind ITC Schedule Reflected in the Current Analysis ......................................... 33

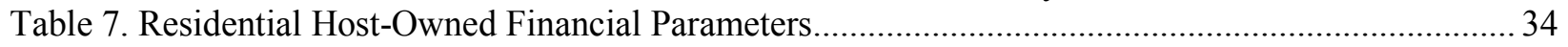

Table 8. Commercial/Industrial Host-Owned Financial Parameters ....................................................... 35

Table 9. Third-Party Owned (Lessor) Hurdle Rates (\$2014) ............................................................. 35

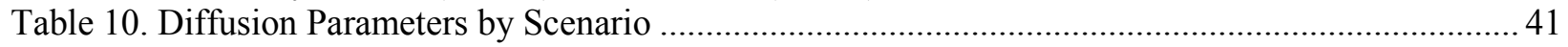




\section{Introduction}

Wind power is one of the fastest growing sources of new electricity generation in the United States. Since the early 2000 s, annual investments in new capacity have exceeded the billiondollar threshold, and totaled more than $\$ 20$ billion dollars in 2012 (Wiser and Bolinger 2016). Cumulative installed capacity was estimated at approximately 74 gigawatts $(\mathrm{GW})$ at year-end 2015 (American Wind Energy Association 2016). Despite the growth of the wind power industry, the distributed wind market segment — including projects that are installed behind the meter and at distribution voltages for local use - has remained limited in its application with approximately 28 megawatts (MW) of capacity additions in 2015. Cumulative installations of distributed wind for the period from 2003 to 2015 total 934 MW (Orrell and Foster 2016). Recent trends in distributed wind also stand in contrast to the distributed photovoltaics (PV) industry, which as of year-end 2015 totaled approximately 11,700 MW of cumulative capacity and has observed a compound annual growth rate in terms of installed capacity of $48 \%$ over the past 5 years (Solar Energy Industries Association 2016).

This first-of-a-kind exploratory analysis characterizes the future opportunity for behind-themeter distributed wind, serving primarily rural or suburban homes, farms, and manufacturing facilities. Broadly speaking, distributed wind encompasses three applications of wind power projects: grid-connected systems that are located behind a meter, grid-connected systems in front of the meter interconnected at distribution, but not transmission, voltages, and remote systems not connected to the centralized grid. In practice, these applications range in size from kilowattscale off-grid installations to multimegawatt (and multiple-turbine) community wind projects operating either behind or in front of the meter.

The work outlined in this report is focused only on the behind-the-meter subset of the larger distributed wind space, excludes aggregated net-metering applications ${ }^{7}$, and is limited to the continental United States. ${ }^{8}$ In effect, we evaluate the prospective opportunity for distributed wind applications that serve an on-site need and compete directly with retail electricity rates in the residential, commercial, and industrial sectors. Our focus on this segment is because of relatively more unique economic and market opportunities for other forms of distributed wind. Opportunities within the community wind, small-scale municipal, aggregated net metering, and off-grid space reflect additional possibilities beyond the results discussed here. A cursory assessment of potential in some of these markets is provided by Forsyth and Baring-Gould (2008).

Analysis provided here was informed by insights and expertise from an independent Technical Review Group. This body of industry, consulting, and national laboratory experts served as a source for empirical project data, analysis peer reviewers, and independent subject matter

\footnotetext{
${ }^{7}$ Aggregated net metering allows multiple end users to connect either physically or contractually to a renewable power system that offsets retail electricity consumption for the entire group. Community solar and wind developers may leverage these policies to capture economies of scale in project costs associated with larger installations while still offsetting retail electricity costs.

${ }^{8}$ Alaska and Hawaii are not assessed because of underlying geographic information system and utility data limitations at the present time.
} 
experts. Input provided by the Technical Review Group was considered, among an array of sources, in the development, framing, and execution of this project.

The total distributed wind market constituted by the behind-the-meter applications that are the focus of this work is not precisely known. However, $73 \%$ of cumulative installed distributed wind capacity is made up of turbines $1 \mathrm{MW}$ and greater, $11 \%$ includes turbines greater than 100 $\mathrm{kW}$ and less than $1 \mathrm{MW}$, and 15\% includes turbines $100 \mathrm{~kW}$ and less (Orrell and Foster 2016). In 2015, approximately half of all distributed wind projects were estimated to be either behind the meter or off grid (Orrell and Foster 2016). Based on project-specific knowledge provided by the Technical Review Group, we know that a substantial share of the total megawatt-scale distributed wind capacity is connected to the distribution grid rather than behind the meter. From these insights, we estimate the portion of the total distributed wind market made up of the behind-the-meter wind applications studied here is less than half of today's current distributed wind capacity.

To characterize opportunities for distributed wind we consider three perspectives. First, we quantify the addressable wind resource potential. Second, we quantify the economic potential for behind-the-meter distributed wind in an array of potential scenarios. Finally, we quantify the market potential for behind-the-meter distributed wind also across an array of potential scenarios. This approach is consistent with the framework for understanding "layers" of renewable energy potential established by Lopez et al. (2012) and further refined in the context of offshore wind by Beiter and Musial (2016). Under these frameworks, renewable energy potential is evaluated as a series of increasingly focused layers of insight and resolution.

Lopez et al. (2012) conceptually framed renewable energy potential in the form of resource, technical, economic, and market potential (Figure 1). Beiter and Musial (2016) split the broader resource category into total and gross resource with the former reflecting recoverable and unrecoverable potential and the latter focusing on the recoverable potential within a defined area, typically associated with a political boundary, and considering such characteristics as power density and height above ground. In both frameworks, moving from one layer to the next provides a progressively more honed estimate of potential, based on an increasing level of detail and resulting in a smaller but more actionable estimate of renewable energy potential. Notably, as one moves toward more refined estimates, there is a tendency to incorporate a larger and more complex set of potential variables, considerations, and assumptions. As a result, estimates of economic or market potential tend to have more variability as a function of the ranges and uncertainties associated with specific individual variables. 


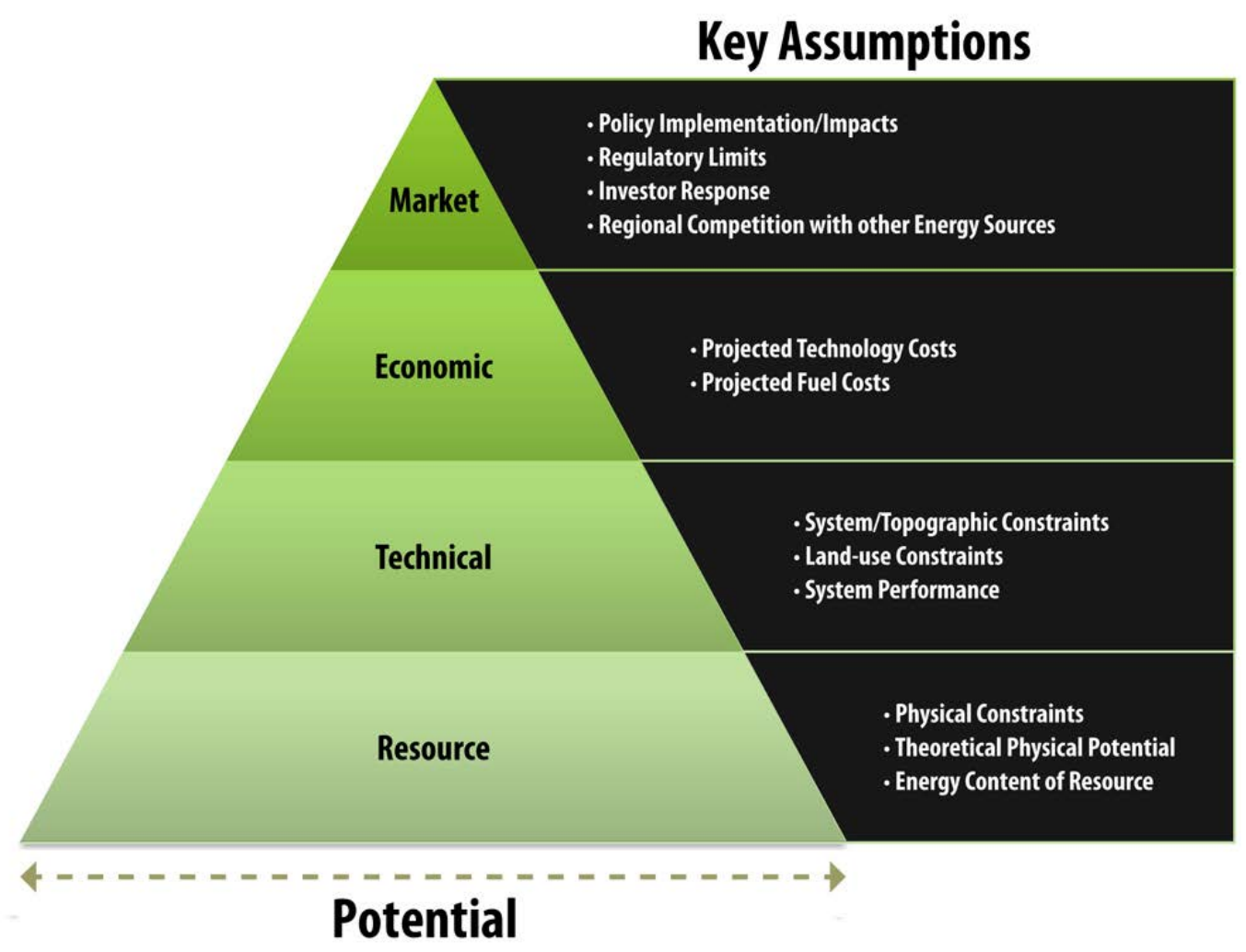

Figure 1. Framework for assessing renewable energy potential (Lopez et al. 2012)

Analysis of behind-the-meter distributed wind potential at all layers detailed here is conducted through the lens of the National Renewable Energy Laboratory's (NREL's) dWind model (Sigrin et al. 2016). The dWind model is a member of NREL's dGen suite of distributed-generation technology diffusion models. dWind evaluates the resource, economics, siting, load, and policy conditions for millions of potential distributed wind sites across the nation. These data are simultaneously considered within the context of consumer behavior patterns to understand potential future deployment trends for behind-the-meter wind turbine installations in scenarios through 2050. The model results including those described here are not intended as forecasts. Rather, dWind provides an internally consistent framework for understanding and characterizing potential future scenarios as a function of the specific modeled inputs.

Addressable resource potential, as seen by dWind, reflects the maximum amount of wind capacity that could be sited proximal to electricity demand and constrained by key siting considerations for those areas. This approach is generally consistent with Beiter and Musial's (2016) gross resource potential within the context of behind-the-meter distributed wind. In this sense, it helps to frame the potential for behind-the-meter distributed wind technologies that serve local needs. Because there are many locations in the United States that could be used either to serve local consumption or (larger) wholesale power needs, the addressable resource quantified here may be interpreted as a subset of more comprehensive estimates of land-based wind resource potential. In locations where siting a megawatt-scale turbine is not feasible, however, the dWind addressable resource includes additional new resources not previously considered by prior wind resource analysis (Lopez et al. 2012; U.S. Department of Energy [DOE] 2015). 
Economic and market potential estimates conducted in dWind are generally analogous to those described by Lopez et al. (2012). Economic potential reflects the quantity of distributed wind capacity and energy that could be installed at a positive net present value (NPV) at a specific point in time and based on prevailing retail rates and technology costs. Market potential reflects the quantity of distributed wind capacity and energy that might be adopted by consumers under the applied scenario inputs.

\subsection{Scenario Analysis Framework}

For addressable resource potential, we identify a single aggregate estimate for all theoretical behind-the-meter distributed wind applications. This estimate is disaggregated for reporting purposes but is calculated for only a single set of conditions. Where applicable, we assume current 2015 technology for energy production.

In contrast, we use scenarios or an array of future conditions to more fully explore economic and market potential. Variables in our scenarios include distributed wind project capital and operation and maintenance (O\&M) costs, distributed wind technology performance, the value of distributed generation, system financing and leasing costs, consumer adoption rates, and siting criteria.

Anchoring the analysis of economic and market potential is the Reference scenario, which consists of our "central" assumptions based on information available today and may be thought of as our closest proxy to a business-as-usual scenario. For example, we assume that the federal tax credits for commercial applications ramp down and expire in 2021 and the residential tax credits expire in 2016, net-metering policy expires as is currently legislated, and we apply a midpoint setback distance from neighboring property lines that is based on known policy. A full description of reference value inputs and a brief rationale for each value is shown in Table 1. 
Table 1. Reference Scenario Input Values and Rationales

\begin{tabular}{|c|c|c|}
\hline Variable & Reference Input Value & Rationale \\
\hline $\begin{array}{l}\text { Capital and } \\
\text { O\&M costs }\end{array}$ & $\begin{array}{l}\text { Up to } 45 \% \text { reduction in capital cost by } 2030 \text { and } \\
70 \% \text { reduction by } 2050 ; 4 \% \text { change in O\&M cost by } \\
2030 \text { and } 10 \% \text { reduction by } 2050\end{array}$ & $\begin{array}{l}\text { Derived from land-based wind } \\
\text { median learning rate, projected } \\
\text { global growth rates, short-term } \\
\text { cost estimates, and the Wind } \\
\text { Vision study cost reduction } \\
\text { assumptions (DOE 2015) }\end{array}$ \\
\hline $\begin{array}{l}\text { Turbine } \\
\text { performance }\end{array}$ & $\begin{array}{l}\text { Up to } 25 \% \text { increase in capacity factor by } 2030 \text { and } \\
55 \% \text { increase by } 2050\end{array}$ & $\begin{array}{l}\text { Consistent with concepts and } \\
\text { technology in development today }\end{array}$ \\
\hline $\begin{array}{l}\text { Value of } \\
\text { distributed } \\
\text { generation }\end{array}$ & $\begin{array}{l}\text { Net metering expires as scheduled, and excess } \\
\text { generation is valued at the wholesale rate; retail } \\
\text { rates based on current data and scaled by the } \\
\text { Annual Energy Outlook } 2016 \text { reference case } \\
\text { (Energy Information Administration [EIA] 2016a) } \\
\text { retail rate escalations }\end{array}$ & $\begin{array}{l}\text { Current policy; Annual Energy } \\
\text { Outlook (AEO) reference } \\
\text { scenario electricity rate } \\
\text { escalation (EIA 2016a) }\end{array}$ \\
\hline $\begin{array}{l}\text { System } \\
\text { financing } \\
\text { and leasing } \\
\text { costs }^{10}\end{array}$ & $\begin{array}{l}\text { Real weighted average cost of capital (WACC) of } \\
5.4 \%, 60 \% \text { debt fraction, } 3.2 \% \text { after-tax real cost of } \\
\text { debt, } 10.2 \% \text { real cost of equity; leasing available in } \\
\text { all states by } 2020 \text {, using a } 7 \% \text { real hurdle rate }\end{array}$ & $\begin{array}{l}\text { Consistent with NREL } 2016 \\
\text { Annual Technology Baseline } \\
\text { (Cole et al 2016) and other dGen } \\
\text { reference or baseline analyses; } \\
\text { leasing rate derived from solar } \\
\text { PV industry estimates (Sigrin et } \\
\text { al. 2016) }\end{array}$ \\
\hline $\begin{array}{l}\text { Consumer } \\
\text { adoption } \\
\text { rates }\end{array}$ & $\begin{array}{l}\text { Fifty-seven years to } 90 \% \text { saturation for commercial } \\
\text { and industrial consumers, } 49 \text { years for residential }\end{array}$ & $\begin{array}{l}\text { Representative referenceable } \\
\text { data sets based on solar PV } \\
\text { survey data (Sigrin et al. 2016) }\end{array}$ \\
\hline $\begin{array}{l}\text { Siting } \\
\text { criteria }^{11}\end{array}$ & $\begin{array}{l}\text { System height setback factor of } 1.1 \text { times, } 12 \text {-meter } \\
(\mathrm{m}) \text { static rotor canopy clearance for areas with } \\
\geq 10 \% \text { canopy cover }\end{array}$ & $\begin{array}{l}\text { Consistent with typical state and } \\
\text { local siting policy and expected } \\
\text { required clearance above canopy }\end{array}$ \\
\hline
\end{tabular}

In addition to the Reference scenario, we consider a series of "single variable sensitivities." In these scenarios, values are changed on an individual basis, whereas all other values are held constant at their Reference setting. Input values are varied in a manner that is consistent with less favorable conditions for behind-the-meter distributed wind as well as conditions that are more favorable for behind-the-meter distributed wind. Less favorable conditions reflect our low values

\footnotetext{
${ }^{9}$ Cost and performance characteristics for turbines $\geq 1 \mathrm{MW}$ are consistent on a levelized-cost-of-energy (LCOE) basis with the NREL Annual Technology Baseline (2016) low wind cost trajectory; however, explicit cost and performance estimates differ because of current dWind model limitations. For submegawatt turbines, new LCOE trajectories were defined as the Annual Technology Baseline is not applicable to submegawatt technologies (See also Section 2.4 and Section 2.5).

${ }^{10}$ Reference scenario financing costs are consistent with the NREL Annual Technology Baseline (2016).

${ }^{11}$ The applied siting criteria govern the maximum size turbine that might be placed in a specific location. However, for the purposes of the economic and market potential estimates, additional constraints are applied that determine the actual turbine size that may be applicable for a specific modeled user (e.g., on-site consumer load). Additional details on the siting criteria are included in Section 3.
} 
and more favorable conditions reflect our high values, commensurate with the anticipated qualitative impacts on behind-the-meter distributed wind economic and market potential. In addition to the high values, we include a series of breakthrough values. Breakthrough values are intended to reflect potential best-case outcomes for a given variable.

Scenario results are bounded by Combined Low and Combined High scenarios. In these scenarios, we apply all designated Low input values and all designated High input values, respectively. As the Breakthrough values are thought of in the vein of best-case outcomes, we do not consider a combined Breakthrough scenario given the exceptionally low likelihood of bestcase outcomes across the full suite of input variables. The full array of Low, High, and Breakthrough input values are detailed in Table 2. Notably, although the Reference scenario relies on policy as currently legislated, our Breakthrough value of generation assumptions consider the possibility for existing net-metering policies to be extended throughout the period of analysis, consistent with prior dGen work on solar PV (Barbose et al. 2016). In addition, we vary siting setbacks across scenarios to reflect the range of actual setback requirements that exist in practice today with the Low value reflecting the larger setback standards of existing policy, the High value reflecting the shorter setback standards of existing policy, and the Breakthrough value reflecting common permitting exceptions granted for distributed wind. For all other model inputs, policy remains as currently legislated across the full array of model variables. A more complete description of the sources and derivation of the various input values are detailed in Section 4 (economic potential) and Section 5 (market potential).

Table 2. Low, Reference, High, and Breakthrough Input Values

\begin{tabular}{|c|c|c|c|c|}
\hline Variable & Low Value & $\begin{array}{c}\text { Reference Input } \\
\text { Value }\end{array}$ & High Value & $\begin{array}{c}\text { Breakthrough } \\
\text { Value }\end{array}$ \\
\hline $\begin{array}{l}\text { Capital and } \\
\text { O\&M costs }\end{array}$ & $\begin{array}{l}\text { No change in capital } \\
\text { cost relative to } 2016\end{array}$ & $\begin{array}{l}\text { Up to } 45 \% \text { reduction } \\
\text { in capital cost by } \\
2030 \text { and } 70 \% \\
\text { reduction by } 2050, \\
4 \% \text { reduction in O\&M } \\
\text { cost by } 2030, \text { and } \\
10 \% \text { reduction by } \\
2050\end{array}$ & $\begin{array}{c}\text { Up to } 52 \% \text { reduction in } \\
\text { capital cost by } 2030 \\
\text { and } 71 \% \text { reduction by } \\
2050,4 \% \text { reduction in } \\
\text { O\&M cost by } 2030 \text {, } \\
\text { and } 10 \% \text { reduction by } \\
2050\end{array}$ & $\begin{array}{c}\text { Up to } 70 \% \text { reduction in } \\
\text { capital cost by } 2030 \\
\text { and } 75 \% \text { reduction by } \\
2050,4 \% \text { reduction in } \\
\text { O\&M cost by } 2030 \text {, } \\
\text { and } 10 \% \text { reduction by } \\
2050\end{array}$ \\
\hline $\begin{array}{l}\text { Turbine } \\
\text { performance }^{12}\end{array}$ & $\begin{array}{l}\text { No change in } \\
\text { capacity factor } \\
\text { relative to } 2016\end{array}$ & $\begin{array}{c}\text { Up to } 25 \% \text { increase } \\
\text { in capacity factor by } \\
2030 \text { and } 55 \% \\
\text { increase by } 2050\end{array}$ & $\begin{array}{c}\text { Up to } 25 \% \text { increase in } \\
\text { capacity factor by } \\
2030 \text { and } 55 \% \\
\text { increase by } 2050\end{array}$ & $\begin{array}{l}\text { Up to } 25 \% \text { increase in } \\
\text { capacity factor by } \\
2030 \text { and } 55 \% \\
\text { increase by } 2050\end{array}$ \\
\hline
\end{tabular}

\footnotetext{
${ }^{12}$ Changes in capital costs and turbine performance were combined to calculate LCOE, which was compared to historical LCOE reductions from other technologies to inform realistic Reference, High, and Breakthrough values. The implication is that reduction in LCOE is mostly expressed in terms of cost reduction, rather than performance improvement.
} 


\begin{tabular}{|c|c|c|c|c|}
\hline Variable & Low Value & $\begin{array}{c}\text { Reference Input } \\
\text { Value }\end{array}$ & High Value & $\begin{array}{c}\text { Breakthrough } \\
\text { Value }\end{array}$ \\
\hline $\begin{array}{l}\text { Value of } \\
\text { distributed } \\
\text { generation }{ }^{13}\end{array}$ & $\begin{array}{c}\text { Net metering } \\
\text { expires as } \\
\text { scheduled in } \\
\text { statute, and excess } \\
\text { generation receives } \\
\text { no value; retail rates } \\
\text { based on current } \\
\text { data and scaled by } \\
\text { the AEO } 2016 \text { High } \\
\text { Oil and Gas } \\
\text { Resource and } \\
\text { Technology Case } \\
\text { (EIA 2016a) }\end{array}$ & $\begin{array}{l}\text { Net metering expires } \\
\text { as scheduled, and } \\
\text { excess generation is } \\
\text { valued at the } \\
\text { wholesale rate; retail } \\
\text { rates based on } \\
\text { current data and } \\
\text { scaled by the AEO } \\
2016 \text { Reference } \\
\text { Case (EIA 2016a) } \\
\text { retail rate escalations }\end{array}$ & $\begin{array}{l}\text { Net metering expires } \\
\text { as scheduled in } \\
\text { statute, and excess } \\
\text { generation is valued at } \\
\text { the wholesale rate; } \\
\text { retail rates based on } \\
\text { current data and } \\
\text { scaled by the AEO } \\
2016 \text { Low Oil and Gas } \\
\text { Resource and } \\
\text { Technology (EIA } \\
2016 \text { ) }\end{array}$ & $\begin{array}{l}\text { Existing net metering } \\
\text { continues in } \\
\text { perpetuity, and excess } \\
\text { generation is valued at } \\
\text { the wholesale rate; } \\
\text { retail rates based on } \\
\text { current data and } \\
\text { scaled by the AEO } \\
2016 \text { Low Oil and Gas } \\
\text { Resource and } \\
\text { Technology Case (EIA } \\
\text { 2016a) }\end{array}$ \\
\hline $\begin{array}{l}\text { System } \\
\text { financing and } \\
\text { leasing costs }\end{array}$ & $\begin{array}{l}\text { Real WACC of } \\
10.2 \%, 0 \% \text { debt } \\
\text { fraction, } 3.2 \% \text { after- } \\
\text { tax real cost of debt, } \\
10.2 \% \text { cost of } \\
\text { equity; leasing not } \\
\text { available }\end{array}$ & $\begin{array}{c}\text { Real WACC of } 5.4 \% \text {, } \\
60 \% \text { debt fraction, } \\
3.2 \% \text { after-tax real } \\
\text { cost of debt, } 10.2 \% \\
\text { real cost of equity; } \\
\text { leasing available in } \\
\text { all states and sectors } \\
\text { by } 2020 \text { using a } 7 \% \\
\text { real hurdle rate }\end{array}$ & $\begin{array}{c}\text { Residential: } \\
\text { Real WACC of } 3.1 \% \text {, } \\
80 \% \text { debt fraction, } \\
2.3 \% \text { after-tax real } \\
\text { cost of debt, } 10.2 \% \\
\text { cost of equity } \\
\text { Commercial/Industrial: } \\
\text { Real WACC of } 2.9 \%, \\
70 \% \text { debt fraction, } \\
0.7 \% \text { after-tax real } \\
\text { cost of debt, } 10.2 \% \\
\text { cost of equity } \\
\text { Leasing available in all } \\
\text { states and sectors by } \\
2020 \text { using a } 5.4 \% \text { real } \\
\text { hurdle rate }\end{array}$ & $\begin{array}{c}\text { Residential: } \\
\text { Real WACC of } 1.4 \%, \\
100 \% \text { debt fraction, } \\
2.3 \% \text { after-tax real } \\
\text { cost of debt, } 10.2 \% \\
\text { cost of equity } \\
\text { Commercial/Industrial: } \\
\text { Real WACC of } 0.8 \%, \\
90 \% \text { debt fraction, } \\
0.7 \% \text { after-tax real } \\
\text { cost of debt, } 10.2 \% \\
\text { cost of equity } \\
\text { Leasing available in all } \\
\text { states and sectors by } \\
2020 \text { using a } 1.8 \% \text { real } \\
\text { hurdle rate }\end{array}$ \\
\hline $\begin{array}{l}\text { Consumer } \\
\text { adoption rates }\end{array}$ & $\begin{array}{l}\text { Ninety-five years to } \\
90 \% \text { saturation for } \\
\text { commercial/ } \\
\text { industrial } \\
\text { consumers, } 68 \\
\text { years for residential }\end{array}$ & $\begin{array}{l}\text { Fifty-seven years to } \\
90 \% \text { saturation for } \\
\text { commercial/industrial } \\
\text { consumers, } 49 \text { years } \\
\quad \text { for residential }\end{array}$ & $\begin{array}{l}\text { Forty-six years to } 90 \% \\
\text { saturation for } \\
\text { commercial/industrial } \\
\text { consumers, } 37 \text { years } \\
\text { for residential }\end{array}$ & $\begin{array}{l}\text { Thirty years to } 90 \% \\
\text { saturation for } \\
\text { commercial/industrial } \\
\text { consumers, } 27 \text { years } \\
\text { for residential }\end{array}$ \\
\hline $\begin{array}{l}\text { Siting } \\
\text { criteria }\end{array}$ & $\begin{array}{l}\text { System height } \\
\text { setback factor of } 1.5 \\
\text { times, } 12-m \text { static } \\
\text { rotor canopy } \\
\text { clearance for areas } \\
\text { with } \geq 10 \% \text { canopy } \\
\text { cover }\end{array}$ & $\begin{array}{l}\text { System height } \\
\text { setback factor of } 1.1 \\
\text { times, } 12-m \text { static } \\
\text { rotor canopy } \\
\text { clearance for areas } \\
\text { with } \geq 10 \% \text { canopy } \\
\text { cover }\end{array}$ & $\begin{array}{l}\text { System height setback } \\
\text { factor of } 1 \text { times, } 12-m \\
\text { static rotor canopy } \\
\text { clearance for areas } \\
\text { with } \geq 10 \% \text { canopy } \\
\text { cover }\end{array}$ & $\begin{array}{l}\text { System height setback } \\
\text { factor of } 0.5 \text { times, } 12- \\
m \text { static rotor canopy } \\
\text { clearance for areas } \\
\text { with } \geq 10 \% \text { canopy } \\
\text { cover }\end{array}$ \\
\hline
\end{tabular}

\footnotetext{
${ }^{13}$ Net metering expiration dates were estimated by assuming that current policies would expire as stated in statute or by an internal forecast of when distributed generation would meet the listed net-metering cap (i.e., a megawatt target or percent of peak demand).
} 


\subsection{Analysis Limitations}

The current dWind model has limitations and uncertainties including a shortage of distributed wind-sector-specific data, particularly in consumer adoption patterns but also in distributed wind finance and technology evolution. In addition, the dWind model relies on an array of exogenously derived inputs including retail electricity rates and wind technology cost trends. In reality, temporal changes in both technology costs and retail rates entail dynamic feedback that might be affected by disruptive innovations or other factors within the electric sector. The dWind model assumes no wind turbine price elasticity as a function of demand (turbines are always available at the specified price, independent of quantity deployed). As a national-scale deployment model, dWind also lacks the precision to inform individual investment decisions and relies on generalized patterns of consumer behavior that may actually vary by state, region, community, or even neighborhood. Given these data and modeling limitations, a rigorous peer review process by the Technical Review Group described earlier was conducted to obtain additional expert input for consideration in the development and execution of our work. In addition, we used existing historical data, where available, to calibrate model outputs.

The current analysis does not consider the possibility for new or extended federal or state tax credits or policy incentives, which, depending on design, could have significant impacts on behind-the-meter distributed wind. However, as noted above, we do include some variability in net-metering and siting setback standards within our scenario framework. We also do not consider competition from alternative distributed-generation sources such as rooftop solar PV. All else equal, the rapidly declining costs for solar PV could result in significant impacts on the potential for distributed-wind generation, which could be explored in future work.

Given the aforementioned limitations and assumptions, the dWind model and the results detailed in the throughout the remainder of the report are useful for understanding trends in potential as well as key variables and sensitivities. However, they should not be interpreted as predictions of future behind-the-meter distributed wind deployment or DOE targets.

\subsection{Report Organization}

This report characterizes the potential for behind-the-meter distributed wind in the United States by generally following the framework of renewable power potential considered by Lopez et al. (2012) and Beiter and Musial (2016). Section 2 provides a detailed discussion of distributed wind technology assumptions and introduces key terminology and classifications. Sections 3, 4, and 5 leverage these technology assumptions and terminology to present the progressive layers of distributed wind potential. Section 3 focuses on the addressable resource potential considered by the dWind model. Sections 4 and 5 present the economic and market potential for dWind, respectively. Each of these three sections begins with a discussion of key methodologies and assumptions before presenting and discussing results. Section 6 provides a conclusion to the paper, highlighting key findings and discussing potential future work. 


\section{Distributed Wind Technology Characterization}

Analysis results detailed in this report are contingent on a detailed characterization or representation of distributed wind technologies. Even estimates of addressable resource potential require knowledge of potential hub heights and energy generation for wind turbines ranging from kilowatt $(\mathrm{kW})$ - to megawatt-scale. In addition, estimates of economic and market potential require detailed characterizations of future cost and performance for this same broad technology size range. The current technology characterizations described in Section 2.2 and Section 2.3 are representative of recent (2015) technology and costs as informed by empirical data and certified wind turbine equipment. Projecting into the future, technology characterization becomes less certain, particularly given the range of turbine sizes considered, but relies on a combination of data, analytical methods, and recent trends to estimate potential distributed wind cost and performance through 2050. Technology characterization efforts were broken into four specific components: current performance, current costs (capital and O\&M), future performance, and future costs. Each of these components, along with an overview of technology size classes and discrete modeled turbine sizes applied in work completed to date, are detailed here.

\subsection{Distributed Wind Size Classes}

Variation in wind turbine performance and cost is represented in the dWind analysis using four turbine technology classes (Figure 2): residential, commercial, midsize, and large. When used in the context of wind turbine technology, these labels refer specifically to the size of the turbines. Notably, any turbine size may be installed at the consumer's site, independent of sector (residential, commercial, or industrial), with applicability of a specific turbine governed by the ability to site a given machine on a specific parcel of land and the consumer's load.

Residential turbines reflect sizes from 0 to $20 \mathrm{~kW}$. Commercial turbines are greater than $20 \mathrm{~kW}$ and include turbines with a rated capacity as high as $100 \mathrm{~kW} .{ }^{14}$ Midsize turbines are greater than $100 \mathrm{~kW}$ and less than $1 \mathrm{MW}$. Large turbines are $1 \mathrm{MW}$ and greater. For economic and market potential estimates, installation is limited to a single turbine, except for sites with loads larger than 1.5 MW. Within each size class, discrete turbine sizes are considered and characterized to more precisely assess the siting requirements and expected differences in capital costs across a given size class. The discrete turbine representations utilized in analysis are detailed in Figure 2 and Table 3. Table 3 includes the multiple hub-height options considered in dWind for each discrete turbine size.

\footnotetext{
${ }^{14}$ It should be noted that $10--20-\mathrm{kW}$ turbines are often used in commercial applications, particularly for farms. That is, the turbine labels should not be interpreted as being exclusive for each end-use sector.
} 


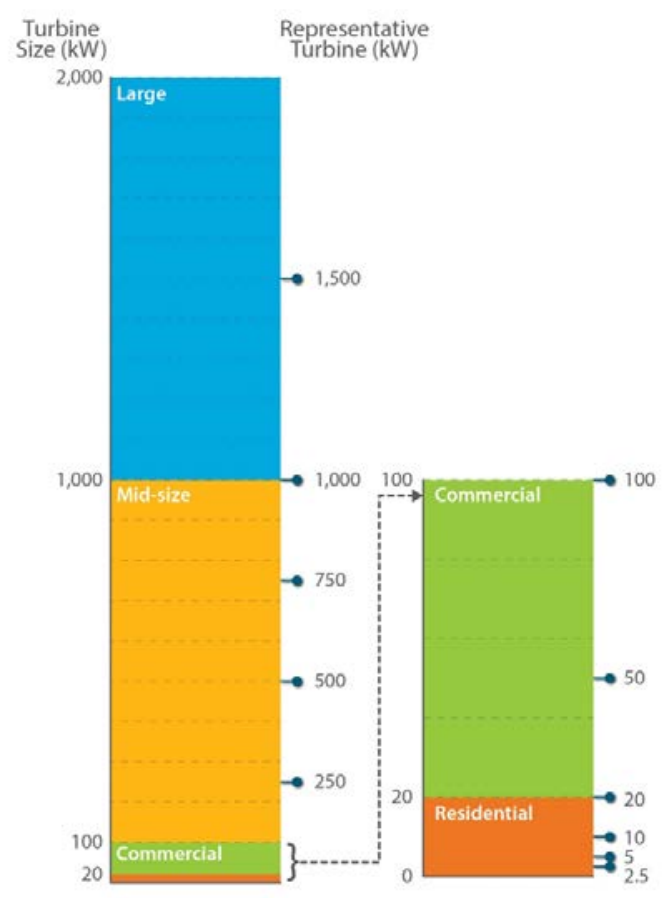

Figure 2. Distributed wind technology size classes and discrete representations in dWind

Table 3. Discrete Turbine Sizes and Dimensions Considered by dWind

\begin{tabular}{ccc}
\hline $\begin{array}{c}\text { System Size } \\
(\mathbf{k W})\end{array}$ & $\begin{array}{c}\text { Allowable Hub } \\
\text { Heights (meters }[\mathbf{m}])\end{array}$ & $\begin{array}{c}\text { Rotor } \\
\text { Radius }(\mathbf{m})\end{array}$ \\
\hline 2.5 & $20,30,40$ & 2.2 \\
5 & 30,40 & 3.1 \\
10 & 30,40 & 4.4 \\
20 & $30,40,50$ & 6.2 \\
50 & $30,40,50$ & 9.8 \\
100 & 40,50 & 13.8 \\
250 & 50 & 21.9 \\
500 & 50,80 & 30.9 \\
750 & 50,80 & 37.8 \\
1,000 & 50,80 & 43.7 \\
1,500 & 80 & 53.5 \\
\hline
\end{tabular}




\subsection{Current Distributed Wind Turbine Performance}

Current distributed wind turbine technology performance was characterized by surveying commercially available turbines within each size class (e.g., residential) and identifying those with certified turbine power curves. ${ }^{15}$ Among those with certified power curves, we screened further to isolate those with an active North American market presence as determined by having 10 or more unit sales in the United States for the period 2013-2014. ${ }^{16}$ For all turbines in a given size class that met our screening criteria, we estimated capacity factors for generic sites with 5.0 meters per second $(\mathrm{m} / \mathrm{s}), 5.5 \mathrm{~m} / \mathrm{s}$, and $6.0 \mathrm{~m} / \mathrm{s}$ annual wind speed at hub height. Using estimated performance for these turbines, we developed a normalized generic power curve for each turbine size class. Representative power curves were developed using a constant coefficient of performance $\left(\mathrm{C}_{\mathrm{p}}\right)$ up to peak power and the average specific power for all turbines meeting our screening criteria. Power curves were defined such that they would result in performance aligned with the approximate average capacity factor for the full set of turbines meeting our screening criteria at wind speeds of $5.0 \mathrm{~m} / \mathrm{s}, 5.5 \mathrm{~m} / \mathrm{s}$, and $6.0 \mathrm{~m} / \mathrm{s}$. Representative power curve and existing turbine capacity factors for the residential size class are illustrated in Figure 3. Although our efforts were focused on matching actual turbine performance over a defined wind speed range, estimates of annual energy production were comparable between the actual screened turbines and the representative power curve applied to each discrete turbine size within a given wind turbine size class. This approach avoided the complexity of pitch control versus stall-regulated and variable-speed versus constant speed power curve shapes, with a trade-off of generalizing the performance characteristics for what has historically been a highly diversified technology space.

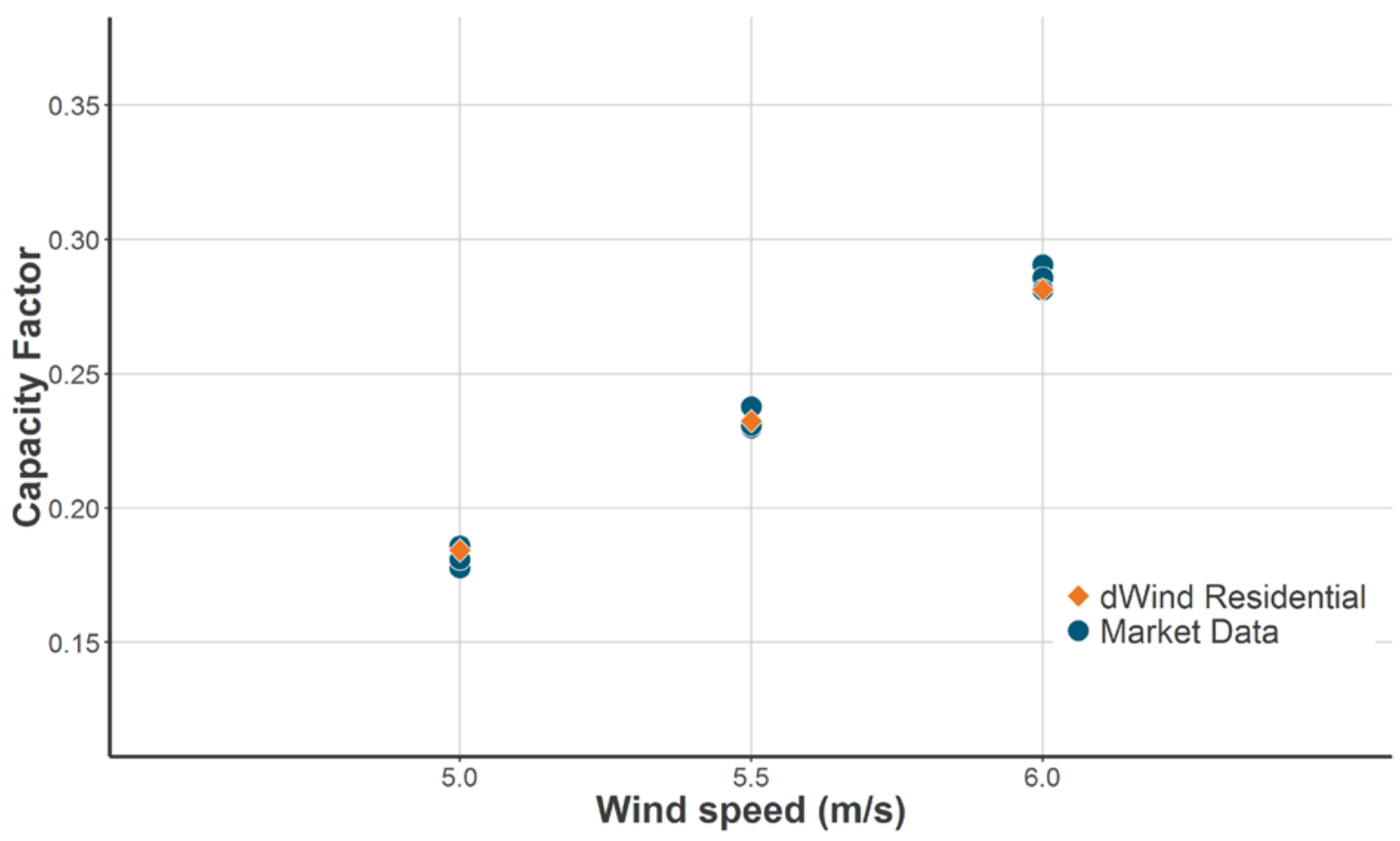

\footnotetext{
${ }^{15}$ Midsize and large turbine classes are subject to a different power curve certification process than historically "small" turbines, which are defined as having a swept area of less than 200 square meters.

${ }^{16}$ As informed by the database of projects maintained at the Pacific Northwest National Laboratory.
} 
Figure 3. Estimated capacity factors for actual turbines satisfying the applied screening criteria and the representative residential size class power curve at multiple wind speed points

Note: Market data reflect turbines in this class $(2.5 \mathrm{~kW}-20 \mathrm{~kW})$ that are commercially available in North America, have certified turbine power curves, and had 10 or more unit sales in the United States in two-year period from 2013 through 2014; three specific turbines we identified met these criteria. Wind speed values reflect hub-height annual averages.

Two deviations from the method described earlier were executed for the midsize and large turbine size classes, respectively. In the midsize class, there were no turbines that met the required number of unit sales to claim an active North American market presence. In the large class, there were a number of megawatt-scale turbines that met our criteria with wide-ranging differences in potential performance, in part as a function of original design for differing wind resource regimes.

To resolve the challenge presented in the midsize turbine class, we identified six commercially available turbines greater than $100 \mathrm{~kW}$ and less than $1 \mathrm{MW}$ that had certified power curves and were available for sale in the United States but did not meet our active market presence criteria of 10 or more unit sales during the period from 2013 to 2014. Within these six different turbines, we observed a bimodal distribution in turbine performance with three turbines clustering at a relatively lower level of performance. As the performance of these machines was relatively lower across the board given their relatively dated vintage, we elected to derive our representative generic power curve from average specific power and performance of the three better-performing turbines within this size class.

To address the challenge presented in the large turbine class, we identified a single marketleading turbine technology, the GE 1.6-100, as informed by Wiser and Bolinger (2015) and data from projects that applied for the 1603 Cash Grant program (see Section 2.3). Next, we determined that this turbine is broadly applicable for typical distributed-wind megawatt-scale deployment opportunities. Finally, using actual turbine characteristics (i.e., specific power) and estimated capacity factors for this single turbine across the previously mentioned wind speed range, we constructed a representative power curve that generally matched the estimated performance of the GE machine.

Based on the methods described herein, the four generic power curves applied for the various turbine size classes reflected in our analysis are shown in Figure 4. Notably, estimated performance is best for the commercial and large size class turbines. The relatively better performance for these two size classes generally reflects the level of advanced technology incorporated in the certified and available turbines identified in those classes. The residentialscale turbines are shown to have somewhat lower performance at least in part as a function of physical design and efficiency limits for turbines of their size. Even though we focus on the relatively better-performing midsize turbines, this class of turbine size still has the lowest overall level of performance as a function of the dated vintage of turbines that are commercially available in this size range. 


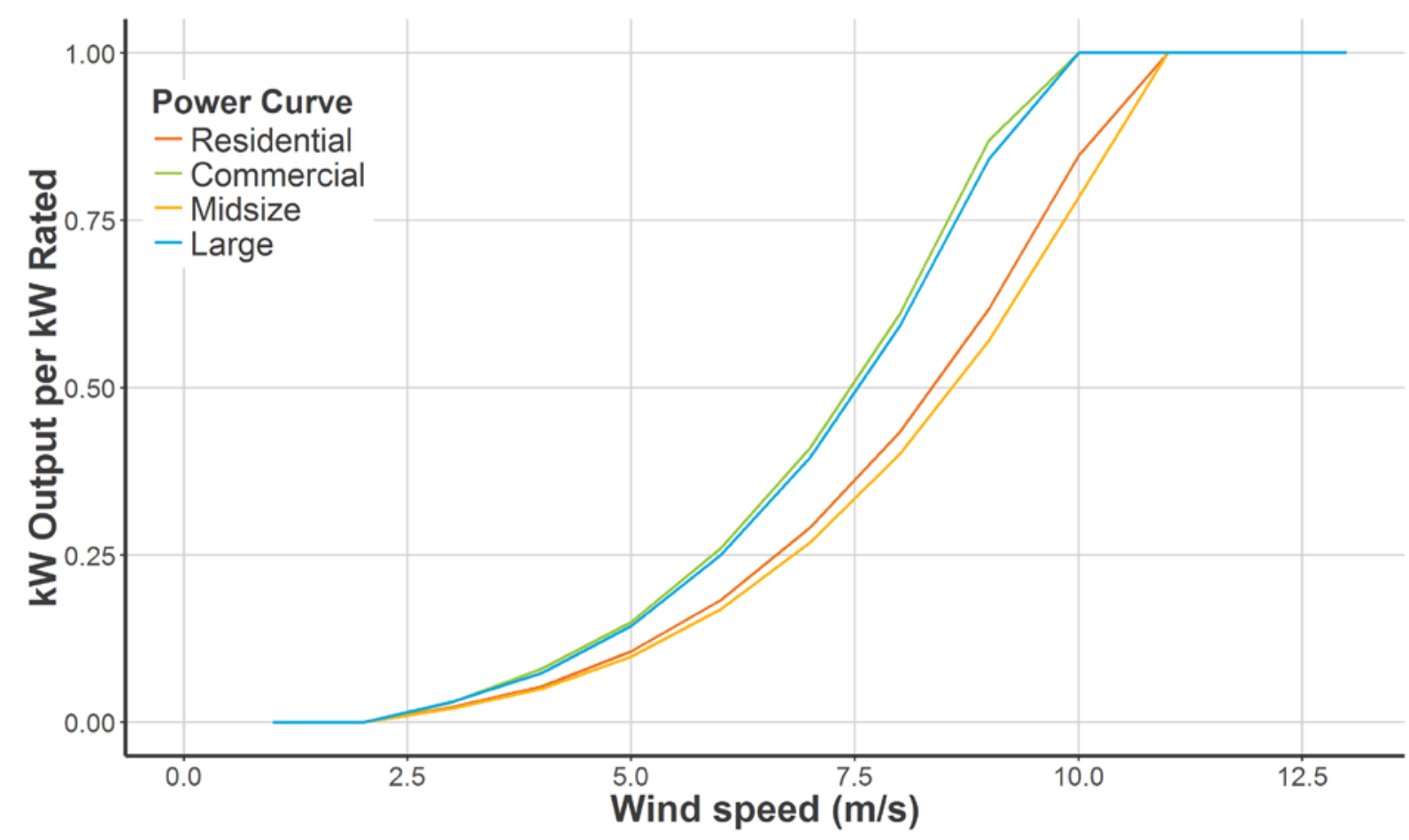

Figure 4. Representative generic power curves applied to each turbine size class

Note: Turbine cut-out speed is $25 \mathrm{~m} / \mathrm{s}$ for all power curves in dWind. 


\subsection{Current Distributed Wind Turbine Capital and O\&M Costs}

Current distributed wind project capital costs were developed from empirical data sources and validated with parallel internal laboratory data collection efforts, industry stakeholders, and other independent data sources. To identify specific costs for the discrete turbine sizes, we applied statistical curve fits to the empirical data and used these mathematical functions to estimate costs for the nameplate capacities of the individual discrete turbines. Because of the absence of a clear, continuous trend in capital costs across turbine size classes, we calculated cost curves independently for each size class.

The primary data source used to identify empirical costs was the database of applications to the U.S. Treasury Department's 1603 Cash Grant program. The 1603 program was created as part of the American Recovery and Reinvestment Act of 2009. ${ }^{17}$ Under this act, an option was provided in the longstanding wind power production tax credit (PTC) that allows qualified facilities to choose to take the $30 \%$ investment tax credit (ITC) or a cash grant in lieu of the PTC, effectively creating a refundable tax credit that could be fully captured in a single tax year. ${ }^{18}$ As part of the application process, project-specific cost data as well as other descriptive characteristics of the wind power projects were gathered. These data were analyzed — working within the confidentiality requirements of the program applications - to develop the summary statistics applied here.

Additional survey data from the Pacific Northwest National Laboratory (PNNL), state incentive program data from the New York State Energy Research and Development Authority (NYSERDA), and data reported by Wiser and Bolinger (2012), among other less comprehensive sources, were also identified and considered. These alternative data sources were ultimately used as a means of validating the results extracted from the 1603 data set because of their lack of comprehensive turbine size class coverage, limited geographic scope, limited project-specific details, and general incompatibility with the 1603 data set. ${ }^{19}$ The 1603 data were the only national data set with project-specific resolution to identify certified turbines and with sufficient detail to control for tower or hub height in reported capital costs.

Within the 1603 data set, a number of data processing and cleaning actions were executed before developing the final capital cost curves. In addition, the data were used in conjunction with individual data points from distributed wind original equipment manufacturers (OEMs) to estimate changes in capital cost as a function of changes in tower or hub height. Data processing steps included: adjusting cost data to reflect certified rated power as opposed to nameplate or peak power capacity, filtering the project data for only those using turbines with certified power curves, normalizing costs for tower height, and eliminating data points outside of two standard deviations, which was particularly critical for smaller projects in which costs are highly sensitive to site-specific considerations (e.g., an access road being included in project costs). After applying these processing and cleaning steps, statistical curve fits were developed to characterize

\footnotetext{
${ }^{17}$ Pub.L. 111-5: https://www.gpo.gov/fdsys/pkg/PLAW-111publ5/html/PLAW-111publ5.htm

${ }^{18}$ A more detailed description of the renewable-energy-related tax provisions within the American Recovery and Reinvestment Act and the 1603 Cash Grant program can be found in Bolinger et al. (2009).

${ }^{19}$ In many cases, original project-specific data and key project characteristics such as hub height and turbine type and manufacturer were not available.
} 
costs at each dWind discrete turbine size (Figure 5). Table 4 details the final capital cost values for the minimum hub height considered for each turbine size.

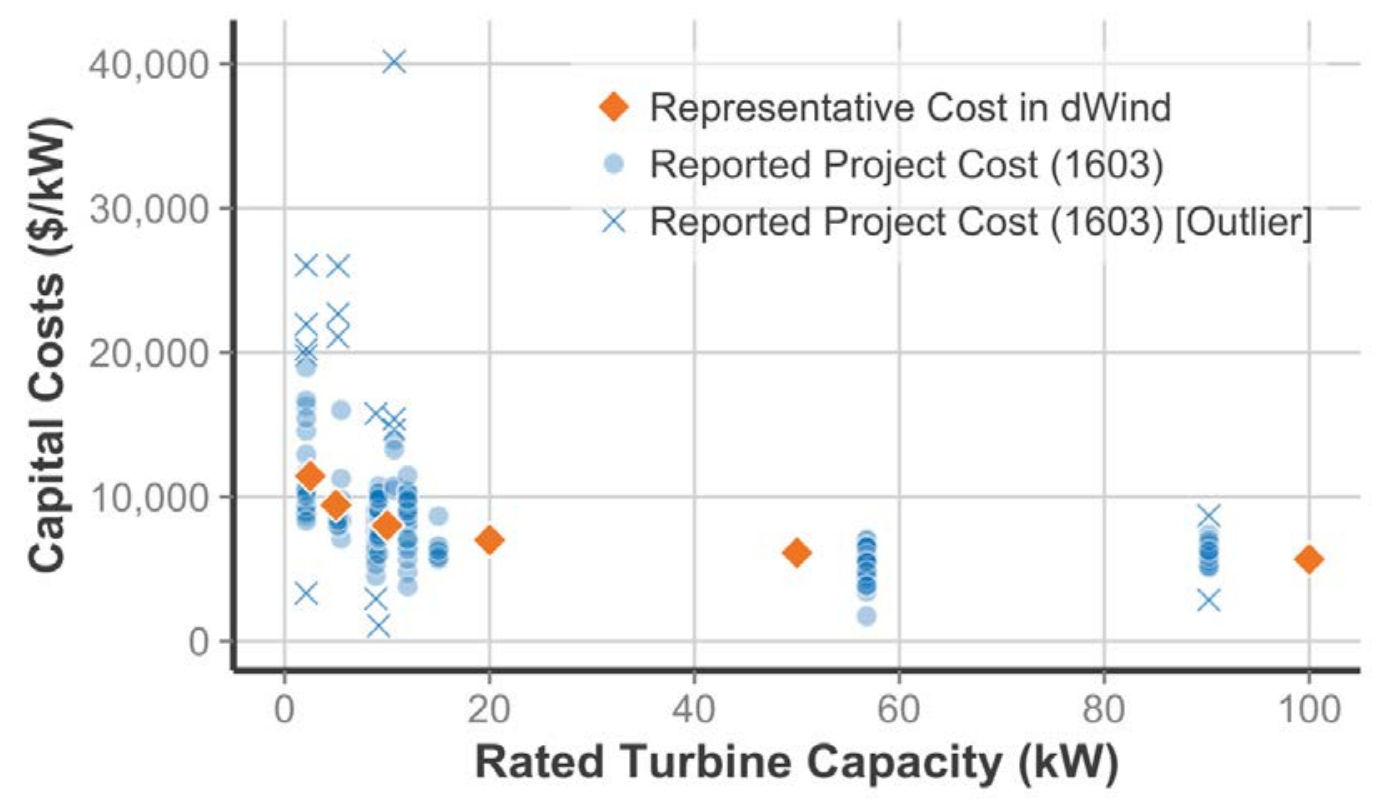

Figure 5. Empirical market data and statistical curve fit utilized to inform estimates of current capital costs for turbines from $2.5 \mathrm{~kW}$ to $100 \mathrm{~kW}$

Note: Representative costs in dWind were derived from a statistical curve fit on nonoutlier data.

Table 4. Estimated Capital Cost and Associated Turbine Parameters for Current (2014) Technology

\begin{tabular}{|c|c|c|c|}
\hline $\begin{array}{c}\text { System Size } \\
\text { (kW) }\end{array}$ & $\begin{array}{c}\text { Base Cost } \\
(\$ / \mathrm{kW})\end{array}$ & $\begin{array}{c}\text { Minimum Hub } \\
\text { Height }(\mathrm{m})\end{array}$ & $\begin{array}{c}\text { Rotor } \\
\text { Radius }(m)\end{array}$ \\
\hline 2.5 & $\$ 11,400$ & 20 & 2.2 \\
\hline 5 & $\$ 9,400$ & 30 & 3.1 \\
\hline 10 & $\$ 8,000$ & 30 & 4.4 \\
\hline 20 & $\$ 7,000$ & 30 & 6.2 \\
\hline 50 & $\$ 6,100$ & 30 & 9.8 \\
\hline 100 & $\$ 5,700$ & 40 & 13.8 \\
\hline 250 & $\$ 2,900$ & 50 & 21.9 \\
\hline 500 & $\$ 2,700$ & 50 & 30.9 \\
\hline 750 & $\$ 2,500$ & 50 & 37.8 \\
\hline 1,000 & $\$ 2,400$ & 80 & 43.7 \\
\hline 1,500 & $\$ 2,200^{20}$ & 80 & 53.5 \\
\hline
\end{tabular}

In comparing the data developed via this process with that from the additional sources noted earlier (e.g., PNNL, NYSERDA, Wiser and Bolinger 2012), we observed that the final

\footnotetext{
${ }^{20}$ Costs assumed for 1-MW and 1.5-MW projects may be higher than those recently reported in utility-scale wind reports (e.g., Wiser and Bolinger 2016) as they reflect single-turbine projects that do not capture economies of scale in multiturbine farms. Moreover, these starting point costs for 2014 are based on data from the 1603 data set and do not reflect current fourth-quarter 2016 turbine pricing trends. Cost reductions observed between 2014 and 2016 are reflected in our future cost and performance projections.
} 
representative cost estimates fell well within the typical range of costs. However, for the smaller residential class machines, costs tended to be skewed higher than other sources. These observed differences are believed to be a result of multiple factors including: normalizing costs by turbinerated capacity, which is often less than nameplate or peak capacity that might be marketed by OEMs, a potential for upward bias in the 1603 data as the $(30 \%)$ tax credit basis is derived from the reported costs, and a potential for downward bias in other data sources that rely on surveys of industry stakeholders rather than empirical project specific data.

Current O\&M costs were determined by reviewing the literature (e.g., Orrell and Foster 2015; Orrell and Foster 2016) and by soliciting additional cost data from OEMs, field servicing companies, and industry consultants. Data from literature were scarce and focused primarily on large wind plants. OEM data for large and midsize turbines were often restricted to what is charged for scheduled or preventive maintenance. Field service data were also scarce and, where available, often based on a small sample of fairly new turbines still under warranty. The resulting data were very scattered and had no clear trend by size. Accordingly, current O\&M costs were modeled as a constant $\$ 35 / \mathrm{kW} /$ year across the size classes of distributed wind. ${ }^{21}$ The range of values captured and the relative positioning of our constant size assumption is shown in Figure 6. Given the relative uncertainty around O\&M costs and the high sensitivity of smaller turbine economics to frequent on-site maintenance, future efforts could target efforts to provide higher resolution insights regarding O\&M.

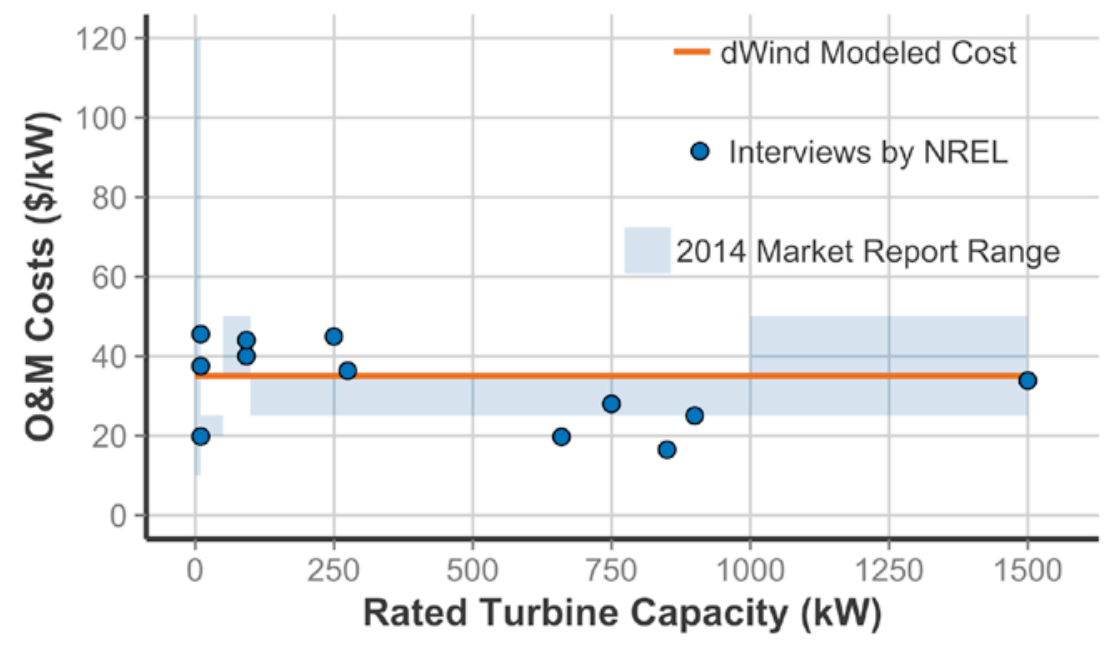

Figure 6. Estimated current (2014) O\&M costs for distributed wind turbines

Note: The 2014 market report range is reported by Orrell and Foster (2015); these data are not included in later versions of this report (e.g., Orrell and Foster 2016).

\footnotetext{
${ }^{21} \mathrm{O \& M}$ costs reflect turbine O\&M only. We do not estimate or incorporate land-lease costs or property tax payments into the economic assessment of distributed wind as we assume these turbines are installed on host-owned land and are not subject to significant property tax, though these costs would likely apply for projects on nonhostowned land.
} 


\subsection{Future Distributed Wind Turbine Performance}

Future performance of distributed wind technologies was characterized using two primary assumptions. ${ }^{22}$ First, we assume that turbine-specific power will continue to decline to levels of approximately 150 watts per square meter $\left(\mathrm{W} / \mathrm{m}^{2}\right){ }^{23}$ Although future specific power estimates will ultimately be determined by the relative cost of additional blade length and rotor growth to additional generator capacity along with the anticipated time spent operating at maximum power, the $150 \mathrm{~W} / \mathrm{m}^{2}$ endpoint is supported by a handful of known concepts or prototype machines designed for the distributed wind space. Additionally, there is an increased incentive to go to lower specific power in the lower wind quality locations that distributed wind often finds itself (i.e., a different design optimum). It may also be the case that some existing distributed wind turbine platforms have relatively robust design margins in other portions of the turbine (e.g., the turbine mainframe) as a function of more limited means to have unique custom components that could further facilitate a move to relatively lower specific power. Second, we assume that performance of the residential turbine sizes is lower than for the other size classes as a function of physical design and efficiency characteristics that apply to smaller size turbines. For all other size classes, we assume that performance converges over time as technology advancements are adopted within and across each of the respective size classes. This assumption is grounded in the absence of technical constraints that would preclude convergence. As a simplifying assumption, capacity factor improvements are equivalent across all modeled scenarios and analysis that includes performance improvements.

Functionally, we utilize the same generic power curve generation approach described for the current performance characterization discussed earlier and the new specific power $\left(150 \mathrm{~W} / \mathrm{m}^{2}\right)$ to define a common representative power curve for commercial, midsize, and large turbines. For residential turbines, we have a single independent generic power curve that uses the same end point-specific power and a lower $\mathrm{C}_{\mathrm{p}}$ commensurate with known physical limits. Although our current characterization of midsize turbine performance is relatively lower, we assume that there are no technical limits on midsize turbines and therefore allow performance to equate to that of the large turbines in all future years. This approach implicitly assumes a modern wind turbine designed specifically for midsize applications becomes commercially available.

To characterize the temporal rate of change in performance, we assume that improvements will be relatively sizable in the near term and that innovation will have diminishing returns over time such that by 2050 continued annual improvements in capacity factor will be well below 1\% per

\footnotetext{
${ }^{22}$ Overall, large turbine technology ( $\left.\geq 1 \mathrm{MW}\right)$ follow a common LCOE trajectory as detailed in the NREL Annual Technology Baseline 2016 Low Wind Cost projection. However, we were not able to match the explicit Annual Technology Baseline capital cost and capacity factor assumptions for this scenario because of limitations in the current dWind modeling capabilities. For all submegawatt technologies, new LCOE trajectories and associated cost and performance characteristics were defined as detailed throughout Section 2 as they are at a different point in the research, development, demonstration, and deployment process relative to the large turbine technology that is the focus of the Annual Technology Baseline.

${ }^{23}$ The lowest specific power wind turbines commercially available today (e.g., the GE 1.7-103) have a specific power of approximately $200 \mathrm{~W} / \mathrm{m}^{2}$ (Wiser and Bolinger 2016). All else equal, lower specific power reduces LCOE and makes lower wind resource sites more economic by increasing the energy production of a particular turbine. The specific power of the GE turbine referenced here is $204 \mathrm{~W} / \mathrm{m}^{2}$. The average specific power for residential machines that met our screen criteria today is $224 \mathrm{~W} / \mathrm{m}^{2}$.
} 
year. Resulting capacity factors to 2050 by turbine size class and based on the methods described earlier are shown in Figure 7.

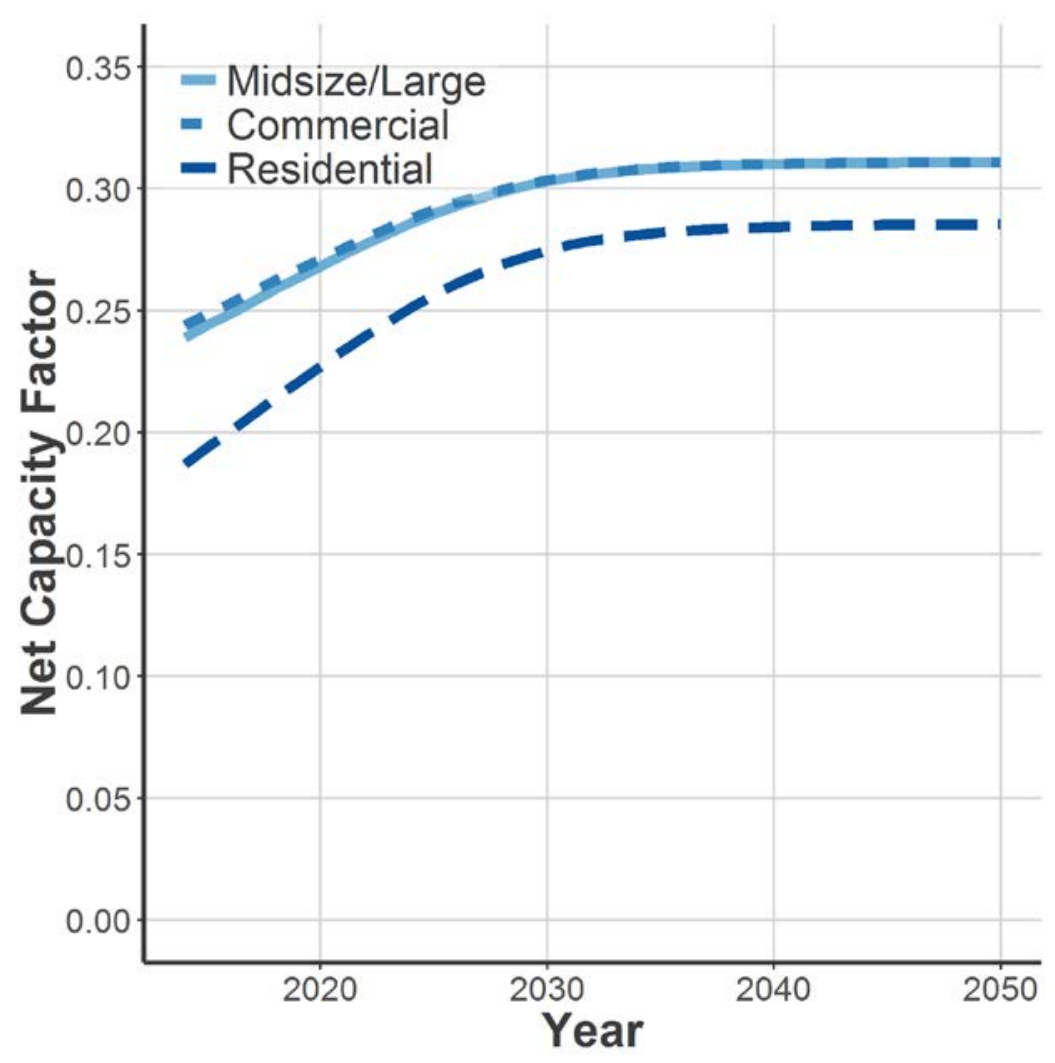

Figure 7. Applied trends in distributed wind turbine capacity factors with time by turbine size class (5 m/s annual average wind speed)

\subsection{Future Distributed Wind Turbine Capital and O\&M Cost}

The single-most difficult task in characterizing distributed wind technology in this work was estimating future capital costs. The current status of the industry coupled with substantial uncertainty in terms of future demand and deployment at the global level added to the challenge. The costs modeled here reflect a first assessment, but also a rigorous analytical estimate. Given the substantial uncertainty in this domain, a broad range of values was created to support scenario analysis (see Section 4 and Section 5). O\&M costs were assumed to decline consistently across turbine sizes by a cumulative $10 \%$ (an annual rate of approximately $0.3 \%$ per year) between 2014 and 2050, consistent with the Wind Vision (DOE 2015), for all scenarios that assume a change in distributed wind O\&M.

To resolve the substantial uncertainty in future capital cost estimates for distributed wind applications, we developed an analytical method that forms the basis for our estimates. For residential, commercial, and midsize turbine classes, we used a combination of technology learning rates and estimated global growth rates to identify potential changes in estimated levelized cost of energy (LCOE). The resulting LCOE trajectories were used in conjunction with future performance and O\&M characterizations and constant financing terms to calculate capital 
costs. For reference conditions, an LCOE learning rate of $16 \%$ was coupled with annual installed capacity growth rates beginning at 11\% between 2013 and 2014, which is consistent with global data for turbines $100 \mathrm{~kW}$ and less as reported by Orrell (2015), peaking at nearly 30\% by 2020 and then declining to settle at $12 \%$ per year by 2030 . Post-2030 growth was assumed to continue at $12 \%$ through 2050 . For low-cost conditions, an LCOE learning rate of $19 \%$ was coupled with the same global growth rate trajectory. Learning rates were based on data compiled by Electric Power Research Institute (EPRI) (2013) from studies focusing on historical learning in the landbased wind sector. A $16 \%$ learning rate corresponds to the mean learning rate identified by EPRI $(2013)^{24}$ and falls well within the range of LCOE learning rates reported by Wiser et al. (2016). This learning rate supports anticipated distributed wind capital cost levels for residential and commercial turbine sizes comparable to those targeted by some distributed wind turbine OEMs over the next 5 years. A 19\% learning rate also corresponds with estimates reported by EPRI (2013) and Wiser et al. (2016).

For residential, commercial, and midsize turbine classes, one additional LCOE trajectory was developed independent from learning rates as a breakthrough sensitivity. The breakthrough conditions have a similar LCOE reduction end point to the low-cost conditions mentioned earlier but accelerate the cost reductions such that a 40\% LCOE reduction is achieved by 2020 and $75 \%$ by 2030 . This accelerated cost reduction case was developed based on stakeholder input, which suggested that substantial priority currently exists in the industry to reduce costs more in the near term because of competition from alternative sources of renewable power generation, including distributed solar PV.

For large turbines, we relied on the Low Wind Cost LCOE trajectory detailed by DOE (2015) and in the NREL 2016 Annual Technology Baseline (Cole et al 2016). ${ }^{25}$ This independent LCOE trajectory was used for large wind turbines, which have seen significant public and private sector research and development investment over the past three decades and are believed to have captured a more substantial portion of their long-term cost reduction potential in today's modern technology. This trajectory results in substantially less change in 2050 LCOE than the various trajectories applied to the other distributed wind size classes. Notably, although we used the LCOE trajectory from DOE (2015) for the large turbine sizes, we did not attempt to utilize the specific LCOE input values (e.g., capital cost, O\&M, and capacity factors) detailed in DOE's Wind Vision (2015). Rather, we used the characterizations noted earlier and calculated the requisite capital cost required to achieve the specified LCOE reduction. Based on the assumed changes in capacity factor detailed previously, this approach results in a rather limited reduction in capital cost for the large turbine class.

DOE's Low Wind Cost trajectory (DOE 2015) is applied for two reasons: it is more consistent with subsequent analysis and research on future wind turbine cost trajectories (Wiser et al. 2016), and it is assumed that distributed wind applications have opportunities for innovation and efficiency in development and balance-of-station costs that may increase their probability of relatively greater cost reduction than modern multimegawatt wind power plants. This large

\footnotetext{
${ }^{24}$ Electric Power Research Institute data include studies with learning rates calculated on a cost-per-kilowatt basis and cost-per-kilowatt-hour basis. Estimated statistics (e.g., mean) appear to reflect values for the full sample of surveyed literature.

${ }^{25} \mathrm{http}: / /$ www.nrel.gov/analysis/data tech_baseline.html
} 
turbine trajectory was used in all scenarios that assume a change in distributed wind technology costs.

Although the future LCOE trajectories for residential, commercial, and midsize turbines were more substantial than the LCOE trajectory for large turbines, the capital costs for large turbines were treated as the effective floor on future capital costs. Accordingly, the smaller turbine size classes were not allowed to be cheaper on a normalized capital cost $(\$ / \mathrm{kW})$ basis than the large turbine size class. The resulting LCOE trajectories are detailed in Figure 8. Figure 9 illustrates the change in distributed wind capital costs associated with capital cost values for each of the LCOE trajectories.

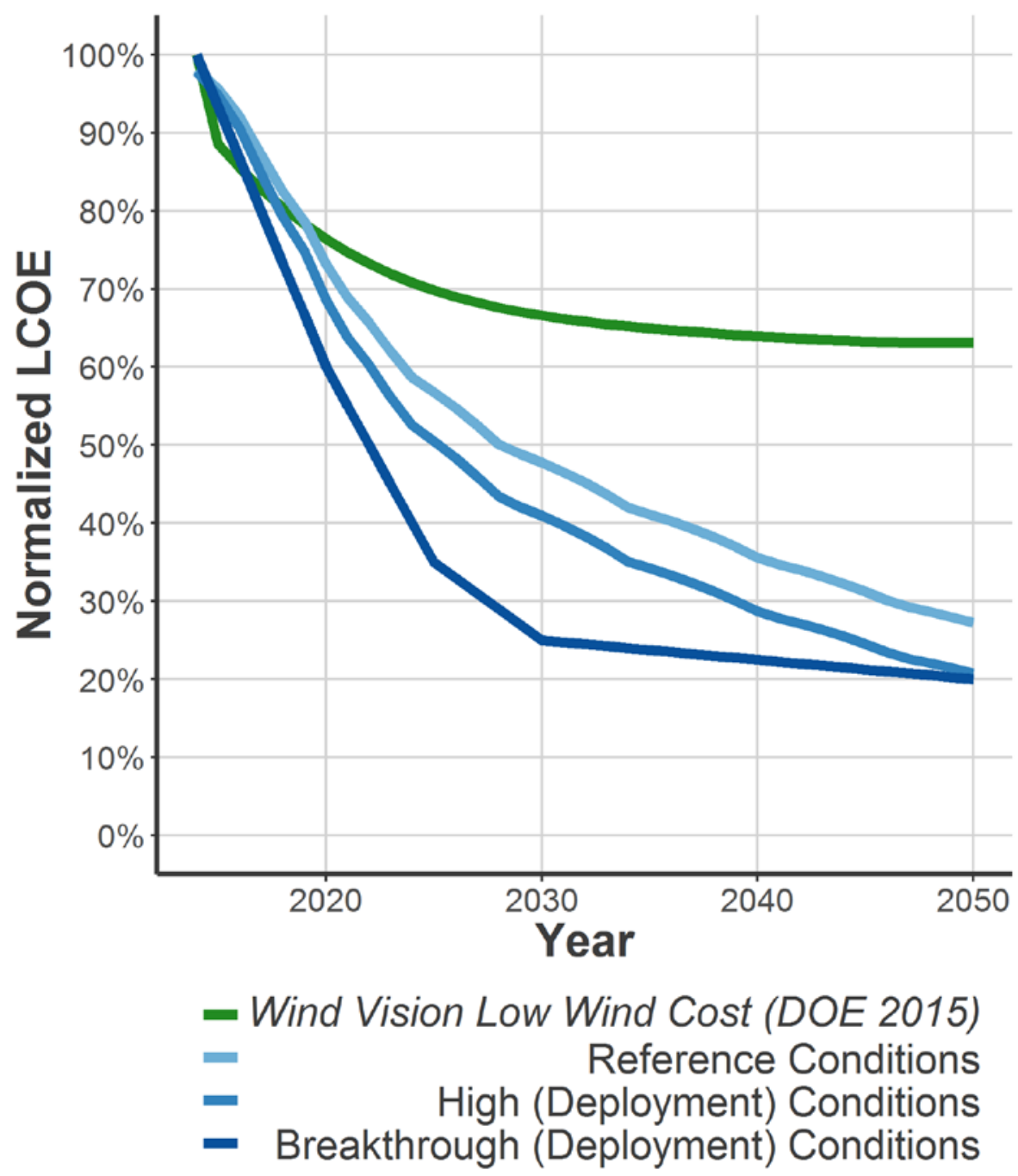

Figure 8. Distributed wind LCOE trajectories used in modeling analysis 


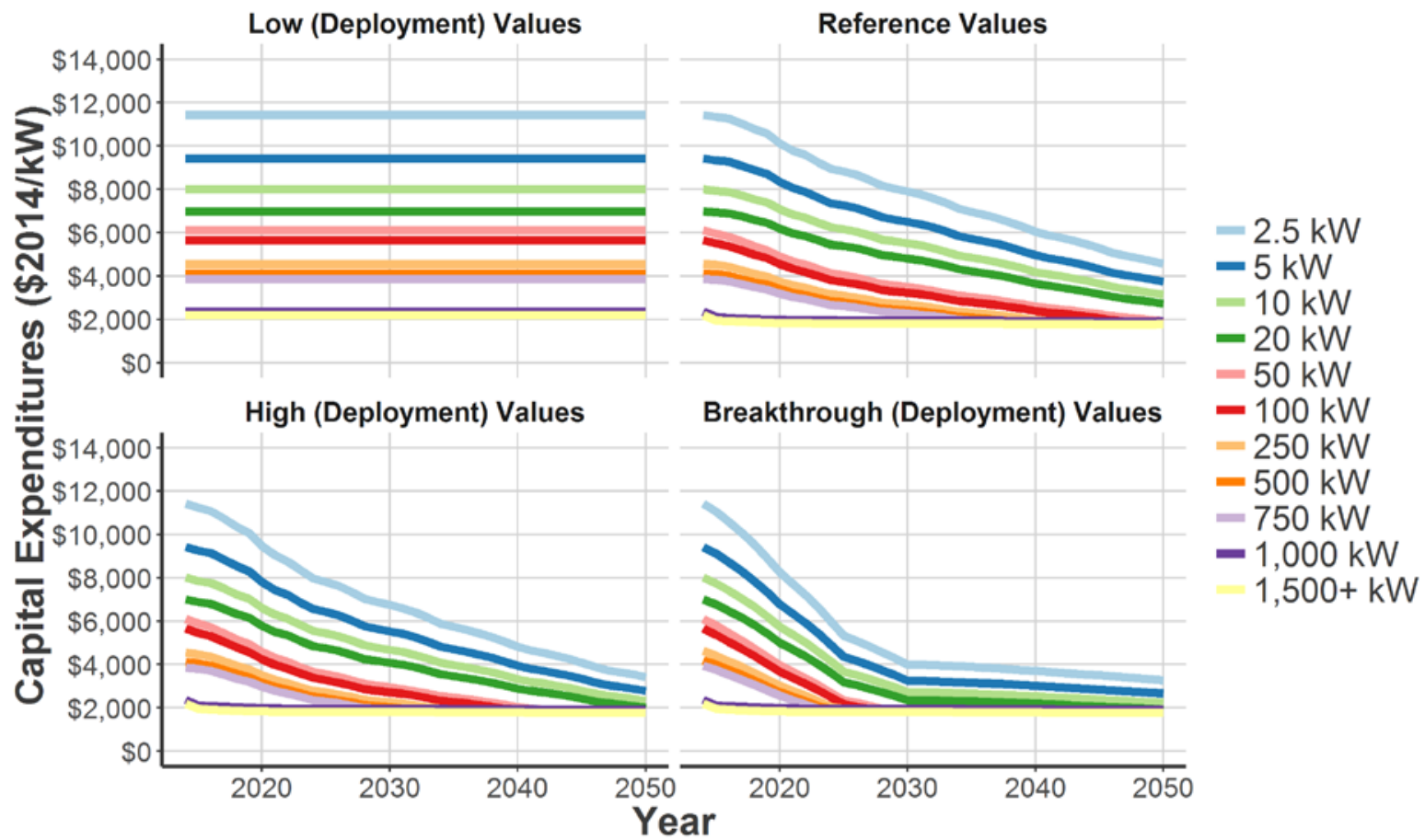

Figure 9. Applied trends in distributed wind turbine capital cost with time by discrete turbine size 


\section{Addressable Resource Potential}

Analyses of renewable energy potential typically begin with assessments of resource and technical potential. In this study, we have not included a formal resource or technical potential assessment. Instead, we introduce the concept of "addressable resource potential," which we define as the upper limit of potentially developable behind-the-meter distributed wind resource considered by the dWind model. Although not perfectly aligned with the resource or technical potential, our assessment of addressable resource potential encompasses elements of both. Specifically, it includes geospatially resolved wind speed data, as well as site-specific factors that would affect the siting of, and therefore, technical feasibility of distributed wind turbines. It is important to note, however, that the assessment of addressable resource potential for behindthe-meter distributed wind presented here is less comprehensive than formal technical potential estimates, particularly in comparison to other published studies such as Lopez et al. (2012) and Gagnon et al. (2015).

\subsection{Methods and Assumptions}

Addressable resource in this analysis is defined as the maximum amount of wind capacity that could be sited proximal to electricity demand and constrained by key siting considerations for those areas. This definition explicitly excludes consideration of the actual amount of end-use electricity demand. Turbines must be located in areas near buildings but are sized to maximize annual energy generation, subject only to key siting constraints and not to account for whether the generated energy could actually be consumed behind the meter or on site.

The underlying basis for our estimate of behind-the-meter distributed wind addressable resource is a geospatially resolved data set of typical wind resource. This data set was licensed from AWS TruePower (2012) and consists of hourly average, typical meteorological year wind speeds for multiple hub heights at a spatial resolution of $200 \mathrm{~m} .{ }^{26}$ For the dWind model, we leverage these data to calculate geospatially resolved, hourly generation profiles, using the turbine power curves described in Section 2. For the addressable resource presented here, we only use the power curves for the current distributed wind technologies (Section 2.2). The resulting data set provides an estimate of the typical performance of these current distributed wind technologies at various hub heights across the United States, encapsulating the key elements of both resource potential and technology performance.

To refine this data set into an estimate of addressable resource, we then incorporate factors to account for the technical feasibility of distributed wind development across the continental United States. Part of the challenge in assessing the technical feasibility of distributed wind is that determining the true suitability of a parcel of land to host turbines is likely to depend on several site-specific details, many of which are not available as nationwide geospatial data sets or would require a site-by-site assessment for validation. In addition, local and regional jurisdictions may vary in regulations governing site permitting. Thus, to conduct a national assessment of the addressable resource for distributed wind, we use four criteria as proxies for the factors that might impact distributed wind development:

1. Proximity to buildings. Defined as a proxy for proximity to end-use electric demand.

${ }^{26}$ For a detailed description of these data, refer to Sigrin et al. (2016). 
2. Characteristics of nearby canopy cover. Defined as a proxy for vertical obstructions that would affect local wind resource quality or turbine obstructions.

3. Average size of land parcels. Defined as a proxy for turbine height setbacks, from neighboring parcels.

4. Turbine power density. Defined as a proxy for interturbine wake or performance effects.

In defining the siting constraints, we focused on first-order factors affecting distributed wind development that are supported by nationally measurable and highly resolved geospatial data sets.

To perform this analysis, we evaluated each of the four selected criteria at the geographic resolution of U.S. census blocks. Census blocks are the smallest geographic unit used by the U.S. Census Bureau. There are approximately 11 million blocks in the United States, including about 7 million that contain at least one building. The land area of census blocks varies, but in urban areas they are typically equivalent to a city block. In rural areas, a block may be larger or its shape could be based on local physiographic features. The average size of a block is approximately $1 \mathrm{~km}^{2}$. As a result of this approach, the addressable resource in each block is based on the average characteristics of that block. That is, the average characteristics of each census block are assumed to be representative of all properties in that block, including canopy height, canopy cover, and parcel size. In rural areas, where census blocks are larger, this approach may fail to capture fine-grained spatial variation in the key siting criteria (i.e., canopy characteristics and parcel size).

\subsubsection{Key Assumptions}

There are three critical, overarching points about this methodology that merit emphasis. First, although the four selected criteria capture first-order factors that drive the technical feasibility of distributed wind development, this analysis omits consideration of several other relevant environmental and site-specific factors. Some of the notable factors included in other assessments of wind resources (e.g., Lopez et al. 2012) but are excluded here include land ownership, wetlands, slope or terrain restrictions, and proximity to airports. The omission of these factors is what distinguishes our assessment of addressable resource potential from a more formal and comprehensive assessment of technical potential.

The second key point to emphasize is that the logic and settings applied to the four selected siting criteria do not account for local or regional variation in siting regulations or guidelines. Instead, the settings applied in this analysis are derived from commonly used and cited guidelines and recommendations, as determined by a review of state-level policies recorded in the DSIRE database (DSIRE 2016). The third and perhaps most critical point to note is that the addressable resource methodology presented here does not account for potential competitive or alternative use of developable land by other renewable technologies, most notably including utility wind. This approach is consistent with typical formulations of technical potential (e.g., Lopez et al. 2012), which have previously evaluated technical potential for specific technologies independently and without consideration of one another. This approach is used because an evaluation of potential technology competition must also consider economic and market factors, moving such considerations into the realm of economic and market potential. Nonetheless, it is 
important to emphasize that our addressable resource assessment for distributed wind likely includes a considerable portion of land that would also be suitable for utility wind development. This overlap between technologies is likely to be most prominent in rural census blocks, with large parcel sizes and sparse or short canopy cover. In these areas, our methodology may site one utility-scale (i.e., $1 \mathrm{MW}+$ ) turbine per parcel. In our results and discussion (Section 3.2), we seek to distinguish these areas of overlap by presenting results for utility-scale turbines separately from all small turbine classes. At the same time, in areas where utility-scale turbines are not suitable, the resource estimates detailed here may add new resources relative to the quantities previously estimated in prior resource assessments (e.g., Lopez et al. 2012).

\subsubsection{Turbine Siting Algorithm}

Using the four criteria identified above and described in more detail in Appendix A, we applied the following process to determine the allowable turbine heights and rotor radii allowed ${ }^{27}$ within each census block:

1. Filter out census blocks with no buildings.

2. Calculate the minimum allowable blade tip height for each block based on tree canopy (in blocks with $>10 \%$ canopy, assume a 12-meter $(\mathrm{m})$ minimum clearance above average canopy height).

3. Calculate the maximum allowable blade tip height for each block based on the average parcel size and a $1.1 \mathrm{x}$ system height setback ${ }^{28}$.

4. Identify the set of potential turbine models (hub height and system size) that can be sited in each block, given blade height constraints and turbine blade heights (see Table 3).

5. Select a single turbine model from the available set of turbine size categories modeled for each block to maximize annual energy production that could be produced in the parcel based on the above constraints; assume that each parcel in the block can install no more than one turbine.

6. Cap system counts and capacities to $3 \mathrm{MW} / \mathrm{km}^{2}$ for blocks with large power densities. ${ }^{29}$

\footnotetext{
${ }^{27}$ Simply because a turbine may be allowed on a given parcel does not mean that it will be determined to have economic or market potential. Additional financial and consumer load constraints among others are applied to these estimates. Turbine sizing in particular may face additional binding constraints based on annual consumer load.

${ }^{28}$ As described in Section 1, system height setback is a variable in our assessments of economic and market potential. This variable allows us to understand how sensitivity in those metrics may vary as a function of changes in system height setback requirements. However, for the purposes of estimating addressable resource potential, we use only a single standardized system height setback, consistent with the midpoint value for policy as written in June 2016, consistent with our Reference scenario input values. Low siting criteria detailed in Table 2 reflect the upper end of current policy standards, High siting criteria reflect the lower end of current policy standards, and Breakthrough siting criteria reflect a policy future whereby typical variances today are codified more broadly.

${ }^{29}$ Note that the potential constraints relating to interconnecting new systems at the distribution level are not considered in the addressable resource potential estimates nor as a constraint on market growth.
} 


\subsection{Results and Discussion}

Based on the methods and assumptions detailed above, the addressable resource for distributed wind in the continental United States is substantial. As explained in Section 3.1.1, our assessment does not consider potential alternative or competing uses of developable land for other technologies - most notably large wind plants serving utility-scale demand. Nonetheless, our methodology does provide for some insight into the potential overlap between distributed wind's addressable resource and utility wind. Specifically, where our methodology shows that megawatt-scale turbines are technically feasible, it is likely that utility wind development would also be suitable and in some cases potentially preferable. On the other hand, our estimates for submegawatt-scale distributed development most likely represent areas that would not be suitable for utility wind development because of factors such as property setbacks and building density. Therefore, we present results in this section using the four turbine classes highlighted in Section 2.1, with a focus on the submegawatt-scale addressable resource (i.e., residential, commercial, and midsize turbines). Results for megawatt-scale turbines (i.e., large turbines) should only be considered within the context that they represent a substantial potential overlap with utility wind development.

Using our applied siting criteria, behind-the-meter distributed wind development is technically feasible for approximately 49.5 million sites, or about $44 \%$ of the continental U.S. building stock. ${ }^{30}$ The majority of these developable systems $(42.8$ million, or $86 \%)$ are small $(\leq 100 \mathrm{~kW})$ residential or commercial-scale turbines (Figure 10). Midsize and large turbines comprise approximately $5 \%$ and $9 \%$ of the developable systems, respectively. Notably, these estimates do not consider whether sufficient on-site load exists to utilize this generation. As a result, portions of the commercial, midsize and large system counts may ultimately be better suited for smaller turbines. These constraints are included in Figure 14 and in economic and market potential estimates.

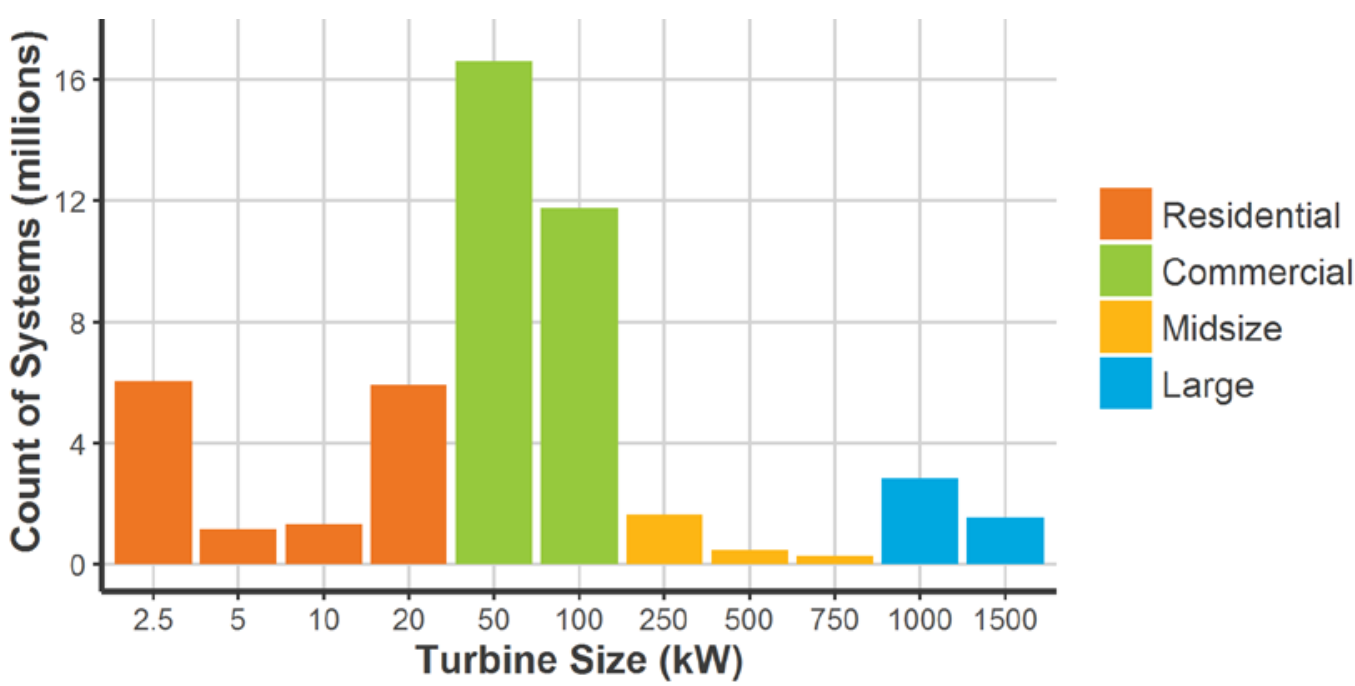

Figure 10. Addressable resource in system counts by system size and size class

\footnotetext{
${ }^{30}$ That is, there are tens of millions of potential consumers that could technically utilize the behind-the-meter distributed wind systems that are the focus of this analysis; we do not consider building-mounted turbine technologies.
} 
Our assessment also shows that submegawatt-scale turbines could provide up to $3.0 \mathrm{TW}$ of capacity and 4,400 TWh of annual energy generation. The Energy Information Administration (EIA) estimates 2015 electricity consumption on its website at approximately 3,700 TWh. Figure 11 shows the breakdown of capacity by turbine size for residential $(152 \mathrm{GW})$, commercial $(2,006$ $\mathrm{GW})$, and midsize turbines (844 GW). Due in part to their size, large (i.e., megawatt-scale) turbines could provide an additional 5.1 TW of capacity and 14,000 TWh of annual energy generation to the addressable resource for distributed wind; however, much of that capacity could be equally or potentially even more suitable for utility wind power production than behindthe-meter applications.

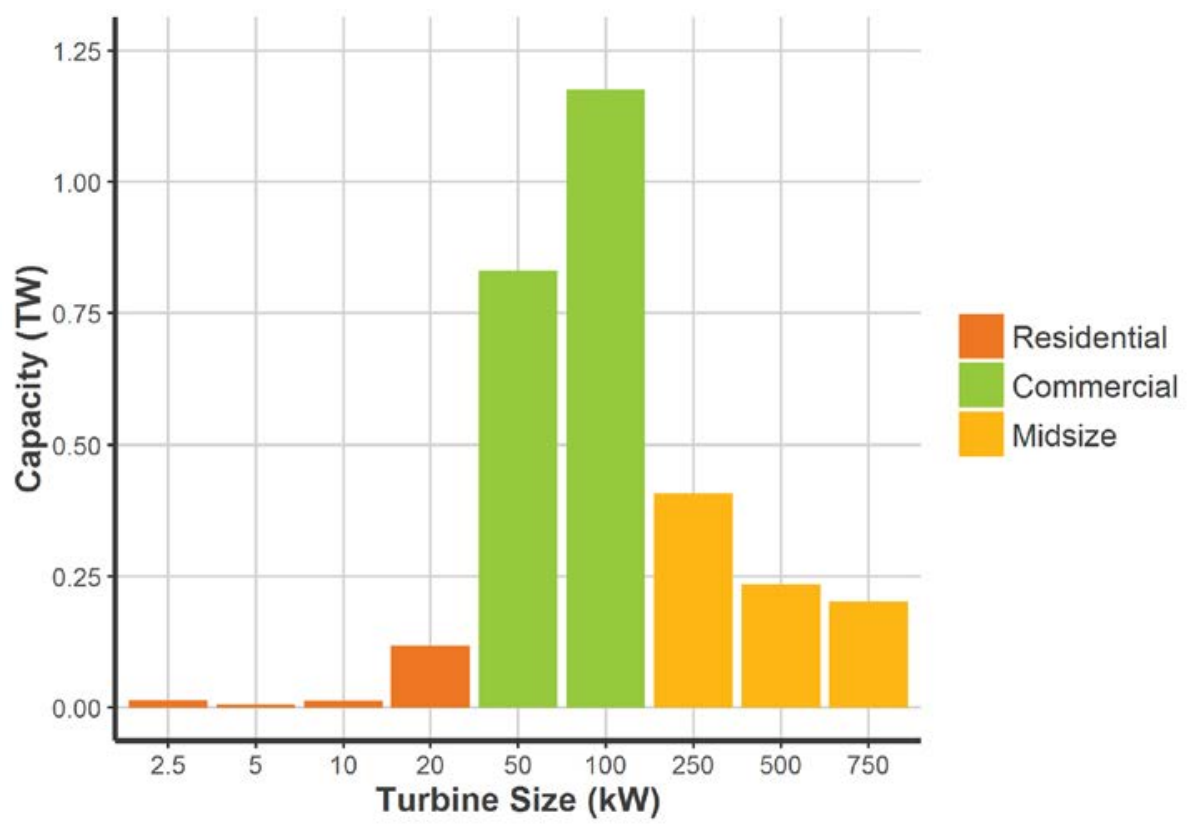

Figure 11. Addressable resource in capacity by system size and class

(Submegawatt turbines only)

Our assessment also reveals strong regional trends in addressable resource for distributed wind (Figures 12 and 13). These differences are driven by regional variation in building and population density, canopy cover and height, typical parcel size, and the overall number of buildings in each state. Strictly from an addressable resource perspective, opportunities for submegawatt-scale turbines appear most substantial in regions with large rural and suburban populations such as California, Pennsylvania, North Carolina, Florida, and Texas, whereas opportunities for megawatt-scale turbines appear most substantial in historically agricultural regions that are relatively more populated, such as Illinois, Iowa, Minnesota, Missouri, Wisconsin, and Texas.

Based on our assessment, the addressable resource for distributed wind is very large and could contribute substantial power production relative to U.S. electricity demand. The preceding sections have highlighted a number of critical assumptions and limitations underlying this assessment - the most important of which are described in Section 3.1.1 and merit reconsideration to evaluate their potential impacts. First, the omission of additional environmental and site-specific siting criteria likely results in the addressable resource estimates being biased high relative to a more comprehensive technical potential estimate. By comparison, 
the effect of excluding regional and local variation in siting guidelines is less obvious; it might have resulted in higher estimates in some regions but lower estimates in others. Finally, as discussed at length in this section, a substantial portion of distributed wind addressable resource, mostly for megawatt-scale turbines, may be equally or more suitable for utility wind development. We have presented the results in this section to account for and make clear where those potential overlaps may occur. Despite these limitations, our assessment of addressable resource provides a first-of-its-kind foundational understanding of the opportunity space for distributed wind.

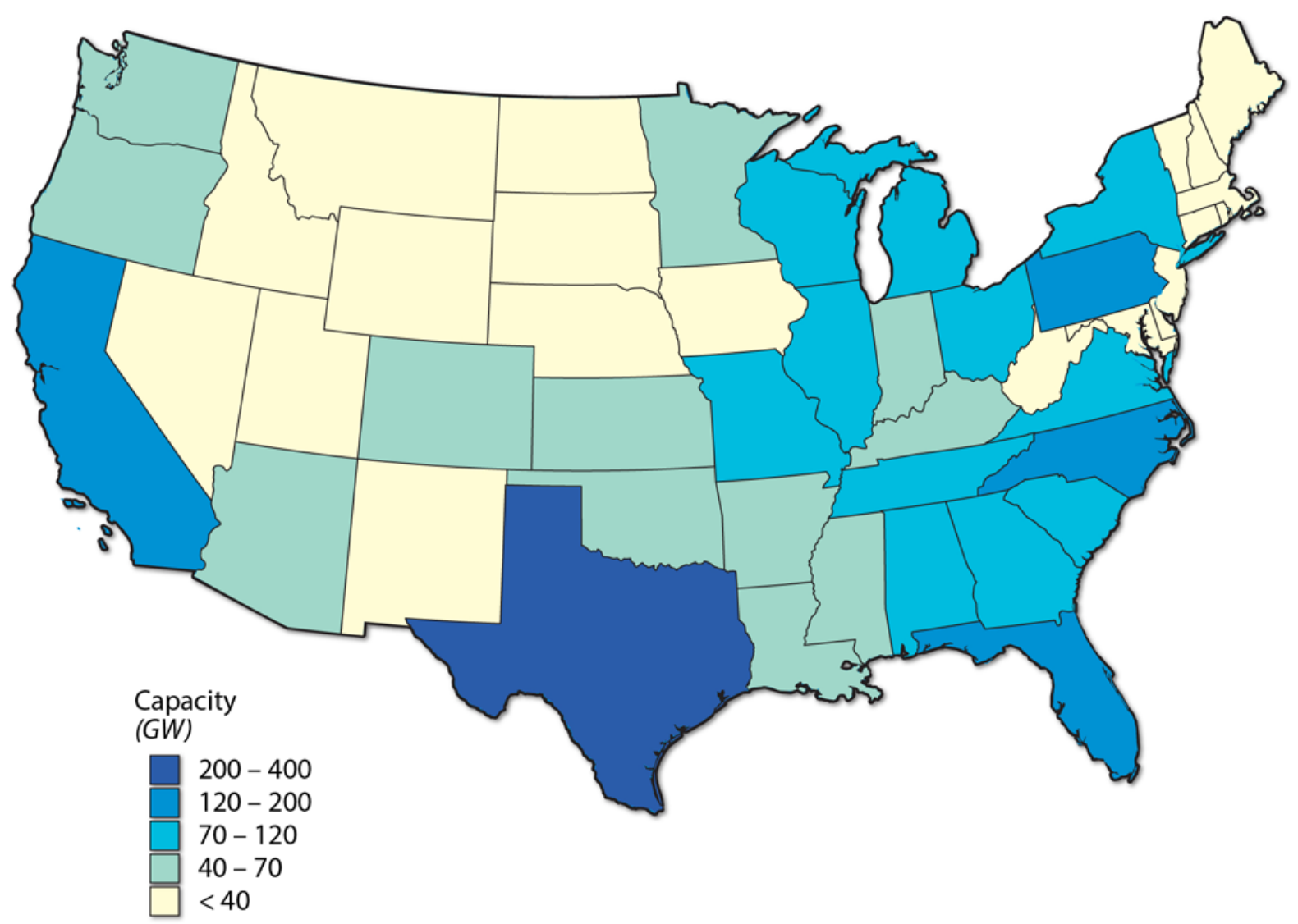

Figure 12. Addressable resource of submegawatt-scale turbines by state

Note: Regional distribution is driven by variation in building and population density, canopy cover and height, typical parcel size, and the overall number of buildings in each state but is not correlated with wind resource quality. In contrast, economic and market potential are correlated with wind resource quality. 


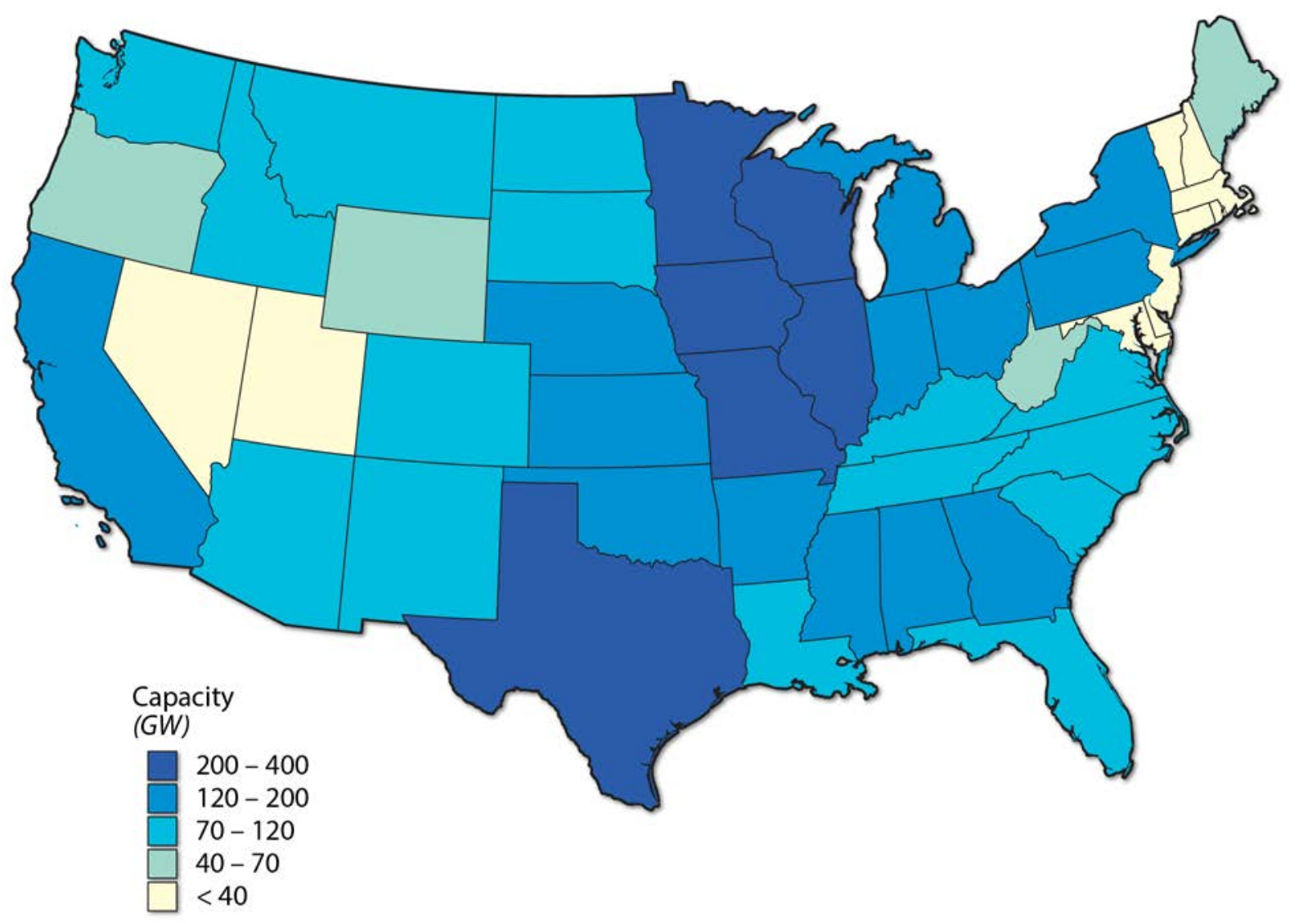

Figure 13. Addressable resource of megawatt-scale turbines by state 


\section{Economic Potential}

Though prior studies have assessed the economic potential of U.S. land-based wind (Lopez et al. 2012; Brown et al. 2016), few have explicitly considered the economic potential of distributed wind. Several factors distinguish a characterization of distributed wind economic potential from utility-scale potential. For one, distributed-scale systems generate value against marginal retail electricity rates, rather than wholesale rates. In addition, customer-owned systems are eligible for a different set of rebates or policies, such as the federal Business Energy ITC or Renewable Energy Tax Credit and net energy metering, where applicable. Financial assumptions could also differ, most notably with respect to the leasing business model that requires no equity on the part of the customer but also in terms of the type and cost of credit available to potential customers. Finally, distributed wind is typically sized to offset the owner's on-site electrical consumption, unlike utility-scale turbines, which sell generation into wholesale markets. Although distributed wind has historically been installed at a higher cost per unit capacity than utility-scale wind (Section 2.3), these characteristics suggest that the relative economics of distributed wind deserve an explicit focus. Moreover, as consumer adoption patterns for distributed wind are relatively less well understood, in the current market state, economic potential provides an additional useful indicator of technology viability relative to current estimates of market potential.

\subsection{Methods and Assumptions}

Economic potential in this analysis is defined as the amount of continental U.S. customer-sited capacity in a given year that could return a positive NPV. Constraints included in the economic potential are that the system must be sized to meet the on-site electrical consumption and that generation is valued based on local retail rates and net metering (if available) as well as other applicable policies. ${ }^{31}$ Economic potential is calculated under a range of financial conditions, which are reflected in the NPV discount rate. The economic potential is calculated for each model year, based on time-varying conditions for the given year (i.e., capital costs and retail rates). As we focus only on on-site electrical consumption, business models that pool the demand of many customers - to collectively purchase larger but lower-cost turbines - are not reflected in our analysis.

\subsubsection{On-Site Electrical Consumption}

At the highest level, economic potential is limited by the quantity of on-site load that might be served by behind-the-meter distributed wind. To estimate on-site load, the dWind model simulates retail loads and load patterns regionally (Sigrin et al. 2016). Hourly consumption patterns rely on representative modeled profiles as described by Sigrin et al. (2016). The total sum of electrical consumption represents the consumer load or the total amount of load that could be offset with distributed wind generation. A simple heuristic is then used to size a wind turbine based on the end user's load profile. This heuristic determines the largest turbine capacity that could be installed, subject to siting and turbine height restrictions and maintaining annual system generation below annual electricity consumption. For end users without a current netmetering policy, the annual generation is limited to a reduced share of annual consumption to minimize the amount of generation exported to the grid at a lower compensation value. Figure 14

\footnotetext{
${ }^{31}$ State and federal policy incentives are modeled as written in statute as of June 2016. Incentives that do not include a specified end date are assumed to expire at year-end 2016.
} 
aggregates these data by consumer sector to demonstrate the national electrical load seen by the model for each sector in 2016 for three sequential constraints, all customers modeled $(3,300$ TWh demanded annually), the set of customers without siting restrictions (1,455 TWh demanded annually), and the set of customers without siting restrictions and a capacity factor of $\geq 20 \%$ ( 286 TWh demanded annually).

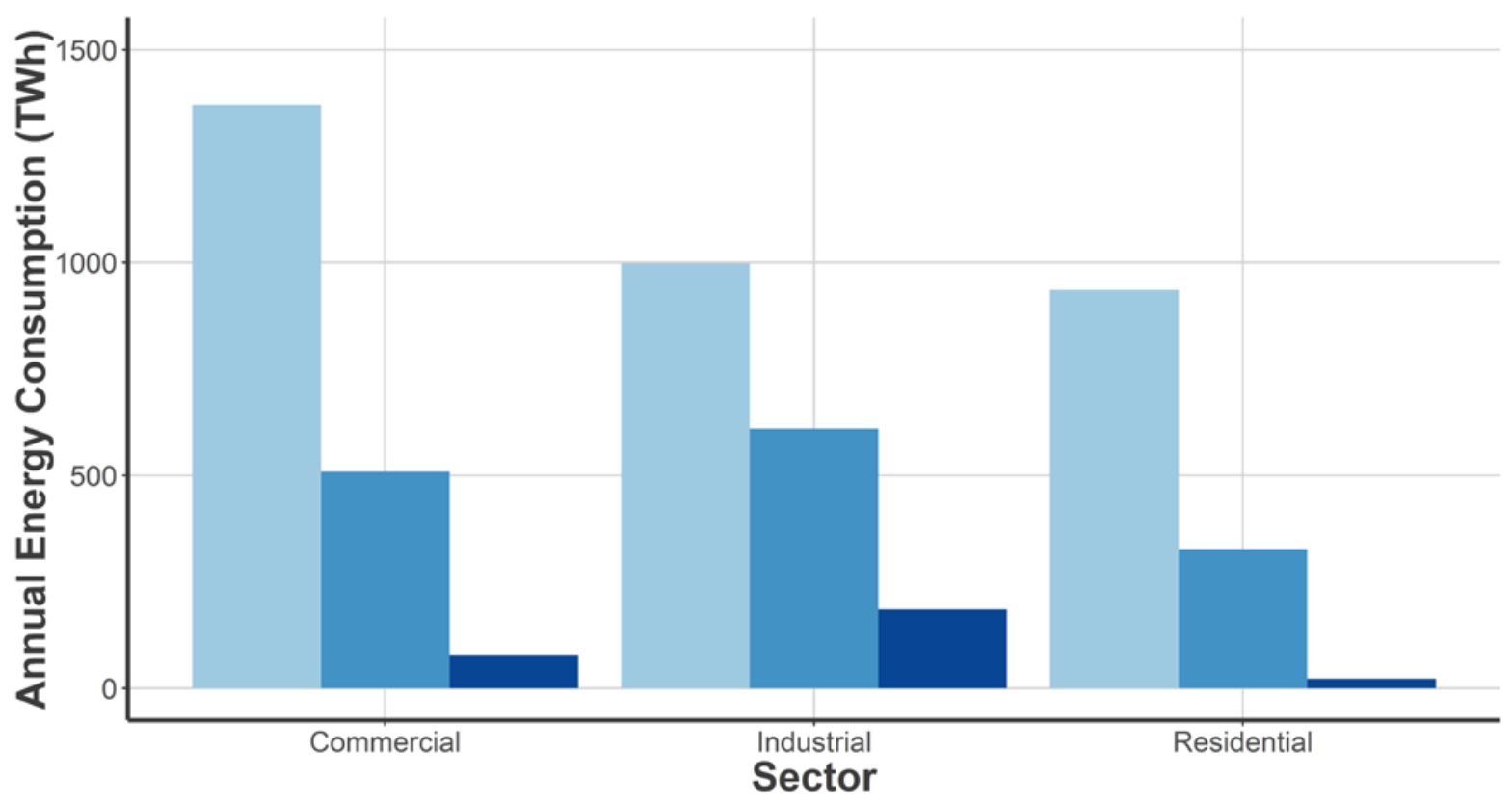

All Modeled Customers —Customers Without Siting Restrictions —Customers With $>20 \%$

Figure 14. Terawatt-hours of consumer load by sector for all end users, for buildings without siting restrictions, and buildings that could achieve a $\geq 20 \%$ capacity factor in 2016

These data demonstrate important differences in potential load by sector, as well as the fact that turbine siting has a substantial effect on potential consumption of distributed wind energy. Nevertheless, they also illustrate the gross magnitude of the consumer load opportunity for behind-the-meter distributed wind. To place these numbers in context, total wind power capacity operating at year-end 2015 was estimated at nearly $75 \mathrm{GW}$ (Wiser and Bolinger 2015) and total wind power generation for the full calendar year of 2015 was estimated at $191 \mathrm{TWh}$ (EIA 2016b).

\subsubsection{Value of Generation}

After considering the quantity of load that might be served by distributed wind as well as the performance of distributed wind turbines at the specified sites, economic potential requires we consider the fundamental financial viability of the system. A key element in determining financial viability is the value created by offsetting retail electricity purchases. In this vein, the value of distributed generation is largely a function of location-specific retail rates and the structure of the rates (e.g., volumetric, demand-based, and time of use). Availability of net metering is also critical. To estimate the value of wind generation to model agents, ${ }^{32} \mathrm{dWind}$

\footnotetext{
${ }^{32}$ Representative end users or electricity consumers in dWind.
} 
calculates the projected electricity bills with and without a turbine over the turbine lifetime. Of course, future value of generation is uncertain because of many factors - fuel costs, net-metering availability, interaction with other generation technologies - and thus, value of generation inputs are varied within the scenario framework detailed in Section 1.1.

More specifically, the value of generation is calculated on an hourly basis using the "utilityrate3" module of the NREL System Advisor Model (Blair et al. 2014). Savings from offsetting energy consumption are based on a bottom-up calculation of the potential bill savings including, where applicable, fixed charges, seasonal rates, tiered rates, time-of-use rates, and demand charges. Value from excess generation is based on the credit received for energy exported to the grid during hours when system generation exceeds consumption. Retail rates are based on the OpenEI Utility Rate Database, illustrated in Figure 15. As described by Sigrin et al. (2016), agents are assigned an applicable rate structure based on their location, sector, and demand range. In total, the model uses 2,370 rates from the database, corresponding to utilities serving approximately $80 \%$ of residential and commercial load in the United States. For areas without rate coverage, agents are assigned to the nearest known utility.

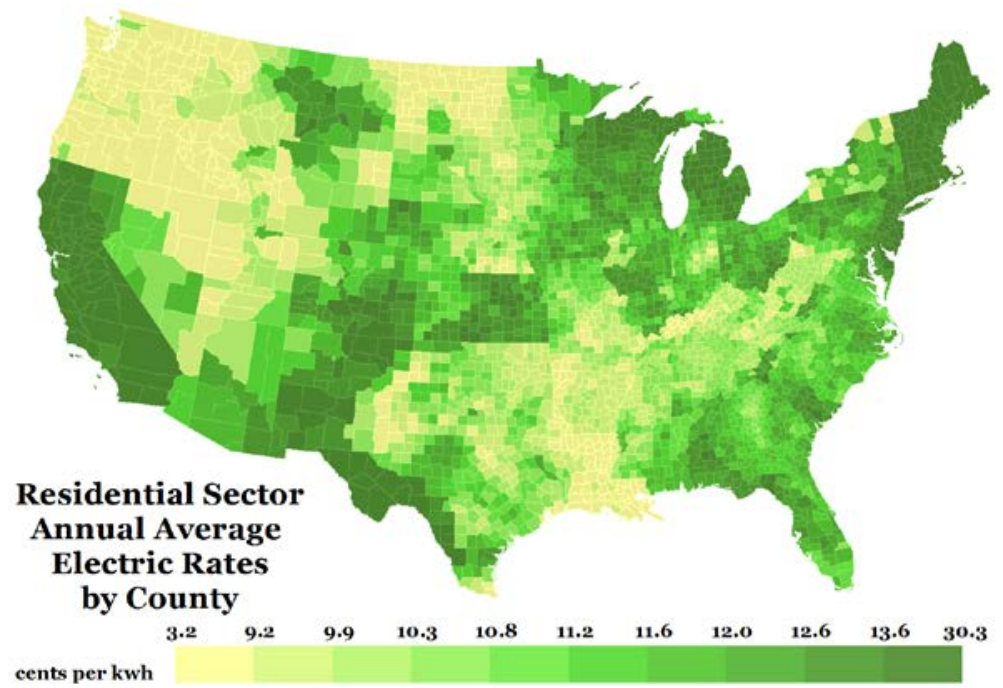

Figure 15. Retail cost of electricity for residential customers by county Source: OpenEI Utility Rate Database

Net metering in dWind is modeled at the state level using policies that are current as of June 2016 (DSIRE 2016). Model representations reflect some simplification from actual policy. The two primary simplifications are that substate variations are not modeled (e.g., rules that differ for municipal or investor-owned utilities), and that net metering is modeled as providing full retail credit, whereas the absence of net metering results in compensation for exported energy at wholesale electricity costs. For each state, the maximum capacity $(\mathrm{kW})$ that would qualify for net metering is modeled, as well as the projected year of net-metering expiration. Default expiration dates were estimated by assuming that current policies would expire as stated in statute or by an internal forecast of when distributed generation would meet the listed net-metering cap (i.e., a megawatt target or percent of peak demand) (Table 5). For states without net metering or after net-metering expiration, excess energy generation (i.e., quantities above that which can be consumed on-site) is credited at the defined conditions specified by the scenario. For conditions 
in which excess energy is valued at wholesale rates, wholesale electricity prices are grounded in state-level rates extracted from the NREL Regional Energy Deployment System model for the 2016 Standard Scenarios central reference case (Cole et al. 2016) and escalated using data from the Annual Energy Outlook (EIA 2016a).

Table 5. Allowable System Sizes and Projected Last Year of Net-Metering Coverage as Represented in dWind (Current as of June 2016)

\begin{tabular}{|c|c|c|c|c|c|c|c|}
\hline State & $\begin{array}{l}\text { Residential } \\
\text { Size Limit } \\
(\mathrm{kW})\end{array}$ & $\begin{array}{l}\text { Commercial } \\
\text { and } \\
\text { Industrial } \\
\text { Size Limit } \\
\text { (kW) }\end{array}$ & $\begin{array}{l}\text { Estimated } \\
\text { Last Year }\end{array}$ & State & $\begin{array}{l}\text { Residential } \\
\text { Size Limit } \\
(\mathrm{kW})\end{array}$ & $\begin{array}{l}\text { Corporate } \\
\text { and } \\
\text { Industrial } \\
\text { Size Limit } \\
\text { (kW) }\end{array}$ & $\begin{array}{l}\text { Estimated } \\
\text { Last Year }\end{array}$ \\
\hline$A L$ & \multicolumn{2}{|c|}{ Not Available } & 2014 & NC & 1,000 & 1,000 & 2050 \\
\hline AR & 25 & 300 & 2050 & ND & 100 & 100 & 2050 \\
\hline$A Z$ & \multicolumn{2}{|c|}{ No Size Limit } & 2050 & NE & 25 & 25 & 2038 \\
\hline CA & 1,000 & 1,000 & 2016 & NH & 1,000 & 1,000 & 2030 \\
\hline CO & \multicolumn{2}{|c|}{ No Size Limit } & 2050 & NJ & \multicolumn{2}{|c|}{ No Size Limit } & 2020 \\
\hline CT & 2,000 & 2,000 & 2050 & NM & 80,000 & 80,000 & 2050 \\
\hline DC & 100 & 100 & 2050 & NV & 1,000 & 1,000 & 2016 \\
\hline DE & 25 & 1,500 & 2022 & NY & 25 & 2,000 & 2018 \\
\hline FL & 2,000 & 2,000 & 2050 & $\mathrm{OH}$ & \multicolumn{2}{|c|}{ No Size Limit } & 2050 \\
\hline GA & 10 & 100 & 2014 & OK & 17 & 17 & 2050 \\
\hline IA & 500 & 500 & 2050 & OR & 25 & 2,000 & 2014 \\
\hline ID & \multicolumn{2}{|c|}{ Not Available } & 2014 & PA & 50 & 3,000 & 2050 \\
\hline IL & 2,000 & 2,000 & 2046 & RI & 5,000 & 5,000 & 2034 \\
\hline IN & 1,000 & 1,000 & 2044 & SC & 20 & 100 & 2036 \\
\hline KS & 25 & 200 & 2028 & SD & \multicolumn{2}{|c|}{ Not Available } & 2014 \\
\hline KY & 30 & 30 & 2046 & TN & \multicolumn{2}{|c|}{ Not Available } & 2014 \\
\hline LA & 25 & 300 & 2020 & TX & \multicolumn{2}{|c|}{ Not Available } & 2014 \\
\hline MA & 2,000 & 2,000 & 2018 & UT & 25 & 2,000 & 2040 \\
\hline MD & 2,000 & 2,000 & 2020 & VA & 20 & 500 & 2040 \\
\hline ME & 660 & 660 & 2016 & VT & 500 & 500 & 2022 \\
\hline MI & 150 & 150 & 2038 & WA & 100 & 100 & 2018 \\
\hline MN & 1,000 & 1,000 & 2050 & WI & 20 & 20 & 2050 \\
\hline MO & 100 & 100 & 2020 & WV & 25 & 500 & 2050 \\
\hline MS & 20 & 2,000 & 2016 & WY & 25 & 25 & 2050 \\
\hline MT & 50 & 50 & 2050 & & & & \\
\hline
\end{tabular}

Note: Substate variability net-metering policy is not reflected in dWind; accordingly, dWind modeled values may not correspond to all policies in a given state. 
Using projected load, utility rate, and net-metering data, the agent's annual electricity costs (\$/year) with and without the proposed system are calculated. The difference of the costs is the cost savings (revenue) the agent would receive in the first year of system ownership. First-year bill savings are used as the basis for estimating bill savings over the system lifetime, subject to rate-escalation forecasts (EIA 2016a). Two critical implicit assumptions in our approach include: retail rates and rate structures will not dramatically change over the system lifetime, and an agent's adoption decision is based on their expectations of bill savings in the year they adopt. In each year, nonadopters update their expectations based on changing conditions and may subsequently adopt in later years.

\subsubsection{State and Federal Financial Incentives}

Distributed wind turbines may be eligible for additional state and federal financial policy incentives in some cases, significantly affecting their economic viability. Federal incentives include the Business Energy ITC (26 U.S.C. § 48), the Residential Renewable Energy Tax Credit (26 U.S.C. § 25D), and the Renewable Electricity PTC (26 U.S.C. § 45). Modified Accelerated Cost Recovery System (MACRS) tax depreciation (for commercial and industrial users) may also be applicable to commercial and industrial consumers.

In the current analysis, all leased systems as well as all commercial and industrial systems are assumed to be eligible for the ITC option under the federal PTC. Table 6 outlines the applied schedule for the ITC based on the 2016 extension (DSIRE 2016). Model implementation of the ITC allows for the 4-year grace period between commencing construction and project commissioning, although in practice this specific policy feature may offer relatively less value for distributed wind projects (Mai et al 2016). Where applicable, MACRS is modeled using the $50 \%$ bonus depreciation schedule which, phases down through 2024.

Table 6. Distributed Wind ITC Schedule Reflected in the Current Analysis

\begin{tabular}{cccc}
\hline Year & $\begin{array}{c}\text { Residential } \\
\text { (Host Owned) }\end{array}$ & $\begin{array}{c}\text { Residential } \\
\text { (Third-Party Owned) }\end{array}$ & Commercial/Industrial \\
\hline $\mathbf{2 0 1 4}$ & $30 \%$ & $30 \%$ & $30 \%$ \\
$\mathbf{2 0 1 5}$ & $30 \%$ & $30 \%$ & $30 \%$ \\
$\mathbf{2 0 1 6}$ & $30 \%$ & $30 \%$ & $30 \%$ \\
$\mathbf{2 0 1 7}$ & $0 \%$ & $24 \%$ & $24 \%$ \\
$\mathbf{2 0 1 8}$ & $0 \%$ & $18 \%$ & $18 \%$ \\
$\mathbf{2 0 1 9}$ & $0 \%$ & $12 \%$ & $12 \%$ \\
$\mathbf{2 0 2 0 +}$ & $0 \%$ & $0 \%$ & $0 \%$ \\
\hline
\end{tabular}

State policies are consistent with those reported in the DSIRE database as of June 2016 (DSIRE 2016). As with net-metering policies, the default assumption is that financial and other policy incentives will not be renewed and will expire as stated in statute. Incentives that do not include a specified end date are assumed to expire at year-end 2016. 


\subsubsection{Financing and Leasing Cost Models}

Access to capital, cost of capital, and the availability and terms of third-party owned or leased systems also weigh heavily on estimates of economic viability. The U.S. distributed wind financial industry is relatively undeveloped, which challenges the availability and rates of debt financing. To address this uncertainty, financial assumptions vary by scenario, with an assumption that as markets mature, projects can increasingly be financed through debt rather than equity. Because debt is lower cost than equity, and because interest on debt can also be deducted from taxable burden, higher-leveraged projects are generally financed at a lower weighted average cost of capital (WACC). Amortizing system costs over the turbine lifetime and lowering costs of servicing debt both significantly improve a potential project's economic viability.

In addition, third-party ownership or leasing has been identified as helping to scale adoption of other distributed energy resources, including rooftop solar PV (Drury et al 2012; Rai and Sigrin 2013). These models can be effective in increasing adoption because they often require no down payment. This has the potential to expand consumer access and allows for pricing of capital at the investor threshold rate of return, which may be relatively lower than alternative sources of capital and may allow for immediate monthly bill savings, relative to simple payback financing assessments.

Detailed financial assumptions applied in the current scenario analysis, differentiated by consumer sector, are summarized in Tables 7, 8, and 9. Under Low deployment conditions, financing for all sectors is assumed to be priced at typical consumer or long-term utility-sector equity discount rates with no debt; leasing is assumed to be unavailable to distributed wind. Under Reference conditions, financing assumptions include debt for approximately $60 \%$ of the project costs, consistent with typical debt levels for renewable power as well as conservative lending practices and typical long-term utility-sector debt and equity costs; leasing is available at a cost or real hurdle rate informed by data from current solar PV leasing estimates (Sigrin et al. 2016). ${ }^{33}$ The High deployment scenario assumes costs of capital at typical current home equity and corporate capital rates and debt levels up to $80 \%$; leasing is available at a cost or real hurdle rate consistent with long-term average utility-sector finance costs. The Breakthrough scenario utilizes debt levels up to $100 \%$ and assumes lending costs remain at current rates throughout the full period of analysis; leasing is available at a cost or real hurdle rate consistent with a corporate strategy that is increasingly reliant on corporate bonds to provide project-level capital and a competitive business environment that constrains margins.

Table 7. Residential Host-Owned Financial Parameters

\begin{tabular}{lcccc}
\hline & Low & Reference & High & Breakthrough \\
\hline Debt Fraction & $0 \%$ & $60 \%$ & $80 \%$ & $100 \%$ \\
Debt Interest Rate (Nominal) & $8.0 \%$ & $8.0 \%$ & $6.5 \%$ & $6.5 \%$ \\
Equity Rate (Nominal) & $13 \%$ & $13 \%$ & $13 \%$ & $13 \%$ \\
Tax Rate & $40 \%$ & $40 \%$ & $40 \%$ & $40 \%$ \\
WACC (Nominal) & $13.0 \%$ & $8.1 \%$ & $5.7 \%$ & $3.9 \%$ \\
WACC (Real) & $10.2 \%$ & $5.4 \%$ & $3.1 \%$ & $1.4 \%$ \\
\hline
\end{tabular}

\footnotetext{
${ }^{33}$ Reference scenario financing assumptions are consistent with the NREL Annual Technology Baseline (2016).
} 
Table 8. Commercial/Industrial Host-Owned Financial Parameters

\begin{tabular}{lcccc}
\hline & Low & Reference & High & Breakthrough \\
\hline Debt Fraction & $0 \%$ & $60 \%$ & $70 \%$ & $90 \%$ \\
Debt Interest Rate & $8.0 \%$ & $8.0 \%$ & $3.7 \%$ & $3.7 \%$ \\
Equity Rate & $13 \%$ & $13 \%$ & $13 \%$ & $13 \%$ \\
Tax Rate & $40 \%$ & $40 \%$ & $40 \%$ & $40 \%$ \\
WACC (Nominal) & $13.0 \%$ & $8.1 \%$ & $5.5 \%$ & $3.3 \%$ \\
WACC (Real) & $10.2 \%$ & $5.4 \%$ & $2.9 \%$ & $0.8 \%$ \\
\hline
\end{tabular}

Table 9. Third-Party Owned (Lessor) Hurdle Rates

\begin{tabular}{lcccc}
\hline & Low & Reference & High & Breakthrough \\
\hline Residential & N/A & $7.0 \%$ & $5.4 \%$ & $1.8 \%$ \\
Commercial/Industrial & N/A & $7.0 \%$ & $5.4 \%$ & $1.8 \%$ \\
\hline
\end{tabular}

\subsubsection{Combined Discounted Cash Flow Model}

Combining the factors described earlier, dWind calculates a detailed assessment of economic value using a discounted cash flow analysis over the system lifetime ( 25 years) for each agent. Components of the cash flow include system payments, O\&M costs, revenue from generation, revenue from depreciation, revenue from interest deductions, and revenue from applicable incentives. From the cash flows, a number of standard metrics are output, including NPV, LCOE, and payback period. These values inform the economic potential results highlighted in Section 4.2 as well as the market potential results described in Section 5.

\subsection{Results and Discussion}

Economic potential estimates considered here represent the amount of capacity that could be deployed at a positive NPV in a given year (i.e., a snapshot in time or annual estimates), while excluding parcels with siting restrictions and limiting the system capacity to serve on-site electrical load. Unlike addressable resource potential, the economic potential estimates explicitly consider time-varying parameters such as changes in technology costs, expiration of incentives, and changes in retail rate compensation. Reported results focus on the Reference scenario and the Combined High scenario assumptions for capital and O\&M costs, turbine performance, value of generation, financing and leasing costs, and siting criteria. ${ }^{34}$ Estimates of the change from the Reference scenario for additional single variable sensitivities described in Section 1.1 are also included.

Applying the array of input values detailed earlier and in Section 2, annual behind-the-meter distributed wind economic potential in the Reference scenario is estimated to be $42 \mathrm{GW}$ in 2020 , in part based on the availability of federal policy incentives and net metering, as is currently legislated. Post-2020 estimated annual economic potential decreases to $19 \mathrm{GW}$ in 2030, before increasing again to $37 \mathrm{GW}$ in 2050 (Figure 16). Changes observed in 2030 and 2050 reflect multiple time-varying trends, the most important of which is the assumption that the federal ITC (including the ITC option under the PTC) will not to be extended. Additional important factors are technology cost reductions, which are mostly concentrated in the small and midsize turbine

\footnotetext{
${ }^{34}$ Siting criteria defined in Section 3.1.2 are applied in the Reference scenario; for the High and Combined High scenarios, system height setbacks are reduced to 1.0x maximum blade tip height. See also Section 1.1. and footnote 14 .
} 
classes, and evolution of the value of generation, in which net metering is assumed to not be extended beyond the current statutes.

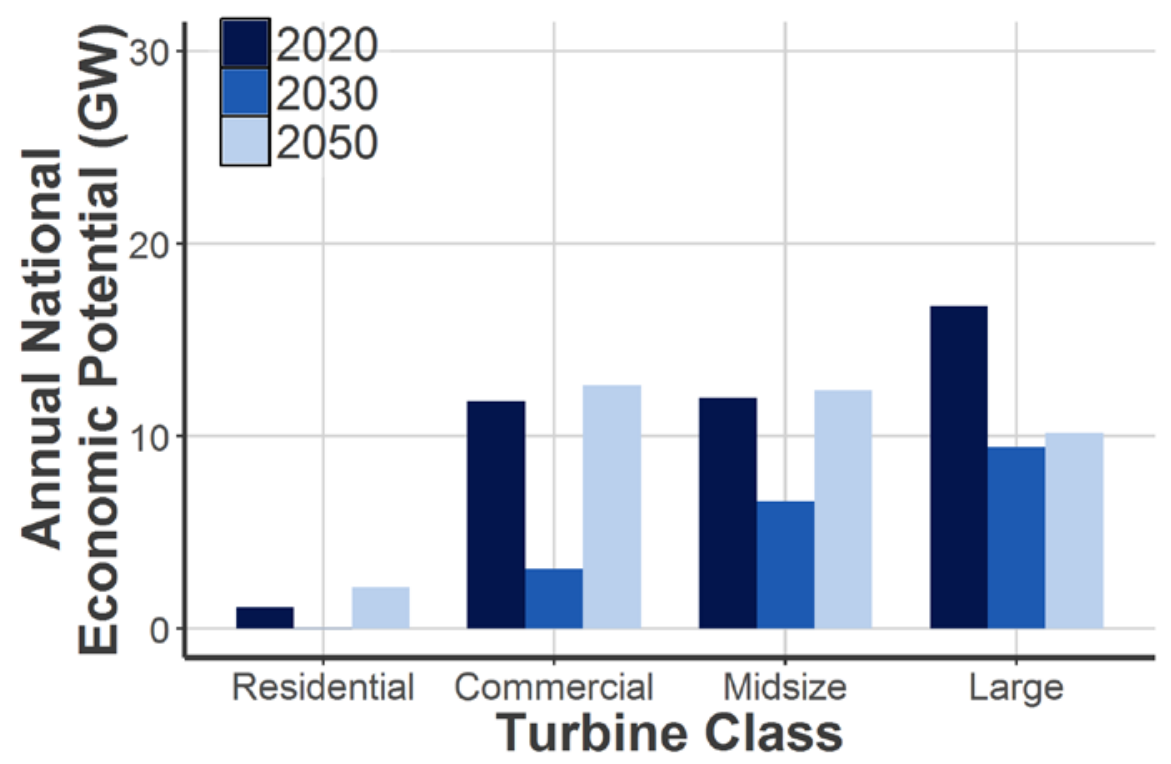

Figure 16. Economic potential by turbine class (Reference scenario)

Digging deeper into the Reference scenario, there are important differences between turbine size classes, wherein residential and commercial turbine sizes are relatively limited in the 2030 timeframe but potentially more substantial by 2050. In the near term, these turbine classes appear to be best positioned to serve sites or localities with favorable policy environments or other unique considerations. For the large size class, relative stable technology costs, expiration of the ITC, and phase-out of the state net-metering policy combine to reduce the long-term opportunity. Though the small and midsize classes are also exposed to ITC expiration and net-metering phase-out, they are compensated by more aggressive technology cost reductions and a larger pool of potential customers.

Considering more favorable technology, finance, and retail electricity rate conditions for distributed wind associated with the Combined High scenario, the outlook for economic viability is dramatically improved across all turbine size classes. In this scenario, an estimated annual quantity of $48 \mathrm{GW}$ of capacity could be economically viable in 2030 , with more than $85 \mathrm{GW}$ in 2050 (Figure 17). The opportunity for residential- and commercial-size turbines increases disproportionately in part as a function of more significant technology cost reductions considered here (e.g., 60\% reduction in LCOE by 2030 and $80 \%$ by 2050). Under these more favorable conditions, additional factors such as consumer adoption, access to finance, siting policy, and competition from alternative distributed generation sources could become the primary constraints on continued growth, particularly for residential and commercial-scale turbines. 


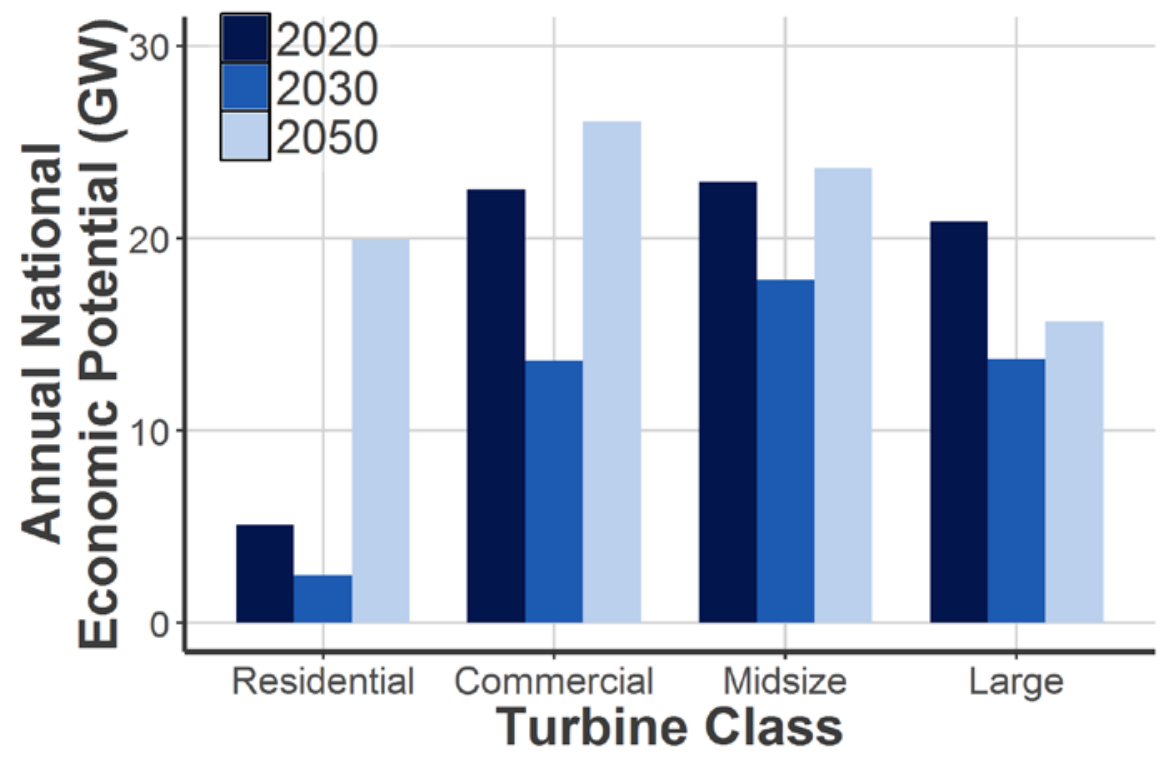

Figure 17. Economic potential by turbine class (Combined High scenario)

Sensitivity of national economic potential is further analyzed for each of the single-variable sensitivities relative to the Reference scenario. Annual data are presented for 2030 and 2050 in Figure 18. Financing assumptions, followed by siting constraints, are determined to have the largest effect on economic potential. Each of these factors affects the economic potential differently. The financing assumptions lower the cost of capital by increasing project leverage with lower-cost debt. Conversely, reducing stringency of siting constraints does not change project economics directly, though it does dramatically increase the potential pool of customers, many of which would have attractive economics. Interestingly, though cost assumptions are important, their impact is relatively less, as compared to financing and siting, particularly in 2050 . 

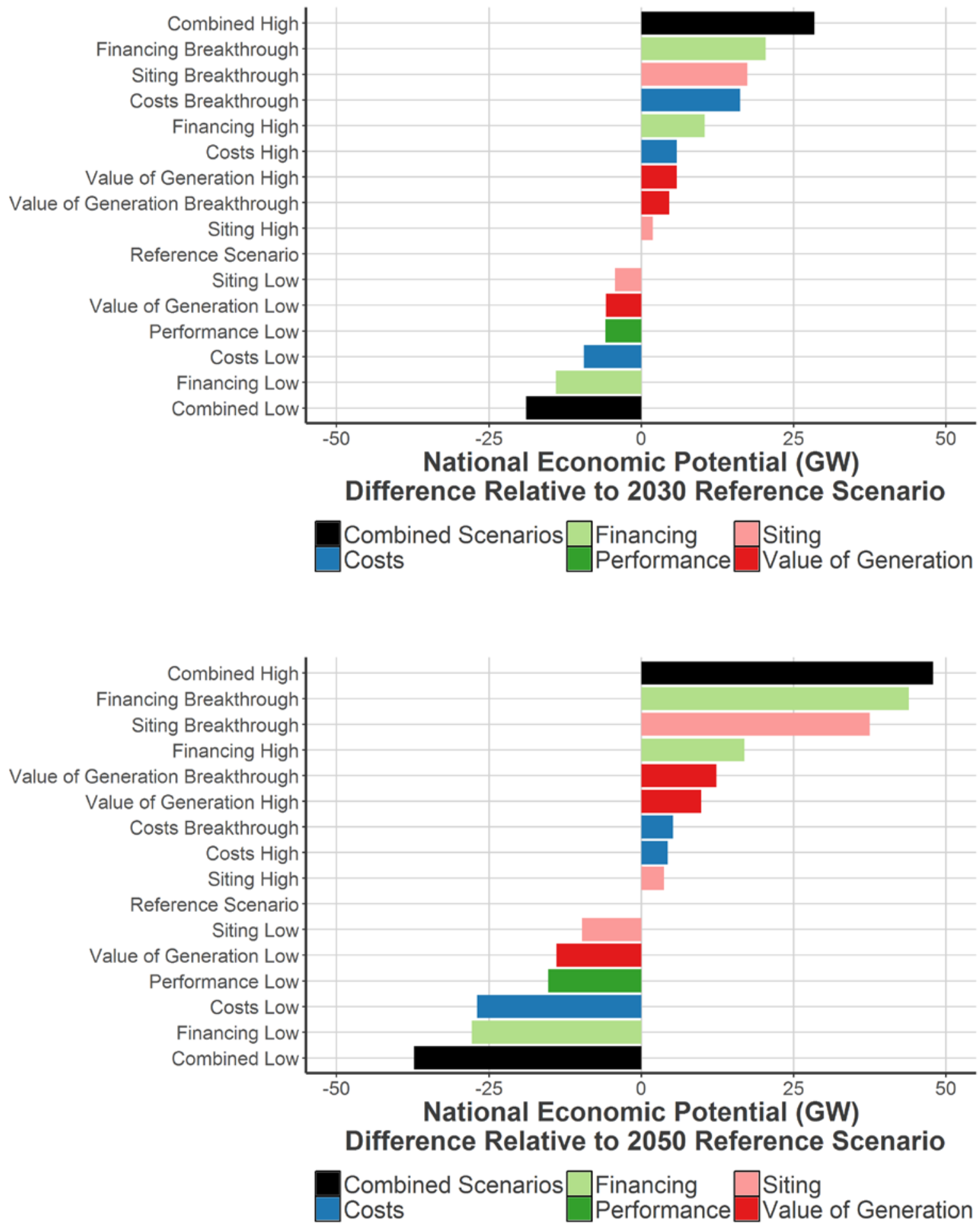

Figure 18. Impact of sensitivities on 2030 (top) and 2050 (bottom) economic potential 
Over the multidecade scale considered in this analysis, fundamental factors, such as wind resource quality and the number of parcels without siting restrictions, are the primary factors determining economic potential. Other state or regional factors not considered here, of course, could alter this calculus. In particular, two additional factors should be considered. First, this analysis excludes any new or extended financial incentives (state and federal) or other policies, outside of net energy metering, meant to encourage market growth. That is, several states could offer financial incentives that could affect financial viability and ultimately economic potential. In fact, such policies are often explicitly designed to provide enough financial support to "tip" project economics from unviable to viable. Second, the true evolution of retail electricity rates is unknowable but is likely to have regional variance. Specifically, this analysis assumes that in the Reference scenario, current net-metering policies will expire as stated in the statutes today — and no new plans will be enacted or existing plans prematurely canceled. Additionally, compensation from retail rates is highly dependent on the structure of retail rates, which could evolve in reaction to aggressive deployment from other distributed generation or as consumers are increasingly proactive in their energy use. ${ }^{35}$

\footnotetext{
${ }^{35}$ Even under the current framework, significant regional variance exists in the economic potential, indicating multiple pathways to a multigigawatt national market. Higher-fidelity state analysis is a potential focus for future work.
} 


\section{Market Potential}

The final lens we apply to characterize the opportunity for behind-the-meter distributed wind is cumulative market potential. Market potential estimates build from the addressable resource potential and economic potential by incorporating trends and patterns in consumer behavior. In particular, market potential considers technology diffusion patterns and rates as well as the potential pool of adopters or market penetration under specific financial conditions. As highlighted in Section 1, and in part due to a relatively early-stage understanding of consumer adoption patterns for behind-the-meter distributed generation including wind technologies, these estimates of market potential are useful for creating greater comprehension of the opportunities and challenges faced by behind-the-meter distributed wind technology. However, the information provided here should not be construed as market forecasts or assessments of likely behind-the-meter distributed wind deployment.

\subsection{Methods and Assumptions}

Customer adoption of new technologies is a complex phenomenon with many moving parts and is simplified for this analysis. The Bass model applied in dWind and more broadly in dGen has been commonly used to analyze adoption of new technologies and understand how these innovations diffuse through a population (Bass 1969). Though the Bass model can be specified in multiple ways, in this analysis three parameters are relevant. The M parameter defines the maximum penetration of a technology among eligible customers (Figure 20), or the potential market size. Over a sufficiently long period, adoption of the technology would asymptotically reach this level. The shape of the Bass diffusion curve, or how quickly diffusion levels are reached, is defined by the $\mathrm{P}$ and $\mathrm{Q}$ parameters. The $\mathrm{P}$ parameter defines the degree to which external influence, such as marketing, affects the rate and degree of adoption. As shown in Figure 19, increasing the $\mathrm{P}$ value shortens the time needed for the technology to gather critical momentum. In contrast, the Q parameter defines the degree to which internal influence, such as peer effects, influences adoption. Increasing the $\mathrm{Q}$ value shortens the time needed for a technology to transition from $10 \%$ to $90 \%$ uptake.
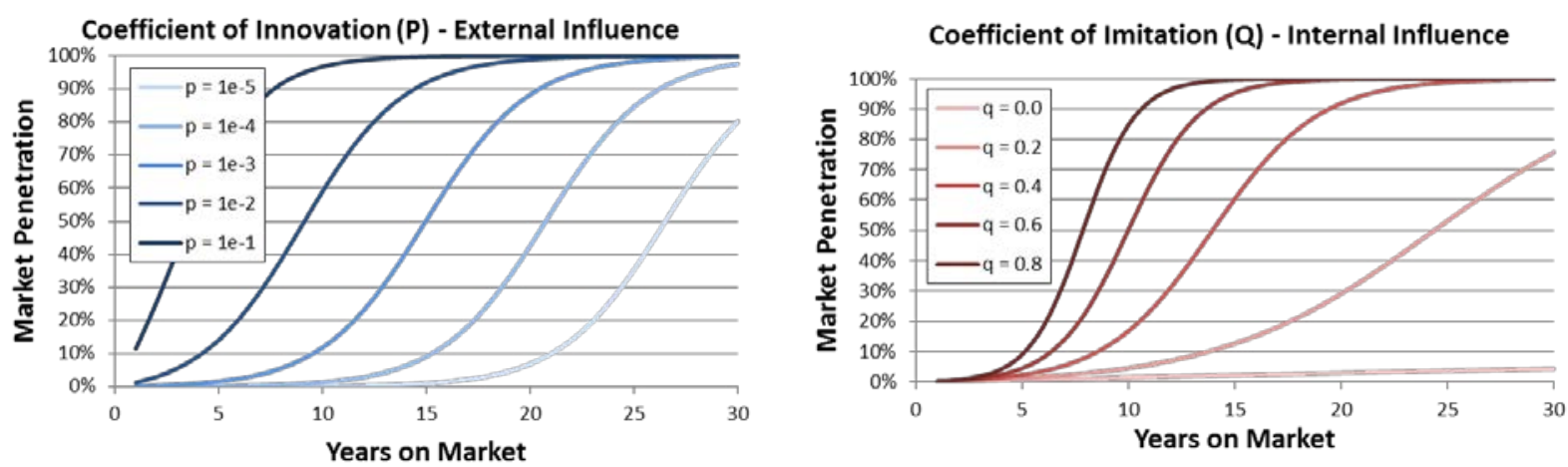

Figure 19. Influence of $P$ and $Q$ parameters on shape and rate of diffusion

For any given technology, each of the Bass parameters can be estimated from literature or, should it exist, using historical sales data. However, these parameters may also vary regionally, based on local opinions of a new technology, and change over time based on evolution of a technology's costs or other attributes. 
In the absence of technology-specific data, the P and Q parameters used in this analysis are based on fitting historical adoption of U.S.-distributed solar parameters by state and sector (Sigrin et al. 2016). ${ }^{36}$ The fitted parameters are comparable to parameters estimated for any array of emerging technologies. A common P parameter is applied across all scenarios in this analysis (i.e., we do not vary our assumptions around time required to achieve critical momentum in these scenarios). We do vary our Q parameter across the Low, Reference, High, and Breakthrough values. This allows the scenarios to illuminate the potential impact associated with a more rapid diffusion of the technology from $10 \%$ to $90 \%$ saturation. Our Q parameter values are based on the $90^{\text {th }}, 75^{\text {th }}$, $50^{\text {th }}$, and $25^{\text {th }}$ percentiles of fitting historical U.S. PV adoption for the Low, Reference, High, and Breakthrough assumptions, respectively (Table 10).

Table 10. Diffusion Parameters by Scenario

\begin{tabular}{|c|c|c|c|c|}
\hline & Low & Reference & High & Breakthrough \\
\hline $\begin{array}{l}\text { Coeff. of } \\
\text { Innovation (P) }\end{array}$ & & & 015 & \\
\hline $\begin{array}{l}\text { Coeff. of } \\
\text { Imitation (Q) }\end{array}$ & $\begin{array}{l}\text { Res: } 0.092 \\
\text { Nonres: } 0.061\end{array}$ & $\begin{array}{l}\text { Res: } 0.135 \\
\text { Nonres: } 0.113\end{array}$ & $\begin{array}{l}\text { Res: } 0.189 \\
\text { Nonres: } 0.146\end{array}$ & $\begin{array}{l}\text { Res: } 0.273 \\
\text { Nonres: } 0.241\end{array}$ \\
\hline $\begin{array}{l}\text { Market } \\
\text { Saturation (M) }\end{array}$ & $\begin{array}{l}\text { Res: Navigant } \\
\text { Nonres: Navigant }\end{array}$ & $\begin{array}{l}\text { Res: NREL } \\
\text { Nonres: Navigant }\end{array}$ & $\begin{array}{l}\text { Res: NREL } \\
\text { Nonres: NREL }\end{array}$ & $\begin{array}{l}\text { Res: NREL } \\
\text { Nonres: NREL }\end{array}$ \\
\hline $\begin{array}{l}\text { Time to } 90 \% \\
\text { Saturation } \\
\text { (years) }^{37}\end{array}$ & $\begin{array}{l}\text { Res: } 67.9 \\
\text { Nonres: } 94.6\end{array}$ & $\begin{array}{l}\text { Res: } 48.6 \\
\text { Nonres: } 57.1\end{array}$ & $\begin{array}{l}\text { Res: } 37.1 \\
\text { Nonres: } 45.6\end{array}$ & $\begin{array}{l}\text { Res: } 26.6 \\
\text { Nonres: } 30.1\end{array}$ \\
\hline
\end{tabular}

Note: "Res" represents the residential sector and "Nonres" represents the nonresidential sectors (i.e., commercial and industrial).

Market penetration parameters applied here are also based on prior studies of demand elasticity for distributed solar adoption. In particular, prior work by Navigant Consulting (Paidipati et al. 2008) and NREL (Sigrin and Drury 2014) are leveraged in the current analysis (Figure 20). Sensitivities executed here utilize the Navigant curve for a lower bound of adoption and the NREL curve as the upper bound. Though limited data exist specifically for distributed wind applications, examining trends of prior technologies, especially distributed solar, is believed to be instructive. In this sense, this report takes a what-if approach to the uncertainty of the longterm diffusion of distributed wind by benchmarking the diffusion parameters on empirical data from comparable technologies. Nevertheless, we urge caution for readers to interpret scenario results from a comparative perspective (i.e., relative difference of scenarios) as opposed to an absolute perspective (i.e., results should not be interpreted as forecasts of outcomes).

\footnotetext{
${ }^{36}$ The authors acknowledge that distributed wind diffusion parameters (P, Q, M) will likely vary from those derived from historical U.S. solar adoption and additional time to diffuse may be required even under comparable economics. As a result, in part, our Q parameter assumptions are skewed towards percentiles of the solar data that reflect a modestly longer time period to go from $10 \%$ to $90 \%$ saturation.

${ }^{37}$ The time to saturation is implicitly defined by the P and Q parameters. A $90 \%$ saturation is reported as it reflects a measure of near-complete saturation without extending too far into the tail of the Bass curve. In the Bass model, achieving $100 \%$ saturation would require an infinite amount of time.
} 


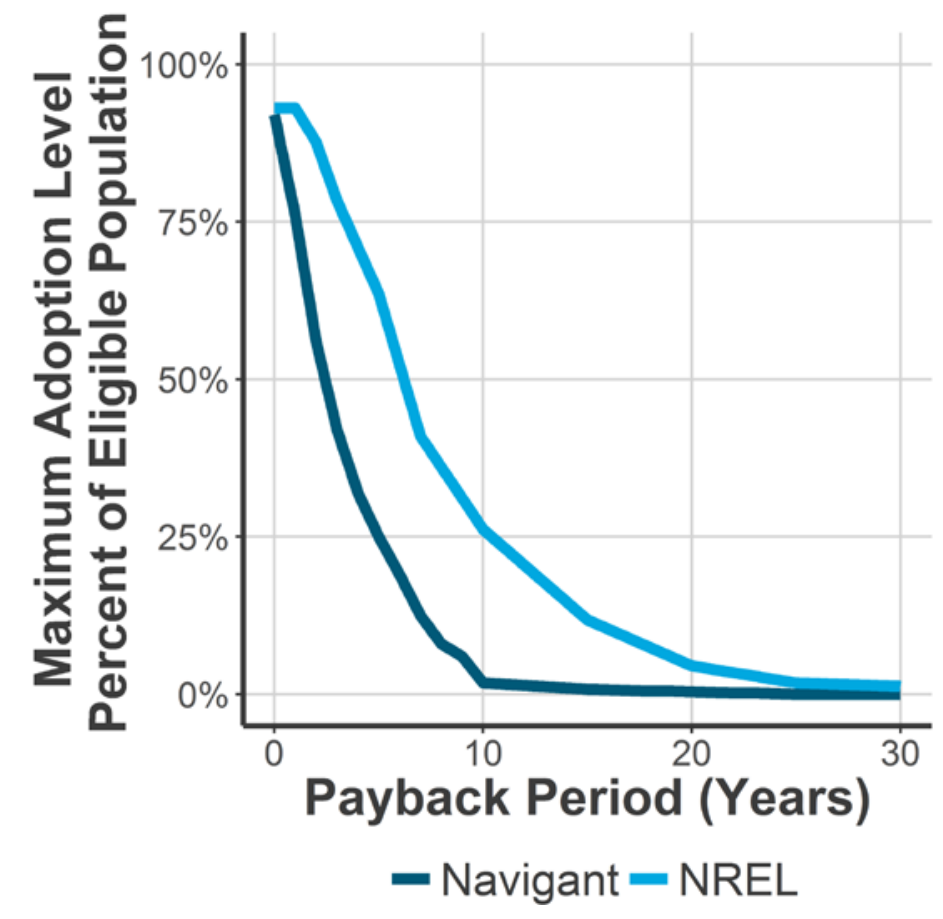

Figure 20. Maximum technology penetration (M parameter) levels modeled based on payback period

\subsection{Results and Discussion}

Applying the consumer adoption data and parameters described above, market potential, as measured by cumulative installed behind-the-meter capacity and based on the Reference scenario inputs, is estimated at $1.5 \mathrm{GW}$ in 2030 and $3.7 \mathrm{GW}$ in 2050 (Figure 21). Assuming behind-themeter applications are about half of today's total installed distributed wind capacity (approximately $500 \mathrm{MW}$ ), which represents an approximate 300\% increase in the market by 2030 and an approximate eight-fold increase or three doublings of cumulative behind-the-meter capacity by 2050 . Although the economics are anticipated to improve and growth rates are nontrivial under a generally business-as-usual approach, the trajectory for behind-the-meter distributed wind is largely consistent with recent historical trends.

Considering the Combined High scenario, the effect of decreasing technology costs, increasing access to low-cost financing, and a favorable retail environment can have a multiplicative effect, moving from a cumulative $3.9 \mathrm{GW}$ market in 2030 to nearly $20 \mathrm{GW}$ of cumulative capacity in 2050. More specifically, cumulative capacity in the Combined High scenario represents an eightfold increase in behind-the-meter capacity, which is observed in the next 14 years. By 2050 , installed capacity in this scenario is increased by a factor of nearly 40, more than five doublings. Despite sizable near-term cost reductions and robust economic potential across turbine classes under these same conditions, typical consumer adoption rates indicate a relatively limited ability to significantly alter the near-term (2020) outlook for distributed wind technologies, without more dramatic market or policy changes. 


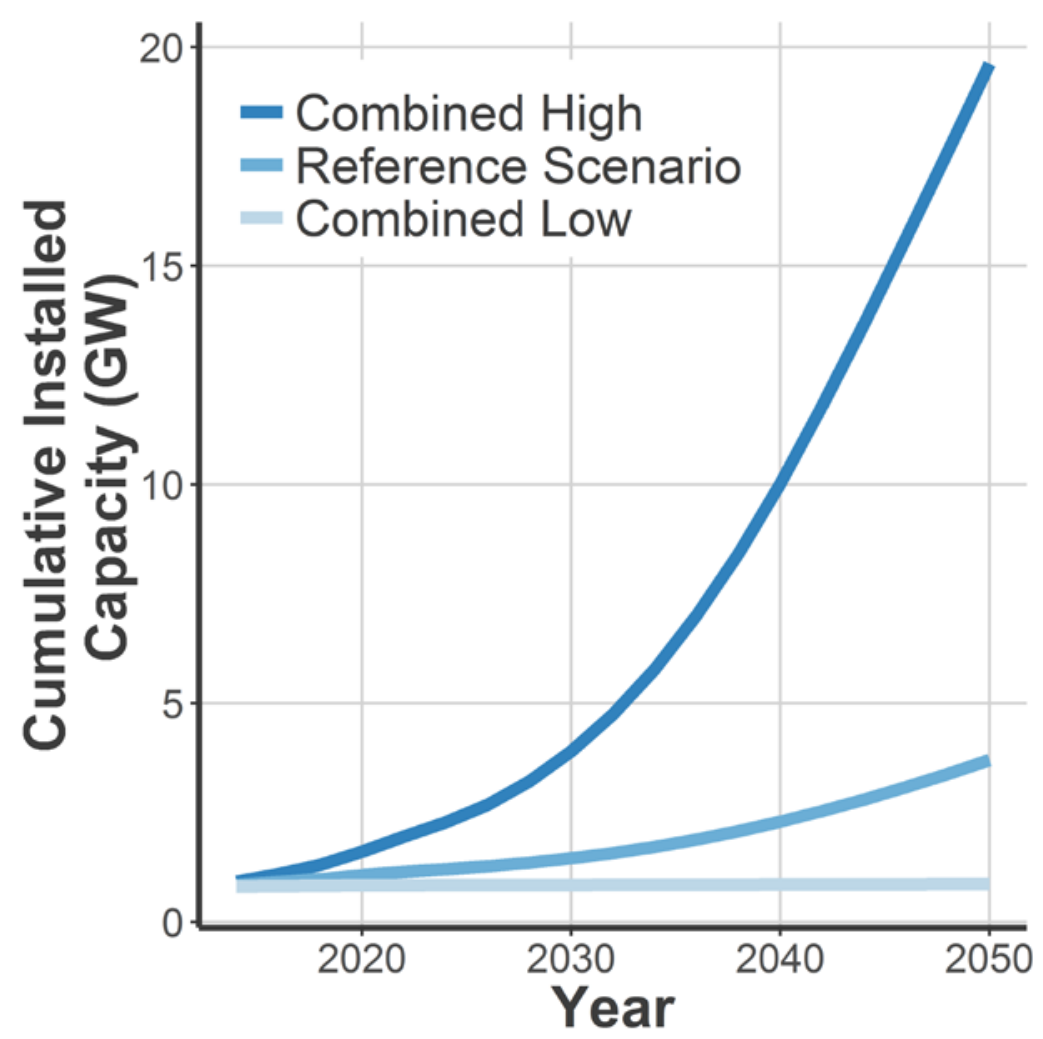

Figure 21. National market potential (Combined scenarios)

Deployment in the Reference scenario is generally concentrated in the large turbine class, though the commercial and midsize turbine classes also see modest growth by 2050, with notable acceleration from 2030 to 2050 (Figure 22). Growth in the residential turbine size class is relatively muted. In comparison, the effect of multiple factors in the Combined High scenario results in more dramatic growth in all turbine classes, with the midsize and commercial classes eclipsing the large category by 2050 (Figure 23). 


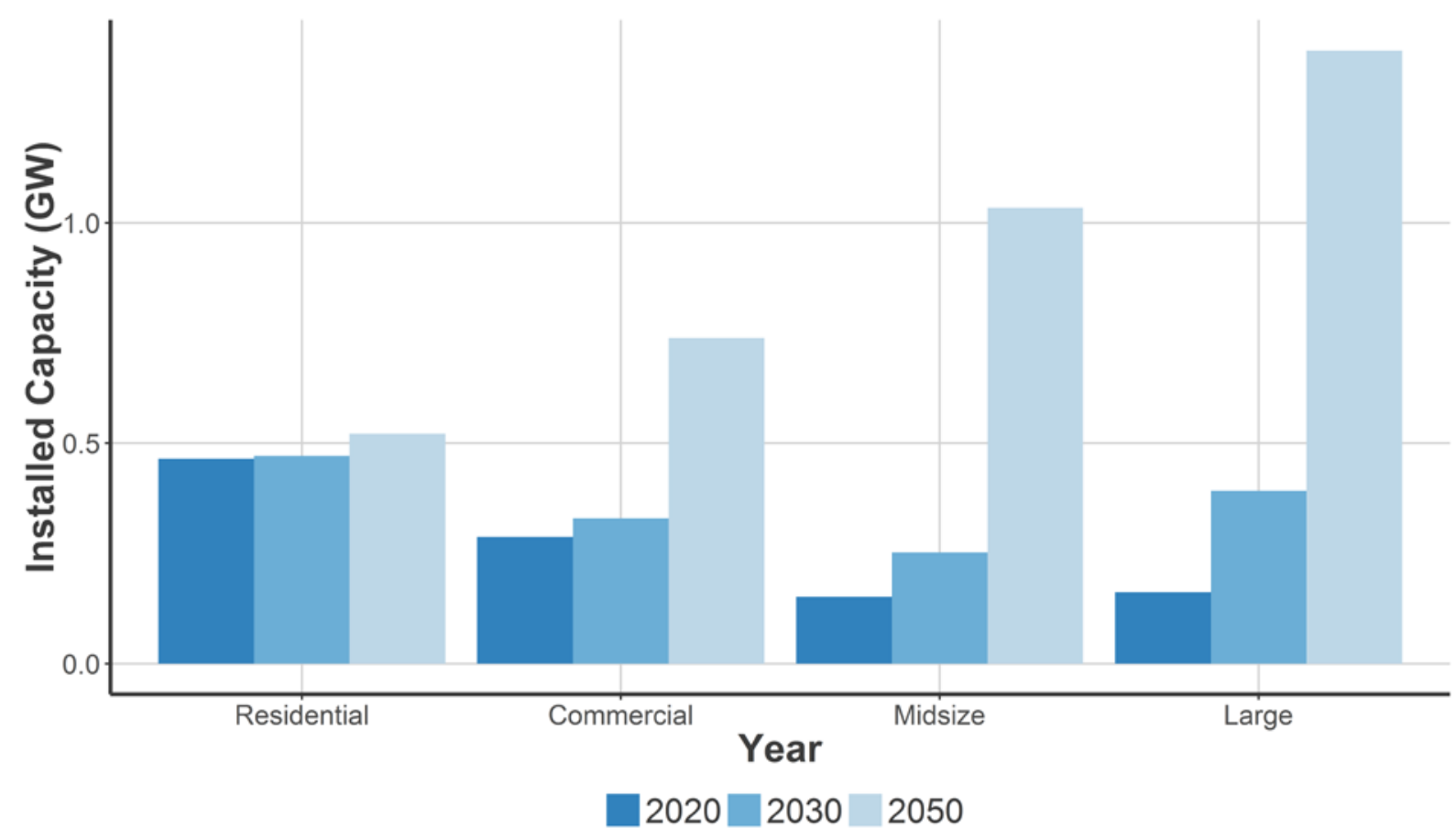

Figure 22. National market potential by turbine class (Reference scenario)

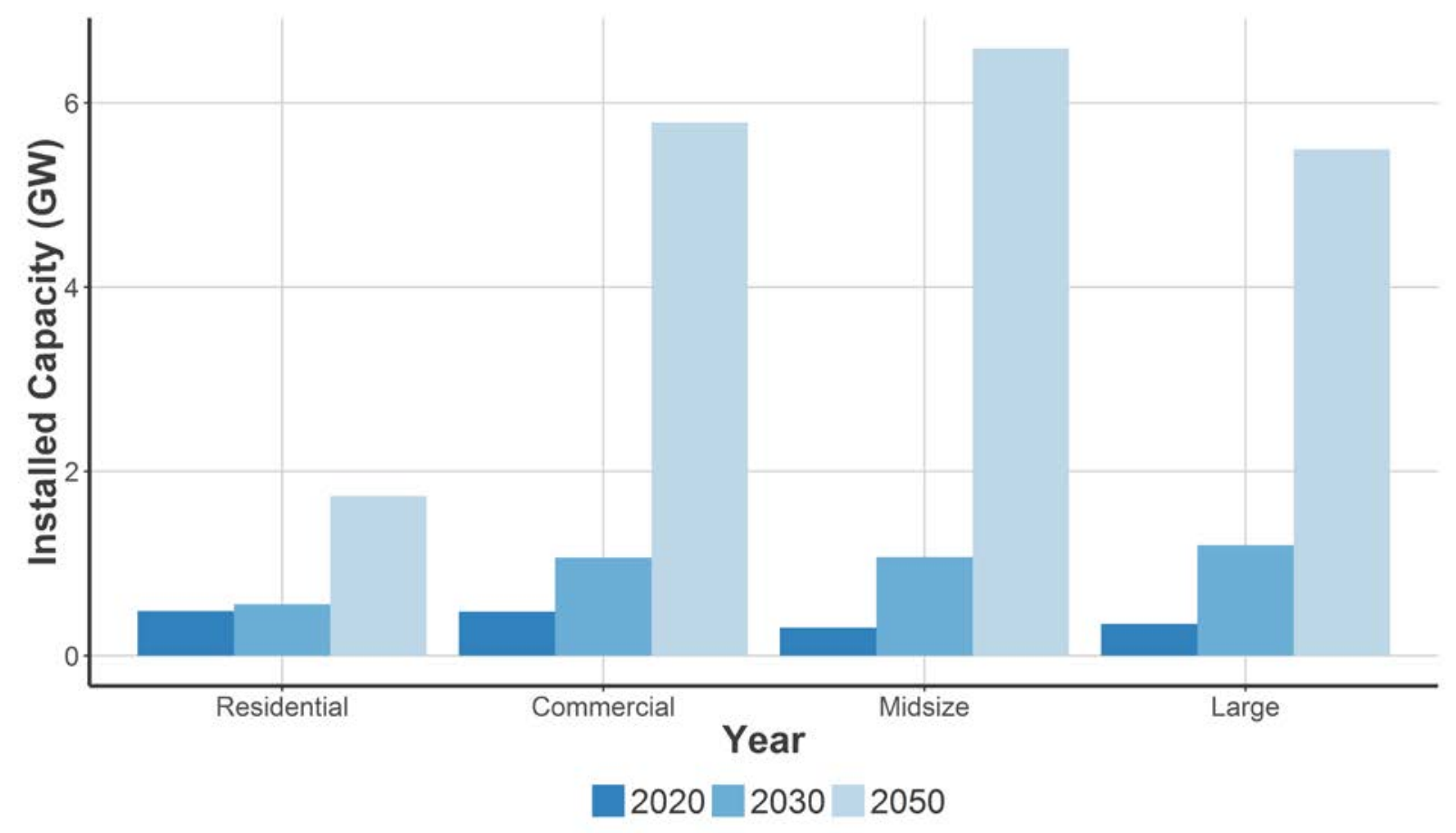

Figure 23. National market potential by turbine class (Combined High scenario) 
Examining the sensitivity of projected deployment to single-variable changes is instructive for understanding the key drivers of market growth and the tipping points therein. These factors are considered symmetrically using the Low, Reference, and High values, as well as a potential Breakthrough value, with outcomes detailed in Figure 24. Notably, each of the factors examined has the potential to increase cumulative 2050 deployment by several gigawatts. Rates of technology adoption, followed by costs of financing and siting constraints have the largest impact on projected deployment (Figure 25). These outcomes suggest that efforts targeting more rapid consumer adoption and diffusion (e.g., marketing, active outreach, and technology design that is aesthetically attractive and consumer friendly) followed by easy access to low cost capital and allowing the potential consumer pool to be as large as possible are likely critical to the future of the behind-the-meter distributed wind sector. Notably, these factors have a different impact on the market potential than on the economic potential as economic potential considers factors affecting project NPV and the timing of project revenue, whereas market potential combines these factors with assessments of how quickly technology uptake could occur and the impact of the rate of uptake. Though cost reductions were seen as being important for market development, their impact was relatively muted because of other factors constraining project attractiveness and because the base installed costs start at a relatively high level.

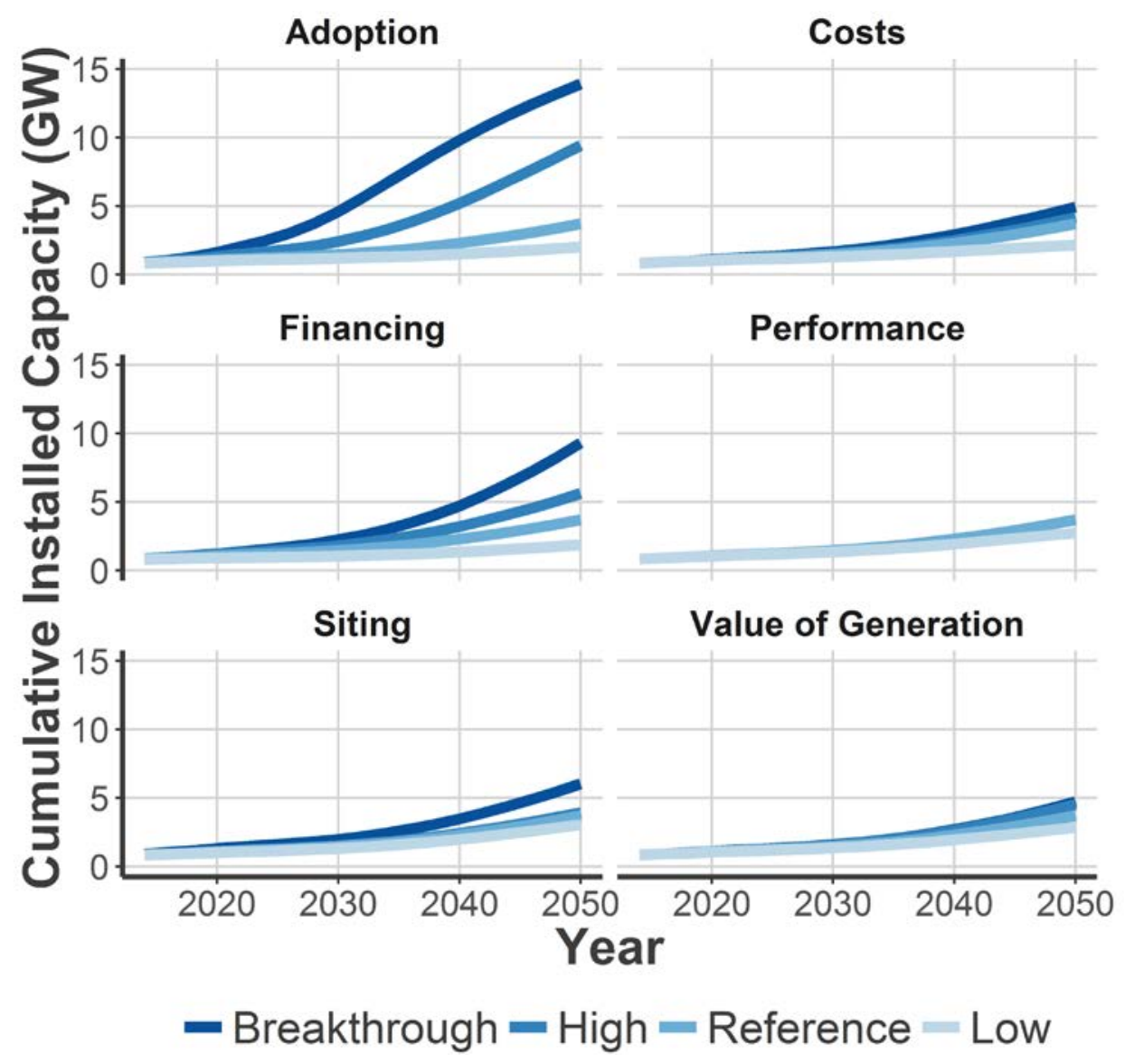

Figure 24. National market potential single-variable sensitivities 


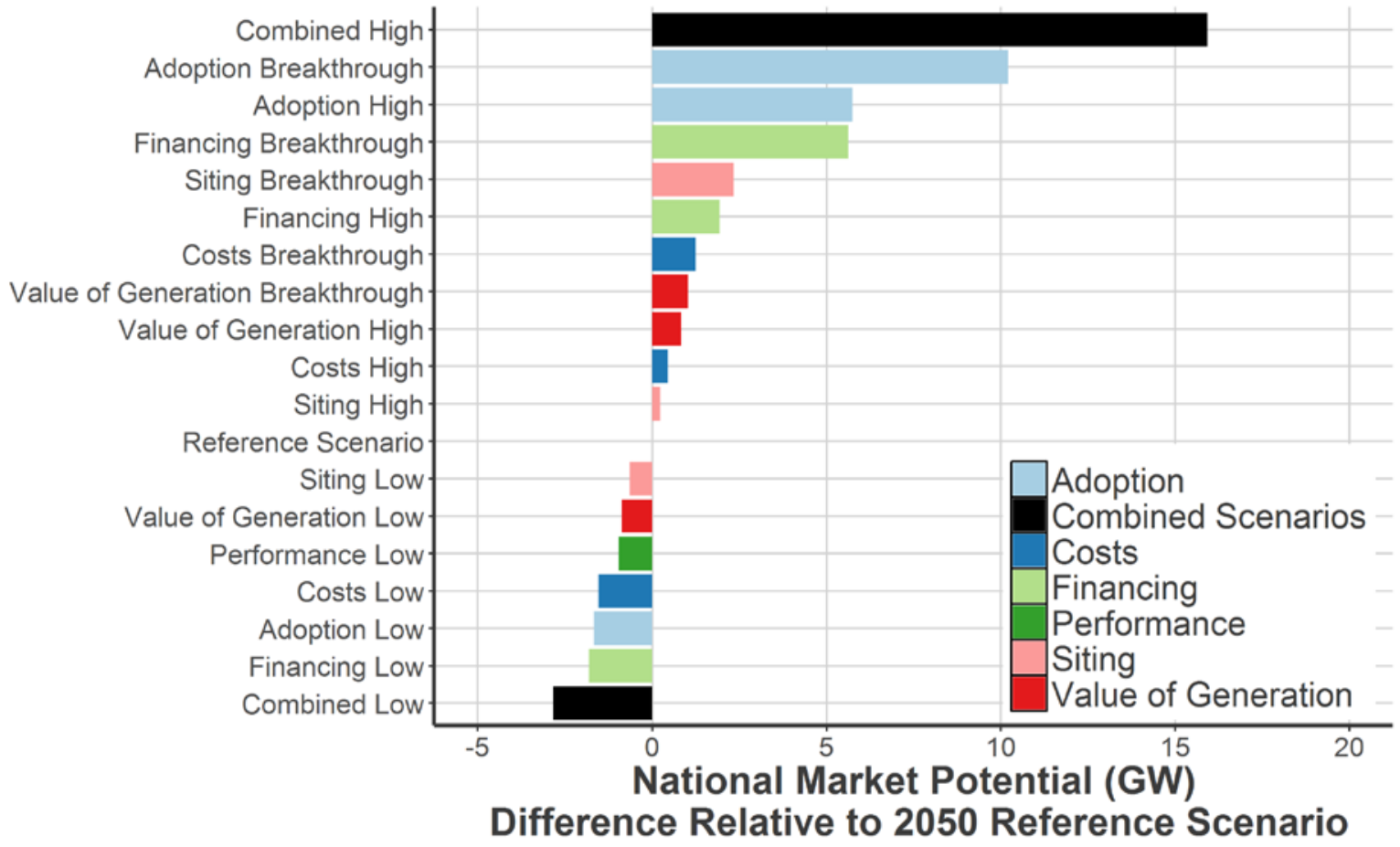

Figure 25. Impact of sensitivities on 2050 market potential 


\section{Conclusion}

This first-of-a-kind assessment suggests that there could be a substantive role in the nation's electricity future for behind-the-meter distributed wind. Notwithstanding some potential overlap with the multimegawatt utility-focused wind power resource and the current exclusion of competition from other distributed generation resources, the potential resource is considerable and there are conditions under which the economics for large quantities (tens of gigawatts) of behind-the-meter distributed wind become viable over time. Although we acknowledge an array of uncertainties in this exploratory analysis, under the conditions assessed, we find that there are a broad range of possibilities for the future of behind-the-meter distributed wind in the United States. On the low end, potential growth could be more limited and focused on the occasional megawatt-scale turbine installation at industrial facilities with large quantities of on-site energy needs. On the high end, the behind-the-meter capacity could observe nearly three doublings of cumulative capacity by 2030 (to approximately $3.9 \mathrm{GW}$ ) and more than five doublings by 2050 (to nearly $20 \mathrm{GW}$ ). Small-scale, multimegawatt-community or municipal wind and distributed wind projects installed at distribution voltages could account for additional growth possibilities within the broader distributed wind sector.

To realize the opportunities presented by scenarios that consider relatively favorable conditions for distributed wind, our analysis suggests that technology cost reduction, including cost reductions in balance-of-plant and installation and performance improvement, are necessary conditions to foster more robust growth. At the same time, cost reduction alone is ultimately insufficient to drive the level of growth that would be required to fundamentally alter the current trajectory for distributed wind. Finding mechanisms to facilitate and encourage consumer adoption as well as the development of new business models that can access low-cost capital, support turnkey solutions, and drive industry-wide efficiencies are also anticipated to be essential components of a vibrant market.

Future work could include refined assessments of behind-the-meter distributed wind potential based on more robust technology cost reduction characterizations, an enhanced understanding of consumer adoption behaviors for distributed wind, and more resolved state-level input data. Future work may also focus more on potential competition among distributed generation technologies, including solar PV, storage, fuel cells, and perhaps others or interactions with utility-scale wind development targeting wholesale power sales opportunities. Assessments of the opportunity for distributed wind in front of the meter including community wind could further inform our understanding of the opportunity for the comprehensive distributed wind market. 


\section{References}

American Wind Energy Association (AWEA). 2016. U.S. Wind Industry First Quarter 2016 Market Report (Technical Report). AWEA Washington, D.C. (US).

http://www.awea.org/1q2016.

Cole, W., P. Kurup, M. Hand, D. Feldman, B. Sigrin, E. Lantz, T. Stehly, C. Augustine, C. Turchi, P. O’Connor. 2016. 2016 Annual Technology Baseline (ATB) Spreadsheet - 2016 Final (Spreadsheet). National Renewable Energy Laboratory, Golden, CO (US).

http://www.nrel.gov/docs/fy16osti/66944-DA.

AWS Truepower, LLC. 2012. 3\% Gross Capacity Factor TMY Profile at $20 \mathrm{~km}$ Locations (Dataset). AWS Truepower, Albany, NY (US).

Barbose, G., J. Miller, B. Sigrin, E. Reiter, K. Cory, J. McLaren, J. Seel, A. Mills, N. Darghouth, A. Satchwell. 2016. On the Path to SunShot: Utility Regulatory and Business Model Reforms for Addressing the Financial Impacts of Distributed Solar on Utilities (Technical

Report). NREL/TP-6A20-65670. National Renewable Energy Laboratory, Golden, CO (US). http://www.nrel.gov/docs/fy16osti/65670.pdf.

Bass, F. M. 1969. “A New Product Growth for Model Consumer Durables.” Management Science 18: 215-227.

Beiter, P. and W. Musial. 2016. Terminology Guideline for Classifying Offshore Wind Energy Resources (Technical Report). NREL/TP-6A20-65431. National Renewable Energy Laboratory, Golden, CO (US). http://www.nrel.gov/docs/fy16osti/65431.pdf.

Blair, N., A. P. Dobos, J. Freeman, T. Neises, M. Wagner, T. Ferguson, P. Gilman, and S. Janzou. 2014. System Advisor Model, SAM 2014.1.14: General Description (Technical Report). NREL/TP-6A20- 61019. National Renewable Energy Laboratory, Golden, CO (US). http://www.nrel.gov/docs/fy14osti/61019.pdf.

Bolinger, B., R. Wiser, K. Cory, and T. James, et al. 2009. PTC, ITC, or Cash Grant? An Analysis of the Choice Facing Renewable Power Projects in the United States (Technical Report). NREL/TP-6A2-45359. National Renewable Energy Laboratory, Golden, CO (US). http://www.nrel.gov/docs/fy09osti/45359.pdf.

Brown, A., P. Beiter, D. Heimiller, C. Davidson, P. Denholm, J. Melius, G. Porro. 2016. Estimating Renewable Energy Economic Potential in the United States: Methodology and Initial Results (Technical Report). NREL/TP-6A20-64503. National Renewable Energy Laboratory, Golden, CO (US). http://www.nrel.gov/docs/fy15osti/64503.pdf.

Cole, W., T. Mai, J. Logan, D. Steinberg, J. McCall, J. Richards, G. Porro. 2016. 2016 Standard Scenarios Report: A U.S. Electricity Sector Outlook. Golden, CO: National Renewable Energy Laboratory. http://www.nrel.gov/docs/fy17osti/66939.pdf. 
Denholm, P., M. Hand, M. Jackson, and S. Ong, S. 2009. Land-Use Requirements of Modern Wind Power Plants in the United States (Technical Report). NREL/TP-6A2-45834. National Renewable Energy Laboratory, Golden, CO (US). http://www.nrel.gov/docs/fy09osti/45834.pdf.

DOE (U.S. Department of Energy). 2009. Small Wind Electric Systems: A Maryland Consumer's Guide. DOE/GO-102009-2857. National Renewable Energy Laboratory, Golden, CO (US). http://www.nrel.gov/docs/fy09osti/45911.pdf.

DOE. 2015. Wind Vision: A New Era for Wind Power in the United States. DOE/GO-1020154557. U.S. Department of Energy, Washington, D.C.

http://www.energy.gov/sites/prod/files/WindVision_Report_final.pdf.

Drury, E. M. Miller, C. M. Macal, D. J. Graziano, D. Heimiller, J. Ozik, and T. D. Perry IV. 2012. "The Transformation of Southern California's Residential Photovoltaics Market through Third-Party Ownership.” Energy Policy. Volume 42, March 2012, P. 681-690.

Database of State Incentives for Renewables \& Efficiency (DSIRE). 2016. "Database of State Incentives for Renewables \& Efficiency.” Accessed January 15, 2016. http://www.dsireusa.org/.

Energy Information Administration (EIA). 2016a. Annual Energy Outlook 2016 with Projections to 2040. U.S. Department of Energy, Washington, D.C.

EIA. 2016b. "Electricity Data Browser." Accessed September 20, 2016. http://www.eia.gov/electricity/data/browser/.

Electric Power Research Institute (EPRI). 2013. PRISM 2.0: Modeling Technology Learning for Electricity Supply Technologies (Technical Report). EPRI-3002000871. September 2013. http://www.epri.com/abstracts/Pages/ProductAbstract.aspx?ProductId=000000003002000871.

Federal Emergency Management Agency. 2016. "Summary of Databases in Hazus-Multi Hazard.” Accessed March 4, 2016. http://www.fema.gov/summary-databases-hazus-multihazard.

Forsyth, T. and I. Baring-Gould. 2008. Distributed Wind Market Applications (Technical Report). NREL/TP-500-39851. National Renewable Energy Laboratory, Golden, CO (US). http:/www.nrel.gov/docs/fy08osti/39851.pdf.

Gagnon, P., R. Margolis, J. Melius, C. Phillips, and R. Elmore. 2015. Rooftop Photovoltaic Technical Potential in the United States: A Detailed Assessment (Technical Report). NREL/TP6A20-65298. National Renewable Energy Laboratory, Golden, CO (US).

http://www.nrel.gov/docs/fy16osti/65298.pdf.

Jin, S., L. Yang, P. Danielson, C. Homer, J. Fry, and G. Xian. 2013. “A Comprehensive Change Detection Method for Updating the National Land Cover Database to Circa 2011." Remote Sensing of Environment 132: 159-175. 
Kellndorfer, J., W. Walker, E. LaPoint, J. Bishop, T. Cormier, G. Fiske, M. Hoppus, K. Kirsch, and J. Westfall. 2012. NACP Aboveground Biomass and Carbon Baseline Data (NBCD 2000), U.S.A., 2000. Oak Ridge, TN: ORNL DAAC.

Lopez, A., B. Roberts, D. Heimiller, N. Blair, and G. Porro. 2012. U.S. Renewable Energy Technical Potentials: A GIS-Based Analysis (Technical Report). NREL/TP-6A20-51946. National Renewable Energy Laboratory, Golden, CO (US). http://www.nrel.gov/docs/fy12osti/51946.pdf.

Mai, T., W. Cole, E. Lantz, C. Marcy, and B. Sigrin. 2016. Impacts of Federal Tax Credit Extensions on Renewable Deployment and Power Sector Emissions (Technical Report). NREL/TP-6A20-65571. National Renewable Energy Laboratory, Golden, CO (US). http://www.nrel.gov/docs/fy16osti/65571.pdf.

OpenEI. 2014. “Utility Rate Database.” Accessed December 15, 2014.

http://en.openei.org/wiki/Utility Rate_Database.

Orrell, A. and N. Foster. 2015. 2014 Distributed Wind Market Report. PNNL-24460. Pacific Northwest National Laboratory, Richland, WA (US).

http://www.osti.gov/scitech/biblio/1220531-distributed-wind-market-report.

Orrell, A. and N. Foster. 2016. 2015 Distributed Wind Market Report. PNNL-25636. Pacific Northwest National Laboratory, Richland, WA (US).

http://www.osti.gov/scitech/biblio/1325409-distributed-wind-market-report.

Paidipati, J., L. Frantzis, H. Sawyer, A. Kurrasch. 2008. Rooftop Photovoltaics Market Penetration Scenarios. NREL/SR-581-42306. Navigant Consulting, Burlington, MA (US). http://www.nrel.gov/docs/fy08osti/42306.pdf.

Rai, V., and B. Sigrin. 2013. "Diffusion of Environmentally-Friendly Energy Technologies: Buy versus Lease Differences in Residential PV Markets.” Environ. Res. Lett. 8014022.

Solar Energies Industries Association (SEIA). 2016. U.S. Solar Market Insight Report Q2 2016 (Technical Report). Solar Energy Industries Association, Washington, D.C. http://www.seia.org/research-resources/us-solar-market-insight.

Sigrin, B., M. Gleason, R. Preus, I. Baring-Gould, and R. Margolis. 2016. The Distributed Generation Market Demand Model (dGen): Documentation (Technical Report). NREL/TP6A20-65231. National Renewable Energy Laboratory, Golden, CO (US). http://www.nrel.gov/docs/fy16osti/65231.pdf.

Sigrin, B. and E. Drury. 2014. "Diffusion into New Markets: Economic Returns Required by Households to Adopt Rooftop Photovoltaics." Paper presented at 2014 AAAI Fall Symposium: Energy Markets and Prediction, Washington, D.C., November 2014.

Wiser, R. and B. Bolinger. 2012. 2011 Wind Technologies Market Report. DOE/GO-1020123472. U.S. Department of Energy, Washington, D.C. (US).

http://www1.eere.energy.gov/wind/pdfs/2011 wind technologies market report.pdf. 
Wiser, R. and B. Bolinger. 2015. 2014 Wind Technologies Market Report. DOE/GO-1020154702. U.S. Department of Energy, Washington, D.C.

http://energy.gov/sites/prod/files/2015/08/f25/2014-Wind-Technologies-Market-Report-8.7.pdf.

Wiser, R. and B. Bolinger. 2016. 2015 Wind Technologies Market Report. DOE/GO-102164885. U.S. Department of Energy, Washington, D.C.

http://energy.gov/sites/prod/files/2016/08/f33/2015-Wind-Technologies-Market-Report08162016.pdf.

Wiser, R., K. Jenni, J. Seel, E. Baker, M. Hand, E. Lantz, and A. Smith. 2016. "Expert elicitation survey on future wind energy costs." Nature Energy, 1, 16135. 


\section{Appendix A}

\section{Turbine Siting Constraints}

Our assessment of the addressable resource potential for distributed wind in the United States focuses on four siting considerations. Each of those siting considerations is described in more detail in the following sections.

\section{Proximity to Electricity Demand Power Density}

Because of our focus on behind-the-meter applications for distributed wind, our assessment of addressable resource is constrained to areas that are proximal to end-use electricity demand. To identify such areas, we focus only on census blocks that contain buildings.

\section{Tree Canopy Cover}

The second siting constraint applied in our assessment was a consideration of the tree canopy cover. Specifically, we account for required clearance of turbine blades above tree canopy. This criterion partially accounts for the well-accepted principle that turbines be sited in unobstructed areas where the rotor blades are clear from other obstacles. This consideration is summarized in a DOE (2009) report focused on distributed wind applications: "A general rule of thumb is to install a wind turbine on a tower with the bottom of the rotor blades at least 30 feet ( 9 meters) above any obstacle that is within 300 feet (90 meters) of the tower."

Although geospatial data describing the specific location, size, and height of man-made obstacles (i.e., buildings) is not publicly available, similar data for natural obstructions (i.e., vegetation) are. We rely on two national 30-meter $(\mathrm{m})$ resolution data sets describing two tree canopy characteristics: percent canopy cover (Jin et al. 2013) and average canopy height (Kellndorfer et al. 2012). For each census block, we calculated the average percent canopy cover and canopy height. Then, for blocks with non-negligible canopy cover $(\geq 10 \%)$, we assigned a minimum turbine blade height at $12 \mathrm{~m}$ above the average canopy height. The 12-m clearance (instead of 9 $\mathrm{m}$ ) is meant to account for interim (since data set creation) and future vegetation growth and offset from average (rather than maximum) canopy height. When combined, these data do not support a perfect replication of the guideline specifying " 9 meters above obstruction within 300 $\mathrm{m}$ " but provide a sufficient proxy.

\section{Parcel Size and Property Setback}

The third constraint we used is based on the assumed parcel size, which serves as a proxy for property line setbacks. Parcel size is commonly used by distributed wind developers as a rule-ofthumb measure for siting various turbine heights; however, existing state legislature rarely specifies minimum allowable parcel size (only three states), and where it is specified, the guidelines are fairly generic (e.g., $\sim 1$ to 2 acres). In contrast to parcel size, turbine setbacks or the minimum radial distance from other property lines is frequently defined in the statute. Over a dozen states provide nonbinding guidelines for distributed wind that suggest setbacks from property lines of either 1, 1.1, or 1.5 times the total turbine height (i.e., blade tip).

Because national parcel boundary data sets are not available publicly for the United States, we relied on a data set of building counts per census block and a series of assumptions and equations to create a proxy for property line setbacks. This analysis was based on a data set giving land 
area and counts of buildings per census block (Federal Emergency Management Agency 2016). For each census block, we determined the average parcel size according to Eq. 1.

$$
\text { Average Parcel Size }=\frac{\text { Land Area in Block }}{\text { Count of Buildings in Block }}
$$

Note that this calculation assumes exactly one building per parcel. Next, we calculated the maximum turbine blade height in each census block as a function of the average parcel size and a property line setback factor, according to Eq. 2.

$$
\text { Maximum Blade Height }(m)=\frac{\sqrt{\text { Parcel Size }\left(m^{2}\right)}}{2 * \text { Setback Factor }}
$$

Eq. 2 is based on the assumption of square-shaped parcels for each turbine setback and solving for the maximum allowable blade height.

$$
\text { Parcel Size }\left(m^{2}\right)=(\text { Blade Height }(m) * \text { Setback Factor } * 2)^{2}
$$

For this assessment, we selected a setback factor of 1.1 because it provides a reasonable midpoint based on our review of state-distributed wind guidelines.

Using Eq. 1-3, constraints are placed on the maximum blade height that can be developed for each parcel within the block or, variously, the minimum area that would be required for each blade height to be considered.

\section{Power Density}

Our final siting criterion is a power density cap of 3 megawatts per square kilometer, which provides an upper bound on development in areas that are otherwise minimally constrained. This constraint is a proxy for overdevelopment and interturbine wake effects and is consistent with the limit used for utility wind in the Wind Vision (DOE 2015) and estimated by Denholm et al.

(2009). 